


\title{
Parental Investments in Early Life and Child Outcomes Evidence from Swedish Parental Leave Rules*
}

\author{
Rita Ginja ${ }^{\dagger}$, Jenny Jans ${ }^{\ddagger}$ and Arizo Karimi ${ }^{\S}$
}

October 29, 2017

\begin{abstract}
We study how parental resources early in life affect children's health and education exploiting the so-called speed premium (SP) in the Swedish parental leave system. The SP grants mothers higher parental leave benefits for the subsequent child without re-establishing eligibility through pre-birth market work if the two births occur within a pre-specified interval. This allow us to use a Regression Discontinuity framework. We find that the SP improves the educational outcomes of the first-born child, but not of the second-born. Impacts are driven by a combination of a positive income shock, and substitution from informal care to maternal time.
\end{abstract}

Keywords: Parental leave, earnings, time investments, child outcomes

JEL-codes: J13, J22, J18

*We thank Jerome Adda, Prashant Bharadwaj, Sandra Black, Joseph Doyle, Janet Currie, David Figlio, Per Johansson, Costas Meghir, Ylva Moberg, Magne Mogstad, Matthew Neidell, Peter Nilsson, Jeffrey Smith, Anna Sjögren and Robert Östling for insightful comments and suggestions. We also thank seminar participants at Uppsala University, Norwegian School of Economics, IZA Summer School 2017, the SOLE 2017 meetings and 2017 EEA for their comments. Arizo Karimi gratefully acknowledges the Jan Wallander and Tom Hedelius Foundation for financial support.

${ }^{\dagger}$ Department of Economics, University of Bergen, Fosswinckelsgate 14, 5007 Bergen, Norway. Tel.: +4755 58 92 00. Uppsala Center for Labor Studies (UCLS); IZA. Email: rita.ginja@uib.no.

‡Department of Statistics, Uppsala University Uppsala, Box 513 SE-751 20, Uppsala, Sweden. Email: jenny.jans@statistik. uu.se

§Department of Economics, Uppsala University Uppsala, Box 513 SE-751 20, Uppsala, Sweden. Tel.: +46(0)18 4711591. Uppsala Center for Labor Studies (UCLS), and Institute for Evaluation of Labor Market and Education Policy (IFAU). Email: arizo.karimi@nek.uu.se. 


\section{Introduction}

How are the health and educational outcomes of children affected by parents' time and monetary resources early in life? Governments in most industrialized countries have implemented family leave programs to help parents reconcile the combination of market work and family responsibilities, but also asserting the positive consequences of paid leave policies for the health and well-being of children. However, the duration of paid leave entitlements and the level of compensation vary widely across countries, which reflects the lack of consensus among policymakers on the optimal design of such programs.

We study how policy-induced differences in the early home environment - in terms of parental time spent with children and the family's monetary resources - affect the outcomes of children from birth into early adulthood. To this end, we exploit a feature of the Swedish parental leave (PL) system commonly referred to as the Speed Premium (SP). To qualify for wage-replaced PL benefits, ${ }^{1}$ parents must have been employed for at least 240 consecutive days ( 8 months) before birth, and benefits are based on the salary received before birth. Thus, part-time work or periods of non-work between births - as is common among new mothers - decreases the benefits received for a subsequent child. To protect the financial situation of families with young children born in close intervals, it became legal practice during the 1970s to allow mothers to keep the PL benefit level for a subsequent child if the two children were born within a pre-specified interval. This administrative rule is called the speed premium, due to its incentives to space births in close intervals. Initially, the eligibility birth spacing interval that granted access to the SP was very short and biologically difficult to achieve. In 1980, the eligibility birth interval was increased to 24 months, and in 1986 it was further extended to 30 months, and also became statutory.

The thresholds to eligibility for the SP generate variation in maternity leave benefits, and we therefore use the 24- and 30-month birth spacing cutoffs as treatment assignments in a Regression Discontinuity (RD) empirical framework. We examine the effects of eligibility to higher benefits by virtue of the SP on the educational and health outcomes of both the existing and new children, from birth up to young adulthood. To understand the channels through which children may be affected, we study the spousal labor supply responses as well as the household's disposable income. Moreover, we perform a wide variety of heterogeneity analyses to further probe the mechanisms. We use longitudinal administrative data with information on both parents and children, such as labor income, household disposable income, gender, hospital admissions in early life, birth outcomes (birth weight, Apgar scores, among other measures), $9^{\text {th }}$ grade cumulative GPA, and college attendance by age 24 .

\footnotetext{
${ }^{1}$ In Sweden, PL benefits are governmentally paid to both mothers and fathers.
} 
Our analyses yield three main findings. First, there is an improvement of the educational outcomes for first-born children of just-eligible mothers relative to those of mothers who just fail to meet the SP eligibility requirements: the $9^{\text {th }}$ grade GPA increases by 3 percent of a standard deviation (about 12 percent relative to the control group mean), and they are 2-3 percentage points more likely of having attended college by age 24 (about 7-9 percent relative to the control mean). The older child benefits, irrespective of whether he/she is the first-born in a two-sibling household, or the second-born in a threesibling household. We do not find any impacts on hospitalizations during childhood or adolescence among first-born children. We do not detect impacts for second-born (or third-born) children. Second, the positive educational impacts for eligibility to SP are stronger for children to high-income mothers. Finally, these effects were stronger under the 24-month regime.

We investigate three possible sets of mechanisms, namely, changes in parental time and monetary resources, the counterfactual child care available for existing children of mothers that become eligible to the SP, and gender composition in the household. First, we find that mothers reduce their labor supply immediately upon finding out whether they will meet the eligibility to the speed premium (which is based on expected due dates), that is before the new child is born, by 5-6 percent relative to those mothers who just fail to meet the spacing requirements for eligibility. There is a compensatory behavior by the fathers, who increase their labor supply. The intra-household adjustment in the labor supply combined with the access to higher parental leave benefits, yield an increase in the household's disposable income after the birth of the new child. Moreover, the increase in the labor supply of the partners of just-eligible mothers persists up to five years after the birth of the new child, and thus the increase in disposable income of the household is persistent. Thus, in interpreting the impact of eligibility to SP for first-born children, we cannot disentangle between time and financial resources. Furthermore, we are unable to detect changes in completed fertility of mothers just-eligible to the SP.

Second, it is possible that the impacts on the existing child are larger among those gaining access to higher PL benefits under the 24-months regime (1980-1985) rather than under the 30-months (19861989) due to differences in the counterfactual care for children in their second and third years of life. In the period of 1980-85 it is more likely that the alternative mode of care for children under the age of two would have been informal care instead of formal care for children under the age of three between 1986-1986.

Finally, by studying the impacts in households with different gender mix of the first two children we find that, irrespective of the first-born gender, the SP has positive impacts mainly when the second-born 
child is a boy. This is the case in both the 24- and 30-months regimes. Thus, it is not likely that children compete for parental resources to differing extents depending on the age-difference of the siblings.

Our findings are robust to a battery of sensitivity tests. First, we find no evidence that parents are perfectly able to time the spacing between two consecutive births by comparing the density of births around both the 24 and 30-month cutoffs. Second, we find no systematic differences across families on either side of the cutoffs in terms of pre-determined characteristics. Third, our results are robust to the trimming of the sample used around the cutoff and to functional form used to capture the underlying trends. Fourth, we do not find discontinuities in household labor income or educational attainment of children at placebo cutoffs for the eligibility to the speed premium. Finally, the impacts on educational achievement are robust to adjusted inference for multiple hypotheses testing.

Our paper contributes to the studies on extending existing and already generous parental leave protection on the outcomes of parents and children. Rossin-Slater (2017) reviews the literature on the causal impacts of leave polices and concludes that the effects of such polices on both the careers of women and child well-being depend on their length, suggesting that introducing leave entitlements has larger positive effects on both mothers and children than extending already existing programs. ${ }^{2}$ Our findings suggest that the benefits of gaining eligibility to higher PL benefits (hereby, extending the duration of leave) when two parental leave episodes are closely spaced accrue to the first-born child.

Second, our paper also contributes to the literature on birth order effects, which demonstrates that educational attainment and cognitive ability decreases with birth order (Black, Devereux and Salvanes, 2005, 2011; Hotz and Pantano, 2015; Black, Grönqvist and Öckert, 2017). ${ }^{3}$ It is possible that later born children spend on average less time with their parents than earlier born children, and they have to share that parental time with the older sibling. If time spent with the mother in the first years of life is more important than when children are older, then later-born children will benefit less from parental time, since that time is competed for with an older sibling (Markus and Zajonc, 1977; Zajonc, 1976; Price,

\footnotetext{
${ }^{2}$ The introduction of short leave programs has been shown to improve the health and schooling achievement of children (Rossin, 2011; Carneiro, Løken and Salvanes, 2015; Stearns, 2015). For mothers, shorter leave programs also seem to benefit their subsequent labor supply (Baum, 2003; Waldfogel, 1999; Baker and Milligan, 2008a; Han, Ruhm and Waldfogel, 2009; Kluve and Tamm, 2013; Rossin-Slater, Ruhm and Waldfogel, 2013; Bergemann and Riphahn, 2015), while more generous leave policies may have adverse consequences on women's careers (Ruhm, 1998; Lequien, 2012; Schönberg and Ludsteck, 2014). Expanding existing and already generous leave programs, however, appears to have no or small impacts on children's outcomes (RossinSlater, 2017; Baker and Milligan, 2008b, 2010, 2015; Liu and Skans, 2010; Rasmussen, 2010; Dustmann and Schönberg, 2012; Dahl et al., 2013; Danzer and Lavy, 2017). However, there appears to be some heterogeneity in the impacts of such policies on children depend on their socio-economic background, with larger benefits for high SES children (see e.g Danzer and Lavy, 2017; Liu and Skans, 2010).

${ }^{3}$ See also Björkegren and Svaleryd (2017) for evidence on birth order and child health, and Breining et al. (2017) on birth order and delinquency.
} 
2008). ${ }^{4}$ Moreover, recent work finds that birth order effects on cognitive and non-cognitive outcomes are driven by differential parental investments across children of different parities after their birth (Pavan, 2016; Black, Grönqvist and Öckert, 2017). A policy like the Swedish speed premium contributes to part of the "birth order penalty". In particular, only the first-born child benefits from it, and our findings suggest that meeting its requirements contributes to 31 percent of the gap between the GPA of first- and second-born children born 2 years apart. ${ }^{5}$

Finally, due to data limitations we cannot study directly the impacts on measures of household consumption, which would allow to understand possible changes in household expenditures. But the impacts found on household income show that meeting the eligibility requirement to the speed premium is associated with a persistent increase in household income. Thus, in line with the findings of the consumption literature, it is likely that these are transferred to household consumption and parental investments (Blundell, Pistaferri and Preston, 2008; Carneiro and Ginja, 2016).

The rest of the paper is organized as follows: section 2 describes the Swedish parental leave system and, in detail, the speed premium rule; section 3 describes the data and the empirical framework. In section 4 we present the main results from our analysis of the effect of the SP on children's outcomes. In section 5, we probe the possible mechanisms for the effects of the SP on children. Finally, section 6 discusses the conclusions drawn from our analyses.

\section{Institutional Setting}

The Swedish parental leave system was introduced in 1974 and initially guaranteed parents six months of paid parental leave. The paid leave was sequentially extended over the subsequent decades, and to date parents are entitled to 16 months of paid leave per child (see Table A.1 for all the components and changes to the parental leave system up to 2010). The mother and the father of a child are given half of the entitled days each (if they have joint custody), but have the option of transferring paid leave days between one another. ${ }^{6}$ Individuals with sole custody of their child get the full number of paid leave days. Parental leave (PL) benefits are divided into three components. First, and most important,

\footnotetext{
${ }^{4}$ de Haan (2010) finds that the birth order effects do not vary with the spacing between births.

${ }^{5}$ To compute this value, we use the estimates in Table 4. Under the 24-month regime, the mean of the GPA for first- and second-born children in the control group is .254 and .155, respectively. Which results in a gap of 39 percent. The impact of accessing the PL benefits under the speed premium is .031, which results in a gap of 46 percent $((.51-.39) / .39)=.31$.

${ }^{6}$ In 1995, one month of paid leave became earmarked to each parent, so that fathers could not transfer all of their paid leave to the mother of the child (as was usual practice). This "daddy-month" was introduced to increase the incentives for fathers to increase their leave-taking. In 2002 and 2016, a second and third month, respectively, of paid leave was earmarked to each parent.
} 
parents receive benefits that replace 90 percent of their salary during the time period studied. ${ }^{7}$ The wagereplaced benefits are conditioned on at least 240 days of employment before child birth (8 months). Those that do not fulfill the 240-day work requirement get a low, fixed, daily amount of PL benefits. Second, since 1978, part of the leave is compensated with a low, fixed daily amount. Third, since 1980, ten days of leave are given exclusively to the father, which he can use during the first 60 days after the birth of the child.

The leave is job protected. During the first 18 months after birth both parents are legally entitled to full-time job protected leave, irrespective of whether they claim PL benefits. Thereafter, parents have the option of reducing their working hours by up to 25 percent until the child turns eight years old, even if they don't have any PL benefits left. Moreover, paid leave benefits can be used on a part-time basis until the child is eight years old; parents can thus save paid leave to e.g., extend vacations. ${ }^{8}$

\subsection{The Speed Premium Rule}

We exploit a feature of the Swedish PL system that is commonly known as the speed premium (SP) rule. Wage-replaced PL benefits are calculated on the pre-birth earnings, i.e., during the qualifying period of employment before birth. Thus, part-time work or periods of non-work between births, as it is common among new mothers, may decrease the benefits received for a subsequent child. To protect the financial situation of families with young children with possible long labor market absences, it became legal practice during the 1970s to base the PL benefits for a subsequent child on the income earned before the preceding child, provided that the time interval between the births did not exceed the period of eligible leave plus six months. This administrative rule thus implied that mothers did not have to return to work between births to re-establish eligibility for (higher) PL benefits, if two births were closely spaced. In 1974, the eligibility birth interval was 12 months, but could in practice be extended by three months. Because entitlement to paid leave was extended to seven months in 1975, the eligibility birth interval for higher benefits (i.e., to the speed premium) increased to 13-16 months. On January 1, 1980, the SP eligibility birth interval was extended to 24 months. A few years later, on January 1, 1986, the birth interval granting access to the SP was further extended to 30 months, and it also became statutory (Proposition, 1984; SfU, 1984). ${ }^{9}$ In this paper, we focus on the SP after 1979, i.e., the 24 - and 30-month spacing rules,

\footnotetext{
${ }^{7}$ Currently, the replacement rate is 80 percent of previous earnings (see Table A.1).

${ }^{8}$ Workers must notify their employers at least two months in advance of any parental leave or work-time reduction, but the employer cannot deny the worker leave given that this requirement is met.

${ }^{9}$ Table A. 2 shows the changes to the eligibility spacing interval over time.
} 
and apply the spacing cutoffs as treatment assignment in a Regression Discontinuity (RD) framework. We present the empirical strategy in detail in subsection 3.2.

It is important to note that, also in the absence of additional children, wage-replaced benefit levels are "protected" for some time after birth so that the qualifying income does not decrease while on leave with a child. The SP merely extended this "protected period". In particular, before 1986, the benefit level for a current child remained unchanged until the child turned 18 months; and from 1986, until the child turned 24 months. This is the protected benefit level period and it ensures the same benefit level for a current child during the first 18 (24) months. The SP stipulates that if by the time the protected benefit level expires the woman is pregnant again with an expected due date within six months from the protected period $(18+6=24$ months between 1980 and 1985; and $24+6=30$ months from 1986 onwards), the mother is entitled to receive the same PL benefit also for the new child (Proposition, 1984; SfU, 1984). Hence, eligibility to the higher benefits for the subsequent child is based on the expected due date, and not the actual date of birth. The fact that access to the SP is based on expected and not actual due dates has implications for the expected timing of any parental responses to the SP. We return to this discussion below in subsection 2.3.

The SP rule creates short-term economic incentives to space births in short intervals. Among mothers with at least one child, giving birth to a subsequent child outside of the eligibility spacing interval implies a lower benefit level for leave taken with the new child, compared to the scenario where the new child is born within 24 (30) months from the previous birth, after the introduction of the 1980 (1986) extensions. These incentives explain why the rule is commonly referred to as the speed premium. Exploring the potential fertility timing effects of introducing the SP is out of the scope of our paper, but for illustration, Figure A.1 in Appendix A shows the average age difference in months between a mother's first two children for different cohorts of second-born kids. Before 1980, there was an increasing trend in birth spacing, which almost instantaneously declined after the introduction of the 24-month rule in 1980, and continued to decline after the implementation of the 30 -month rule in $1986 .{ }^{10}$ The RD framework that we use is based on the inability of parents to precisely manipulate the spacing of births around the eligibility cutoffs, and thus the identification of impacts of the SP will not be affected by changes in the trends in the spacing of births associated with the changes in the rules.

Moberg (2017) studies the 30-month speed premium rule in an RD setup similar to ours to estimate

\footnotetext{
${ }^{10}$ Hoem $(1990,1993)$ study the fertility timing impacts of the SP and he shows that with an eligibility interval of two years or more, couples find it more manageable to fulfill the SP criteria and take advantage of the new benefit. Pettersson-Lidbom and Thoursie (2009) exploit the introduction of the 1980 SP rule to examine the effect of (shorter) birth spacing on children's outcomes and find adverse consequences for children.
} 
the effect of PL benefit levels on the spousal division of PL take-up during the 1990s. She finds that the speed premium increases the benefit level for mothers, and thereby increases her duration on leave. Fathers' benefit levels are unaffected, but they nevertheless decrease their parental leave duration as a response.

Finally, the SP in the Swedish system is similar to the "automatic renewal" in the Austrian system, described and studied in detail by Lalive and Zweimüller (2009). In their paper, they find that an extension of automatic renewal from one to two years increases the short-run higher-order fertility by 5 percentage points. ${ }^{11}$

\subsection{Labor Market Conditions}

In our analyses, we will focus on two-child families in which the second child was born between 1980 and 1989. During the 1980s, Sweden had very low unemployment rates, and high employment rates (see Figure A.2). Moreover, the labor market conditions are relatively similar across the two SP regimes (24-month and 30-month), despite a small increase in real earnings over the decade. Finally, there were no other relevant policies implemented over this time period.

\subsection{Expected Effects of the Speed Premium on Parental Labor Supply}

The SP rule may give rise to behavioral responses on parental labor supply through its implications for the PL benefit level, and thus affect parents' financial resources and the time spent with their young children. In the following paragraphs, we describe how different margins of the household's labor supply decisions are likely to be affected by the SP and lay out the hypotheses that we test, keeping in mind that we are interested in the effects of early investments on children's later age outcomes. In subsection 3.2, we describe the empirical strategy that we employ to estimate these relationships.

First, because eligibility to the SP is determined based on the expected due date of the second child, and not the actual date of birth, women will learn about their eligibility during the second pregnancy. If the expected due date lies outside the SP eligibility interval, but the actual birth occurs within the interval, parents will gain access to the SP after the birth. Thus, market work incentives will decrease for mothers already before the birth of the second child, since there is no longer a need to re-quality for

\footnotetext{
${ }^{11}$ In the Austrian PL system, mothers must meet a work requirement to be eligible for paid leave. Mothers giving birth to a subsequent child within 3.5 months after the end of a previous PL spell are exempted form the work requirement and get an automatic renewal of PL benefits for the subsequent child. In 1990, paid parental leave was extended from one to two years, increasing the eligibility spacing interval for automatic renewal from 15.5 months to 27.5 months (Lalive and Zweimüller, 2009).
} 
full PL benefits. Therefore, we expect a downward shift in the labor supply of mothers before second birth. To assess the validity of the hypothesis that mothers will respond to future PL benefit levels, we compare the labor income in the year prior to second birth of mothers in couples whose second child is born within 24 (30) months after the first, to the labor income of mothers who just failed to meet this eligibility criteria.

In addition to potentially affecting the pre-birth labor supply, higher PL benefits also lower the incentives for market work post second birth (see e.g. Lalive and Zweimüller, 2009). We test this conjecture by comparing the labor income for subsequent years after second birth for mothers who just fulfill the 24 (30) months spacing threshold relative to those mothers who just fail to meet the spacing eligibility threshold for the SP.

While the Swedish Parental Leave Act grants mothers and fathers equal rights to job protected and paid leave, the vast majority of paid leave is used by mothers, who are thus arguably the main caretakers of children. ${ }^{12}$ The SP mainly affects the mother's benefit level, since fathers on average use only a quarter of the paid leave granted for each child to date (and considerably less than that during the time period studied), and therefore re-establish eligibility for subsequent children by default. In other words, we do not expect the SP to affect the benefit level for fathers. ${ }^{13}$ The SP thus shifts the relative incentives within the household in favor of mothers to decrease market work, and any spousal adjustment behavior should therefore be in the direction of compensating for the resulting loss of income on the part of the wife. Alternatively, if mothers' decrease their market work, this may free up time for their spouse to increase their time spent in market activities.

Thus, we expect fathers to increase their market work (potentially) before and after the second child is born. Since data on PL take-up and benefit level is not available to us (and, it only exists from 1988 onward), to gauge the total effect on the household's financial situation, we analyze the effects on the household's disposable income.

As it is clear from the hypotheses laid out above, eligibility to the SP is likely to affect both the monetary and time resources available to parents when their children are young. When assessing the impacts of children, we are unable to explicitly separate between impacts of time investments and monetary investments, but we can provide suggestive evidence on the relative importance of the two channels by

\footnotetext{
${ }^{12}$ In 1992, the male share of total parental leave take-up was approximately 10 percent (see e.g. Karimi, Lindahl and Skogman Thoursie, 2012).

${ }^{13}$ Previous papers have shown that fathers' leave taking behavior is sensitive to economic incentives, as the introduced daddy-months had a significantly positive effects on their take-up (Dahl, Løken and Mogstad, 2014; Cools, Fiva and Kirkebøen, 2015; Ekberg, Eriksson and Friebel, 2013; Avdic and Karimi, 2017).
} 
studying the net effect on the household's total disposable income and through a variety of subgroup analyses. Moreover, also the combined effect of monetary and time investments on children's outcomes is policy relevant.

\section{Data and Empirical Strategy}

\subsection{Data}

Our analysis is based on a panel data set created by combining population-wide Swedish administrative registers, covering families with at least two children.

First, we use the multi-generational register that is a population-wide data set including the links between parents and children through individual identifiers, with information on parity and child gender. Using the individual identifiers of parents, we merge this register to information on labor income and disposable income collected by the Swedish Tax Authority. This data set covers the period 1970-2013, for all individuals aged 16-64. While individual variation in labor income can be generated both by changes in hourly wages and hours worked, short-run changes in labor income are arguably driven primarily by changes in hours worked rather than hourly wage rates, which are contractually set. Therefore, and due to the lack of data on months or hours worked and hourly wages, we use labor income to measure parental labor supply. To get a more complete picture of potential changes to the overall financial situation of the household, we use the measure of disposable income at the household level. Disposable income includes income from market work and governmental transfers such as PL benefits, net of taxes.

For each child in our data, we have information on the exact date of birth from the medical birth register. This register also includes the children's birth weight, birth height, gestation (in weeks), Apgar scores, and a number of different medical diagnosis codes at birth. The medical birth register also includes variables related to the mother's pregnancy and delivery, such as weight and height at birth, and the predicted date of birth based on the last menstruation and ultrasound. Eligibility to the speed premium is based on the expected (predicted) due date, and not on actual date of birth. However, the medical birth register does not have full coverage on the predicted date of birth; only around 50 percent of the sample has information on expected due date based on last menstruation, and 20 percent of the sample report expected due date based on ultrasound checks. Hence, we calculate the spacing between

the first two births based on actual date of birth, which is highly correlated with spacing calculated based on expected due dates from both ultrasound and last menstruation. In subsection 3.2, we discuss this 
data issue in greater detail, and how we handle potential discrepancies between actual and expected due date in our identification strategy.

For children we also study early and later life health outcomes using information from the inpatient register. The inpatient register includes the universe of all hospital visits during the years 1987-2005. In addition to diagnosis codes (ICD10-codes), the inpatient register reports the date of admission, an indicator for planned/emergency care and length of each hospital stay.

Lastly, for each child in our data we match information on schooling outcomes from the grade-9 register, which is available from 1988 onward. Specifically, we calculate (within-graduation year) standardized cumulative GPAs in $9^{\text {th }}$ grade. We also extract an indicator for whether the student's grades are sufficient for high school eligibility.

\subsection{Empirical Strategy}

We use a Regression Discontinuity (RD) framework to study the impact of the SP benefit rule on children's health and schooling outcomes, parental labor supply, and household income. To this end, we use the fact that parents whose first two children were born within an interval of 24 (30) months were subject to the automatic renewal of parental leave benefits, without re-establishing eligibility to paid leave by returning to market work between births. For the 24-month regime, we restrict the sample to families whose second child was born 1980-1985, and for the 30-month regime we focus on families in which the second child was born 1986-1989, i.e., after the respective SP thresholds were implemented. We estimate the following regression model with OLS separately for the two regimes:

$$
y_{i, \tau}=\alpha+\mathbf{1}[t \leq c] \beta+\mathbf{1}[t>c] f_{r}(t-c)+\mathbf{1}[t \leq c] f_{l}(c-t)+\epsilon_{i}
$$

where $y_{i, \tau}$ is the outcome of interest for parent or child $i$, measured at some follow up year $\tau$ after second birth. $t=\kappa-\kappa^{\prime}$ is the spacing between the first two births, where $\kappa^{\prime}$ denotes the date of birth of the first child, and $\kappa$ the birth date of the second child. $c$ is the respective eligibility cutoff spacing interval, i.e., 24 months in the first regime, and 30 months in the second regime. $\mathbf{1}[\cdot]$ is the indicator function that takes the value 1 if the condition in brackets is fulfilled and 0 otherwise, and $f_{l}$ and $f_{r}$ are unknown functions capturing underlying trends in the outcome variables over child spacing. If parents do not

have precise control of the timing of birth, $\hat{\beta}$ provides an estimate of the effect of eligibility to the speed premium at the threshold. The assumption of imprecise control of birth timing implies that births are 
locally randomized around the cutoff. We perform a number of robustness checks to assess the validity of this assumption. Moreover, since data on parental leave take-up exists only from 1988 onward (and, in any case, it is not available to us for this study), we are not able to re-scale the Intent-to-Treat (ITT) parameter $\beta$ by the first stage estimate of the impact of the eligibility to speed premium on the take-up of parental leave. ${ }^{14}$

We use weekly birth data, and set the cutoff $c$ to 104 and 130 weeks for the 24-month and 30-month regime, respectively. Although eligibility to the speed premium is based on the expected due date, and thus the expected birth spacing, we use actual birth spacing as the running variable. This is because, as discussed above, the data lacks full coverage on the expected due dates. However, the expected and actual birth spacing are highly correlated, and on average the difference between the expected due date (based on date of last menstruation) and actual date of birth is of 0.04 weeks (a quarter of a day). Thus, to account for measurement error in the running variable, spacing in weeks, we cluster the standard errors by week of birth (Lee and Card, 2008).

As we study effects on a large number of outcomes, we test which impacts survive adjustment of inference for multiple hypotheses testing. We use the procedure in algorithms 4.1 and 4.2 of Romano and Wolf (2005). The application of this procedure accounts for testing simultaneously several hypotheses (i.e., all null hypotheses under consideration at once). Romano and Wolf (2005) propose an iterative rejection/acceptance procedure, for a fixed level of significance, thus in the tables presented, we mark in bold the coefficient estimates that are still significant at a level of 10\%. We use 1000 bootstrap replications to obtain the adjusted critical values.

\subsubsection{Analysis Sample}

We restrict attention to mothers who were eligible for wage-replaced parental leave for their first child, i.e., who fulfilled the work requirements before the birth of their first child. According to the rules in place during the late 1970s and 1980s (the period of analysis), the benefit level was 90 percent of foregone earnings with eligibility based on the maternal earnings in 9 consecutive months or 12 out of 24 months preceding the birth-related withdrawal. Due to the annual nature of the data on labor earnings, we do not directly observe whether individuals are eligible for wage-replaced leave, and we must rely

\footnotetext{
${ }^{14}$ In addition, the exclusion restriction may not be valid in this setup. It is possible that the take-up of benefits influences the outcomes of children by other channels besides changes in the level of PL benefits. For example, access to higher PL benefits via SP simultaneously may increase household income through changes in the labor supply of fathers and additional benefits. Also, it can change the maternal time with the child. Thus, we would have only one instrument and multiple endogenous regressors (time and monetary resources).
} 
on an imperfect measure, namely using total annual labor earnings to approximate eligibility status, similar to the method used by Carneiro, Løken and Salvanes (2015). We use a value of 32000 SEK as a threshold defining eligibility, which corresponds to the 10th percentile of the annual income distribution for mothers in the year before giving birth to their first child. This is likely an overestimate of the fraction of eligible mothers, and it results in a slightly larger share of eligible mothers than in Carneiro, Løken and Salvanes (2015) for a similar period in Norway. Reassuringly, we show below that our results are not driven by families in the left tail of income distribution. In addition, because non-eligible mothers' incentives are unaffected by the speed premium, a larger fraction of non-eligible mothers in the analysis sample leads to attenuation bias in the estimation of the impact of the speed premium on spousal labor supply. ${ }^{15}$

We further restrict the sample to mothers whose second child was born 1977-1989, and calculate the spacing between their first and second child in weeks. ${ }^{16}$ We additionally restrict the sample to mothers who were aged 20-39 when they gave birth to their first child. ${ }^{17}$ For the 24-month regime, we focus on parents whose second child was born 1980-1985, i.e., after the 24-month rule came into effect, but before the 30 -month rule was implemented. ${ }^{18}$ For the 30 -month regime, we restrict the sample to parents whose second child was born 1986-1989.

As is practiced in an RD setup, model Equation 1 is estimated using families with a spacing between the two first children in a neighborhood of the eligibility cutoffs of 24 or 30-months, in particular, within a 32-week window (Lee and Lemieux, 2010). We test the sensitivity of our results to trimming the data to different ranges of data around the cutoff in section 4.

Table 1 shows summary statistics for the respective regime samples. On average, fathers earn a higher labor income than mothers in both regimes, and the spousal age difference is constant across the regime samples; around 2.8 years. Consistent with studies on birth order effects, first born children on average perform better than second-born children (see e.g. Black, Devereux and Salvanes, 2005, 2011; Hotz and Pantano, 2015, for recent evidence). For example, first-born children have higher grade-9 cumulative GPA:s, they are more likely to be high school eligible by age 16 compared to second-born children, and they are also more likely to have attained some college education by age 24 compared to their younger

\footnotetext{
${ }^{15}$ Because we have only data on labor earnings on an annual basis, we cannot calculate the total earnings of a woman in the 8 months closest to birth. Therefore, choose to set the threshold at the somewhat arbitrary 10th percentile in the calendar year before birth. We have also tried to set the threshold at higher values to define eligibility, to which our main findings are robust.

${ }^{16}$ Out of mothers giving birth to children between 1977 and 1989,12\% had only one child.

${ }^{17}$ Among the cohorts in analysis, only $0.01 \%$ of mothers gave birth to the first child at 40 years old or after; and $8 \%$ gave birth to the first child before turning 20.

${ }^{18}$ The reason for including second-born children in 1977-1979 is that we are then able to perform sensitivity analyses using the 24-month cutoff in placebo years. For the 30-month rule, we use pre-1986 birth cohorts in a similar sensitivity test.
} 
siblings. In the first row of Table 1 we also report mother's earnings in the year before $1^{\text {st }}$ birth, which is the income on which PL benefits for the first child is calculated, as well as for the second child, if she is eligible for the SP. Comparing this income level with mothers' average income in the year before $2^{\text {nd }}$ birth, we note that the average gain of the SP is around SEK 65,800 (USD 8,000) in the 24-month regime $((155.341-82.204) \times 0.9)$, and around SEK 57,300 (USD 7,000) in the 30-month regime. This corresponds to $42 \%$ and $36 \%$ of baseline annual labor income for mothers in the respective regimes.

\subsubsection{Covariate Balance}

We start by presenting estimates of model Equation 1 for variables that are pre-determined at the time of the birth of the second child, and thus for which we should not expect to find a statistically significant discontinuity at the cutoffs. Table 2 reports estimates of $\beta$ from Equation 1 using different specifications of the underlying trends captured by $f_{l}$ and $f_{r}$, for a number of observed pre-determined parental and child characteristics. This covariate balance test provides suggestive evidence about whether the local randomization assumption is likely to hold. In Table 2 we present results using three specifications: a linear and a quadratic parametric specifications, as well as estimates of a non-parametric local linear regression model. The table reports the point estimate for $\beta$, the standard error and the $t$ statistic for a test of whether $\beta$ is statistically different from zero. Given that we are testing simultaneously multiple hypotheses for each specification presented we also adjust inference following Romano and Wolf (2005). This corresponds to testing 26 hypotheses simultaneously. We cannot reject the null that the coefficients reported in the table are statistically different from zero once we perform this adjustment.

Given the results from the balancing tests and the overall robustness of the point estimates to the specification used, we proceed with the linear specification in our main analysis, but we also provide estimates using local linear regression with varying bandwidths as robustness checks.

\subsubsection{Threats to Identification: Strategic Manipulation of Birth Timing}

Identification in the RD framework hinges on the assumption of local randomization of the running variable around the threshold. In our context this assumption requires parents to have imprecise control of the timing of birth, and thus that they are unable to manipulate their assignment to the speed premium. While some parents will aim to meet the eligibility criteria by planning their fertility timing - which would show up as a greater mass in births to the left of the cutoff - the assignment to treatment at the cutoff is random if parents have imprecise control of the exact date or week of birth. Since eligibility to the 
speed premium is based on the expected due date, one potential concern is that parents with due dates close to the cutoff misreport the date of last menstruation in order to be eligible for the speed premium. The covariate balance tests reported in Table 2 suggest that there is little concern for strategic timing of birth in either regime sample, but to corroborate this evidence we perform two additional checks. First, we estimate the difference at the cutoff between actual and expected due date of the second child for the sub-sample of parents in our data for which we have information on expected date of birth. The due date is calculated based on the date of last menstruation, which is self reported. If parents manipulate their assignment to treatment at the cutoff, there should be a larger difference between expected and actual date of birth at the cutoff. We calculate the differences as the expected due date minus the actual due date, so that a difference in the direction of a more negative difference between the two dates would be indicative of strategic manipulation. Figure A.3 in plots the average difference - in days - between expected and actual date of second birth in each weekly bin of birth spacing in a 32-week window around the eligibility cutoffs, for the 24- and 30-month regimes. The figures also report the estimated discontinuity in this difference at the cutoffs. There is no statistically significant discontinuity at the thresholds in either regime sample.

Finally, Figure A.4 presents the results from tests of the discontinuity at the cutoff in the density function of the running variable proposed by McCrary (2008), using daily birth data. The density estimates presented in Figure A.4 use a bandwidth of 20 days in the local linear regression to smooth the data. The underlying density functions are continuous at the cutoff in both regimes. We have performed sensitivity checks to alternative bandwidths. ${ }^{19}$

Taken together, the results from the three different tests suggest that there is little room for concern of bunching at the cutoff. The mass in births, however, lie to the left of the cutoff. We, therefore, allow for separate trends on each side of the cutoff.

\section{Effects on Child Outcomes}

We study three groups of outcomes for children. First, we examine outcomes at birth for the second-born child. Since eligibility to the SP is revealed to mothers once she gets an expected due date, the knowledge of a better financial situation when the parental leave period starts may lead to reduced labor supply during pregnancy, and to reduced maternal stress while in utero, which in turn could have beneficial

\footnotetext{
${ }^{19}$ These results are available upon request. Moreover, among all births in Sweden between 1977 and 1986, 10\% were delivered via C-section (own calculations from the birth register).
} 
impacts for children's outcomes at birth (see e.g. Persson and Rossin-Slater, 2016, for recent evidence on in utero exposure to maternal stress and it's implications for child health). Second, we analyze health outcomes at older ages by estimating the effect of the SP on both the first- and second-born children's likelihood of having been admitted to the hospital at different ages. Since inpatient data is only collected from 1987 onward, we can only study impacts on hospitalizations for all children from age 7 onwards. Therefore, we look at hospital admissions for ages 10 and 14. Finally, we study educational outcomes: an indicator for high school eligibility after finishing grade 9 (i.e., after finishing compulsory schooling), $9^{\text {th }}$ grade cumulative GPA (standardized within graduation year to have a mean of zero and standard deviation one), and an indicator of college attendance by age 24 .

Table 3 presents the results for the second-born children's outcomes at birth. The upper panel depicts the impacts on seven outcomes for children born under the 24-month SP regime, and the lower panel presents the corresponding results for children born under the 30-month regime. In the 24-month regime, there are no effects of the SP on either birth weight, gestation, birth height, or Apgar scores measured at 1 and 5 minutes. For the 30-month regime, there is a small positive effect on gestation of 0.08 weeks (half-day), on average. Overall, eligibility to the SP has no effect on second-born children's outcomes at birth.

Columns 4-5, and 9-10 in Table 4 show the corresponding results for hospital admissions. We find no effects for either first- or second-born children in either regime. However, it is important to keep in mind that hospital admission is a crude measure of health, as it only measures the most severe health issues.

Next, we look at educational outcomes. Table 4 presents the results on the educational outcomes of first- and second-born children, for the 24- and 30-month regimes (the results are also shown graphically in Figure 1 and Figure 2, for the first- and second-born kids, respectively). In both regimes, the SP positively affects the outcomes of the first-born. First-born children to mothers who are eligible for the SP have a higher $9^{\text {th }}$ grade GPA of about 3 percent of a standard deviation in both regimes. Moreover, college attendance by age 24 is higher by 3.5 percentage points in the 24-month regime, which corresponds to $7.4 \%$ of the control mean; and, by about 2 percentage points in the 30 -month regime (4.7\% of the control mean). For second-born children, there are no effects on GPA in either regime, but a significantly positive effect on the likelihood of having attended college by age 24 in the first regime.

We then use the procedure proposed by Romano and Wolf (2005) to test simultaneously the 20 null hypotheses of no effect of SP eligibility on the birth outcomes of the second-born child and on the educa- 
tional achievement and hospitalization of the first- and second-born children, that is, the seven outcomes for both regimes in Table 3 and on the 10 outcomes for both children in Table 4 for both the 24 and 30months regimes. The coefficient estimates significant on the $10 \%$ level are displayed in bold. We find that the impact on the gestational length of the second child under the 30-month regime in Table 3 and that the increase in the likelihood of college attendance of the first-born child in the 24-months regime in Table 4 survive the adjustment for multiple hypotheses testing.

Taken together, parental eligibility to the SP leads to improvements in the educational outcomes of mainly the first-born child. In section 5, we discuss potential mechanisms for this effect and for the differences in the impacts across the two regimes and birth parity.

\subsection{Robustness Checks}

In this section, we test the sensitivity of the RD estimates on children's outcomes to various stress tests.

To interpret the effects on children's schooling outcomes as causal effects of the speed premium, assignment to treatment - i.e., the exact age difference between siblings - must be random at the cutoffs. In subsection 3.2, we show that there is no evidence of strategic manipulation of birth timing as indicated by balancing tests of parental pre-determined characteristics or on first-born children's birth outcomes, and as indicated by the lack of bunching at the threshold. Here, we also look at the balancing of one potentially important covariate that may be related to educational outcomes (see e.g. Buckles and Hungerman, 2013) via e.g., school starting age; namely month of birth. We perform two checks to test the sensitivity of our results to differences in month of birth. First, Table A.3 presents estimates of Equation 1 including fixed effects for calendar month of birth. The results are similar to those from our preferred specification presented in Table 4.

Second, another way to account for this potential seasonality is to combine the regression discontinuity (RD) approach with the difference-in-differences (DD) methodology as in Dustmann and Schönberg (2012) and Carneiro, Løken and Salvanes (2015). Assuming that the effect of month of birth does not vary across birth cohorts, we can use data on children born in the same spacing intervals in years before the 24- and the 30-month cutoffs came into place in a placebo analysis, and then netting out the placebo-difference from the main estimate using an RD-DD design. For the 24-month regime, this prereform sample includes second-born children (and their older siblings) born in 1977-1978, and for the 30-month regime, the pre-reform sample includes second-born children (and their older siblings) born in 1977-1984. The results are presented in Tables A.4 and A.5 for the 24- and 30-month regime, respectively. 
The top panels of the tables depict the main RD results, the middle panels the placebo RD results (non-regime years), and the bottom panels the results from the RD-DD analysis. The results in the two tables show that the impacts of the educational outcomes of the older child from the RD-DD estimation are similar to those obtained in the RD, in particular for the college attendance outcome. The results on the second child are, however, mixed.

We perform three additional sensitivity checks. First, focusing on first-born children (for whom results survive the RD-DD specification), we estimate the impacts on their schooling outcomes using local linear regression with two different bandwidths: 20 and 16 weeks. The results are presented in Figure A.5 and Figure A.6, and show that our main results from the linear specification are robust also using non-parametric estimation.

Second, in Table A.6 and Table A.7, we show that the impacts on educational achievements are robust to variations of the size of the window of data around the cutoff. In particular, 20, 24 and 28 weeks, rather than 32 weeks, which is our baseline sample. Finally, in Table A.8 we re-estimate Equation 1 on the educational outcomes of children, adding year-of-birth fixed effects to take into account potential shocks common to all children born in the same years. These results are very similar to our main RD estimates.

We conclude that our analyses, taken together, suggest a positive effect of the SP on the schooling outcomes of the first-born child, in the 24-month regime. The results for the second-born child, and of the SP under the 30-month regime should be interpreted with caution, and do not allow a clear cut conclusion.

\subsection{Heterogeneous Effects by Child Gender \& by Maternal Income}

Next, we shed light on whether the impacts found on children's schooling outcomes differ by gender and with maternal baseline income. With respect to gender, earlier studies on the effects of maternity leave durations on child outcomes find that boys tend to benefit more from parental care compared to alternative child care (see e.g. Danzer and Lavy, 2017). Table 5 shows the impact of the SP on the educational outcomes of boys and girls for the 24- and 30-month regime, respectively. The results show that first-born boys and girls are similarly affected - in terms of GPA and college attendance - in the 24-month regime. For second-born children, the SP in this regime also yields a similar positive effect on the likelihood of college attendance. The SP in the 30-month regime, however, only seems to benefit first-born boys, except for a marginally significant but small positive impact on girls' likelihood of being 
eligible for high school. At the 10\% level, the impacts on boys' and girls' college attendance in the 24month regime survive adjustments for multiple hypotheses testing, while the impact on the second-born children do not. For the 30-month regime, the impact on first-born boys' college attendance also survives this adjustment.

Figure A.7 and Figure A.8 show that the effects on college attendance of first-born boys are robust also when estimated with local linear regression using varying bandwidths under both regimes, while we lose precision on the estimates for GPA. Figure A.9 and Figure A.10 show that also the impacts on first-born girls' GPA and college attendance are robust to the specification used.

Table 6 and Table 7 present the impacts on children's educational outcomes by the mother's position in the income distribution. Specifically, we divide the sample into three groups, based on mother's belonging to the tertile of the pre-first birth income distribution. For first-born children, there is a positive effect on college enrollment for the children of top- and bottom-income-group mothers, respectively. For children to top-income group mothers, there is also a positive effect on the first-born's GPA. Only the impacts on children to high-income mothers survive adjustments for multiple hypotheses testing, with an increase in the GPA of 6 percent of a standard deviation and of 4 percentage points in college attendance (relative to a control mean in attendance of 60\%). In general, we find no impacts of eligibility to the SP on the second-born child's outcomes. For the 30-month regime the impact of eligibility to the SP is diluted when we split the sample into income groups (see Table 7).

Figure A.11 and Figure A.12 show that the impacts on both GPA and college attendance for first-born children to high-income mothers are robust to estimating the discontinuity at the threshold using local linear regression with varying bandwidths.

\subsection{Birth parity}

We now study whether we can generalize our findings for children's educational outcomes to higherparity children. To do so, we sample all second- and third-born children in couples with at least three kids, and where the mother was not eligible for the SP with her first child, but eligible to PL benefits with the second child. ${ }^{20}$ The results are presented in Table 8, from which we note two things. First, there are positive effects on children's educational outcomes only for the lower-birth order child, i.e., the secondborn. This is consistent with the effects in the main sample in which only the first-born child benefited.

\footnotetext{
${ }^{20}$ We exclude mothers eligible for the speed-premium with her first child, to make sure that we calculate the correct qualifying income for wage replaced leave. That is, to whom we can use the labor income before the birth of the second child.
} 
Second, the positive effects on lower-birth order (second) child are apparent only under the 24-month regime. Again, this is consistent with our prior findings.

\section{Mechanisms}

From the analyses presented in the previous section, three main conclusions emerged: i.) maternal access to the SP had positive impacts on the first-born children, ii.) these effects were stronger (more beneficial) for children to high-income mothers, iii.) these effects were stronger under the 24-month regime. We find strikingly similar results for the second- and third-born children in families with at least three children. In this section, we probe the possible mechanisms. We consider the following potential explanations for the above findings. As explained in subsection 2.3, eligibility to the SP is likely to affect both the time and material resources available for parents when their children are young. It is possible that the SP induces different impacts on spousal labor supply and household total resources across the two regimes. Moreover, parental resources may be altered in the medium- or long-run if the SP affects the likelihood of having more children (family size). Second, the alternative mode of care to maternal care may differ across the two regimes. Third, for the first-born child, the SP induces additional investments at an earlier age compared to their counterparts in the 30 -month regime. ${ }^{21}$ In addition, parental investments may have differing impacts depending on the spacing of children. By design, there is a difference of 6 months at the cutoffs in the spacing of births across the two regimes. Our data does not allow us to explicitly separate between these channels. Instead, we analyze different outcomes that can be viewed as mediators, and perform subgroup analyses to arrive at tentative conclusions about which mechanisms are likely to be more important.

\subsection{Parental Time and Monetary Resources}

\subsubsection{Parental Labor Supply and Household Income}

We estimate Equation 1 for labor income earned in the calendar year before second birth to assess whether mothers who expect their benefits to be high irrespective of her labor supply, by virtue of the SP, will decrease their hours worked even before the second child is born. Ideally, we would have a less

\footnotetext{
${ }^{21}$ Previous evidence shows that investments made at an earlier stage of the child's life appears to have higher reward in terms of later life schooling outcomes (see e.g. Cunha, Heckman and Schennach, 2010). For example, studying sibling spillovers within families, Black et al. (2017) find that when a third child is disabled, the second-born child is more negatively affected than the first-born (older) sibling. This could be due to that the second-born child is younger at the time of the additional constraints posed on parents' money and time resources that arise through a new sibling with disabilities.
} 
crude measure of the timing of labor supply adjustments than that offered by calendar-year annual labor income. The annual nature of our income data implies that for women who give birth late in a calendar year, earnings measured in the calendar year before birth will understate a (potential) downward adjustment in market work during pregnancy. Nevertheless, estimating the effect on labor income in the year before will provide insights about whether mothers indeed react to future benefit levels. Similarly, earnings effects in the calendar year of birth will likely be a combination of pre-birth and year-of-birth labor supply responses, depending on when during the calendar year that the child is born. This feature of the data, however, does not pose issues for identification given that calendar month of birth is evenly distributed across birth spacing (see subsubsection 3.2.3).

We thus perform separate analyses for pre- and post-second birth labor income, where the post-birth income is the aggregate earnings over the calendar year of (second) birth and the calendar year after, i.e., over time periods $\tau=\kappa$ and $\tau=(\kappa+1)$. We study the impacts for mothers and fathers, and to learn about the total effect on the households' financial situation, we estimate the impact of the SP on the household's disposable income in the same time periods.

Table 9 presents the results. First, column (1) shows that mothers respond to future PL benefit levels under both SP regimes; labor supply of mothers in the year before second birth is reduced by nearly 6 percent in the 24 -month regime, and by about 4.7 percent in the 30 -month regime, relative to baseline earnings. Second, column (2) shows that labor supply also declines immediately post-birth for mothers, under both SP regimes. Thus, mothers respond to both future and current PL benefit levels. Third, fathers' labor supply increases, in particular in the post-birth period, under both regimes (column 4). In the 30-month regime, fathers also increase their market activities before the second child is born (column 3). Fourth, post-birth household disposable income is higher in couples where the mother is eligible for the SP (column 6).

In Table 10, we examine extensive margin labor supply reductions of mothers in the year before second birth, and in the year of second birth. Labor market participation is here defined as having positive labor earnings. There is a 1.4 and a (marginally significant) 0.7 percentage point decrease in the pre-second birth participation in the 24- and 30-month regime, respectively, for mothers just eligible to SP. Hence, the positive impacts on the first-born are not entirely driven by mothers reducing their hours of work while working (to e.g., reduce the child's hours per day or week in daycare), but also that they stop working altogether.

Figure 3 and Figure 4 graphically depict the estimated discontinuity at the threshold for mothers' and 
fathers' income, respectively, separately for the year before second birth, year of second birth, and year after second birth. There are some differences in the timing of effects across the two regimes. For mothers, the post-birth reduction in market activities is driven by the year-of-birth in the 24-month regime, while it is more apparent in the year after birth in the 30-month regime. Nevertheless, in both cases, the labor supply responses are made at an early stage of the children's lives. We have also estimated impacts for additional follow-up horizons; year-by-year estimates up to five years after second birth. The results are presented in Figure A.13. The positive effect on household income is driven by a persistent positive labor supply effect on the part of the fathers. Thus, the SP results in an improvement in the household's financial situation in the medium-run.

Looking at parental earnings in higher-parity families, i.e., parents with at least three children, Table A.10 shows that overall, the impacts on mothers' labor earnings are quantitatively similar across the two regimes, although imprecisely estimated for the 24-month regimes. The point estimates on the household's disposable income, however, shows that the SP only under the 24-month regime yields a net positive income shock, as was the case in the main sample.

Summing up, these findings suggest that mothers' leave-taking behavior responds to financial incentives in line with our prior that they will increase their time off from work when both future and current benefits are higher. ${ }^{22}$ We find that fathers adjust their labor supply in the opposite direction, i.e., increasing their labor supply, which yields a net positive effect on household disposable income post second birth. In percentage terms, the increase in household income is twice as large in the 24-month regime. If material resources matter for child outcomes, this may be an explanation for the larger effect of the 24-month regime on children's educational outcomes.

Robustness checks Here, we assess the sensitivity of the RD estimates on spousal and household earnings. The reason for this is the potential concern that parents with different birth spacing may have different earnings due to factors unrelated to the SP. To test this, we perform "placebo" RD estimations using couples in which the second child was born before the 24- and 30-month rules came into effect. For the 24-month regime, we restrict the sample to families in which the second child was born 1977-1978. For the 30-month regime, similar placebo tests are carried out for families whose second child was born 1977-1984. The results are presented in Table A.9. For the 24-month regime, none of the estimates are

\footnotetext{
${ }^{22}$ This is consistent with a recent working paper by Moberg (2017) who studies the effect of parental leave benefit level on the take-up of parental leave by both spouses by exploiting the 30-month threshold. Moberg (2017) finds that the 30-month speed premium increases mothers' benefit level for the second child, and thereby increases mothers' duration of parental leave with the second child.
} 
significantly different from zero for either mothers', fathers' or household earnings in either the pre- or post-birth time periods. Moreover, the point estimates are smaller in absolute terms, and of different sign than our main estimates. The same pattern holds true for the placebo tests of the 30-month regime, except for significant differences in household earnings. However, these estimates are of the opposite sign to the main estimates that showed a positive effect of the speed premium on household disposable income.

\subsubsection{Heterogeneous Effects by Mothers' Position in the Earnings Distribution}

For children, we found that the positive effects on (first-born) children's educational outcomes were driven by children to high-income mothers. Can this be explained by differing impacts on the parental resources across the earnings distribution? In Table 11 and Table 12 we report heterogeneous impacts on spousal earnings and household disposable income by the mother's position in the (maternal) pre-birth earnings distribution. For the 24-month regime, maternal labor supply responses are roughly similar across the earnings distribution. For fathers, however, the positive earnings impact is only apparent among those married to women in the top of the earnings distribution. The net effect on the household's disposable income is statistically and economically significant only among couples in which the mother is a top earner. The same pattern holds true in the 30-month regime. Similar to the average effects for the full sample, the increase in household disposable income among the top tertile group is almost twice as large in percentage terms in the 24-month regime compared to the 30 -month regime.

\subsubsection{Subsequent Fertility}

One possible channel through which the SP could affect children is family size. We estimate the effect of the SP on mothers' completed fertility. Under the 24-month regime, we find a marginally significant, but very small decrease in family size of 0.024 children. For the 30-month regime, we do not find effects on completed fertility. We conclude that changes in family size is unlikely an important channel for the impacts of the SP on children's educational outcomes.

\subsection{Alternative Mode of Care}

We now turn to study what is the mode of child care available to the existing child in the household when mothers engage in market work. For the period under study, there is no individual data on child care enrollment, but it is possible to gather national enrollment rates for children of different ages. This 
is presented in Figure A.14, that shows that for both 1- and 2-year old's the national enrollment rate is higher under the 30-months regime. For the period of 1980-1985 (24-months regime) the enrollment rate in child care among 1 year old was 10-18\% (i.e., the age of existing child in the household); whereas between 1986 and 1989 (30-months regime) this enrollment rate among 2 year old's (i.e., the age of existing child in the household) was over $30 \%$. Thus, if not with the mother, children should be more likely to be enrolled in informal outside-the-home care under the 24-month regime.

Moreover, impacts on pre-birth earnings for high-income mothers and their spouses displayed in Table 11 and Table 12 show that fathers do not increase their labor supply in the year before second birth in the 24-month regime, while they do so in the 30-month regime. This may indicate that for the first-born, there is a shift in time spent with fathers to mothers in the latter regime. If the difference in the quality of care provided by the spouses is lower than that between mothers and outside-the-home care, this could also explain why the SP benefits children only under the 24-month regime.

\subsection{Heterogeneity by Sibling Sex Composition}

So far, we have provided suggestive evidence that the positive effects of the SP on first-born children are larger in families where the first-born is younger at the time the mother receives the SP and thus when additional time- and monetary investments are made. However, across the 24- and 30-month regimes, not only the age of the first-born at SP receipt differs, but also the spacing between siblings; by 6 months. For instance, Breining et al. (2017) investigate birth order effects on delinquency in Florida and in Denmark (a country with similar institutional setting as Sweden), and find that negative birth order effects are larger in Denmark when the children are more closely spaced, suggesting that parental resources are diluted in families with tightly spaced births. Similar to Breining et al. (2017), we test this conjecture by analyzing the impacts on first-born children by sibling sex-mix. In particular, previous studies suggest that boys require more attention from parents (see e.g. Bertrand and Pan, 2013; Autor et al., 2016). Thus, children whose younger sibling is a boy should benefit more from the additional resources incurred by the SP if more closely spaced sibling pairs compete more intensively for parental resources than siblings with a greater age difference.

Table A.11 shows heterogeneous impacts on the first-born child by sibling sex-mix. First, irrespective of the gender of the first-born, the SP has positive impacts mainly when the second-born child is a boy. Second, for first-born boys, also the SP under the 30-month regime has positive impacts, if the younger sibling is a boy. In light of these findings, it is not likely that children compete for parental 
resources to differing extents depending on the age-difference of the siblings (albeit, here only a 6 month difference). Nor does the age at which additional investments are made seem a likely channel. Taken together, the results suggest that boys require more attention than girls and the arrival of a boy into the household, combined with additional time or monetary investments will have positive spillovers on the existing child. This would explain why the SP has greater impacts on first-born's in boy-boy and girl-boy families.

\section{Conclusions}

In an industrialized country setting where parents have access to state-provided paid family leave, are there positive impacts of additional early life material resources and parental time investments in children on health and educational outcomes? To address these questions, we exploit a feature of the Swedish parental leave (PL) system that generates variation in parental labor supply and income during the early years of their children's lives. The speed premium (SP) in the Swedish PL system grants mothers a higher parental leave benefit for a subsequent child without re-qualifying for benefits by going back to work, provided that the spacing between the births of the two children is below a pre-specified threshold. This threshold was set at 24 months between 1980 and 1985, and it was expanded to 30 months in 1986 (where it remains today). Thus, the SP carries incentives to reduce labor supply, while its potential effects on the disposable income are a priori ambiguous by virtue of a higher parental leave benefit level. We study the impacts of fulfilling the speed premium eligibility cutoff on the outcomes of the existing (first-born) and new (second-born) children. To understand the mechanisms through which this policy may impact children, we analyze the labor market earnings of mothers and their spouses, and also the family's disposable income; we also study the alternative child care available for existing children of mothers that become eligible to the SP, and the importance of the sex composition of the siblings.

Implementing a Regression Discontinuity (RD) framework comparing couples whose birth spacing is just below the eligibility threshold with those just above, we find that first-born children of just-eligible mothers fare better in terms of $9^{\text {th }}$ grade GPA, and are 3 percentage points more likely to have been enrolled in college degree by age 24 . The effects on the first-born child are stronger for children of higherincome mothers. Unlike for the first-born child, we do not find impacts at birth, on health in adolescence, or on the educational attainment of the second-born child in the full sample. While first-born boys and girls are similarly affected on average, the positive impacts on first-born children (irrespective of gender) 
are only apparent in families where the second-born child is a boy. Due to the lack of studies on changing household resources at a margin similar to ours, it is difficult to compare the size of our findings to others in the literature. Nevertheless, in the Swedish context Cesarini et al. (2016) find no impacts on birth and educational outcomes of children of lottery winners, despite a decrease in the labor supply of women (Cesarini et al., forthcoming). Studies on the introduction and expansion of paid leave in Norway find no impacts on college attendance of exposed children (Carneiro, Løken and Salvanes, 2015; Dahl et al., 2013), despite an increase in the likelihood of college attendance associated with the expansion of coverage of child care for 3-6 year old's in Norway (Havnes and Mogstad, 2011).

The impacts of the SP found in the present paper seem to be driven by an improvement in financial resources of the household, which in the first two years after the birth of the new child result from higher PL benefits and from an increase in the labor supply of fathers. This last impact is sustained up to five years after the birth of the new child. In addition, mothers just eligible to SP decrease their labor supply immediately during the new pregnancy upon finding that they will meet the eligibility to the SP. However, our findings suggest that total time and monetary resources are not likely to be the only drivers of the positive impacts on the outcomes of the existing child. We explore a other possible mechanisms. Namely, during the first time period studied, i.e., the 24-months regime (1980-1985), it is more likely that the alternative mode of care for children under the age of two would have been informal care instead of formal care for children under the age of three between 1986-1989 (30-months regime). This first period is also where we find stronger impacts of eligibility to SP on children's outcomes. Finally, our results suggest that boys require more attention than girls: the SP allows additional time and monetary investments in children, which benefits first-born boys and girls who have to share parental resources with a younger brother.

This research has implications for the discussion of family policies. First, the SP is a rule that generates variation in replacement rates, but it is found to be regressive in that it only benefits children to high-income mothers. Second, a policy intended to protect the labor market status of women has no long run impacts on her labor supply, but instead it improves overall household resources in medium run through increased labor supply of the husband. This last channel widens the male-female earningsgap within the household. Finally, the extended leave for mothers just eligible to the SP widens the birth order gap by improving the outcomes of the existing (older) child. 


\section{References}

Autor, David, David Figlio, Krzysztof Karbownik, Jeffrey Roth, and Melanie Wasserman. 2016. “Family Disadvantage and the Gender Gap in Behavioral and Educational Outcomes." National Bureau of Economic Research Working Paper 22267.

Avdic, Daniel, and Arizo Karimi. 2017. "Modern Family? Paternity Leave and Marital Stability." Mimeo.

Baker, Michael, and Kevin Milligan. 2008a. "How Does Job-Protected Maternity Leave Affect Mothers' Employment?" Journal of Labor Economics, 26(4): 655-691.

Baker, Michael, and Kevin Milligan. 2008b. "Maternal employment, breastfeeding, and health: Evidence from maternity leave mandates." Journal of Health Economics, 27(4): 871 - 887.

Baker, Michael, and Kevin Milligan. 2010. “Evidence from Maternity Leave Expansions of the Impact of Maternal Care on Early Child Development." Journal of Human Resources, 45(1): 1-32.

Baker, Michael, and Kevin Milligan. 2015. “Maternity leave and children's cognitive and behavioral development." Journal of Population Economics, 28(2): 373-391.

Baum, Charles L. 2003. "Does early maternal employment harm child development? An analysis of the potential benefits of leave taking." Journal of Labor Economics, 21(2): 409-448.

Bergemann, Annette, and Regina T. Riphahn. 2015. “Maternal Employment Effects of Paid Parental Leave." IZA Working Paper 9073.

Bertrand, Marianne, and Jessica Pan. 2013. “The Trouble with Boys: Social Influences and the Gender Gap in Disruptive Behavior." American Economic Journal: Applied Economics, 5(1): 32-64.

Björkegren, Evelina, and Helena Svaleryd. 2017. “Birth Order and Child Health." Mimeo.

Black, Sandra E., Erik Grönqvist, and Björn Öckert. 2017. “Born to Lead? The Effect of Birth Order on Non-Cognitive Abilities." National Bureau of Economic Research Working Paper 23393.

Black, Sandra E, Paul J Devereux, and Kjell G Salvanes. 2005. "The more the merrier? The effect of family size and birth order on children's education." The Quarterly Journal of Economics, 120(2): 669700. 
Black, Sandra E, Paul J Devereux, and Kjell G Salvanes. 2011. “Older and wiser? Birth order and IQ of young men." CESifo Economic Studies, 57(1): 103-120.

Black, Sandra E, Sanni Breining, David N Figlio, Jonathan Guryan, Krzysztof Karbownik, Helena Skyt Nielsen, Jeffrey Roth, and Marianne Simonsen. 2017. "Sibling Spillovers." National Bureau of Economic Research 23062.

Blundell, Richard, Luigi Pistaferri, and Ian Preston. 2008. “Consumption Inequality and Partial Insurance." American Economic Review, 98(5): 1887-1921.

Breining, Sanni N, Joseph J Doyle Jr, David N Figlio, Krzysztof Karbownik, and Jeffrey Roth. 2017. “Birth Order and Delinquency: Evidence from Denmark and Florida." National Bureau of Economic Research 23038.

Buckles, Kasey S, and Daniel M Hungerman. 2013. "Season of birth and later outcomes: Old questions, new answers." Review of Economics and Statistics, 95(3): 711-724.

Carneiro, Pedro, and Rita Ginja. 2016. "Partial Insurance and Investments in Children." The Economic Journal, 126(596): F66-F95.

Carneiro, Pedro, Katrine V Løken, and Kjell G Salvanes. 2015. “A flying start? Maternity leave benefits and long-run outcomes of children." Journal of Political Economy, 123(2): 365-412.

Cesarini, David, Erik Lindqvist, Matthew J. Notowidigdo, and Robert Östling. forthcoming. "The Effect of Wealth on Individual and Household Labor Supply: Evidence from Swedish Lotteries." American Economic Review.

Cesarini, David, Erik Lindqvist, Robert Östling, and Björn Wallace. 2016. “Wealth, Health, and Child Development: Evidence from Administrative Data on Swedish Lottery Players." The Quarterly Journal of Economics, 131(2): 687-738.

Cools, Sara, Jon H. Fiva, and Lars J. Kirkebøen. 2015. “Causal Effects of Paternity Leave on Children and Parents." The Scandinavian Journal of Economics, 117(3): 801-828.

Cunha, Flavio, James J Heckman, and Susanne M Schennach. 2010. “Estimating the technology of cognitive and noncognitive skill formation." Econometrica, 78(3): 883-931. 
Dahl, Gordon B, Katrine V Løken, and Magne Mogstad. 2014. "Peer effects in program participation." The American Economic Review, 104(7): 2049-2074.

Dahl, Gordon B, Katrine V Løken, Magne Mogstad, and Kari Vea Salvanes. 2013. "What is the case for paid maternity leave?" Review of Economics and Statistics, , (0).

Danzer, Natalia, and Victor Lavy. 2017. "Paid parental leave and children's schooling outcomes." The Economic Journal, forthcoming.

de Haan, Monique. 2010. "Birth order, family size and educational attainment." Economics of Education Review, 29(4): 576-588.

Dustmann, Christian, and Uta Schönberg. 2012. “Expansions in Maternity Leave Coverage and Children's Long-Term Outcomes." American Economic Journal: Applied Economics, 4(3): 190-224.

Ekberg, John, Rickard Eriksson, and Guido Friebel. 2013. "Parental leave-A policy evaluation of the Swedish “Daddy-Month" reform." Journal of Public Economics, 97: 131-143.

Han, Wen-Jui, Christopher Ruhm, and Jane Waldfogel. 2009. “Parental leave policies and parents' employment and leave-taking." Journal of Policy Analysis and Management, 28(1): 29-54.

Havnes, Tarjei, and Magne Mogstad. 2011. "No Child Left Behind: Subsidized Child Care and Children's Long-Run Outcomes." American Economic Journal: Economic Policy, 3(2): 97-129.

Hoem, Jan M. 1990. “Social Policy and Recent Fertility Change in Sweden." Population and Development Review, 16(4): 735-748.

Hoem, Jan M. 1993. "Public Policy as the Fuel of Fertility: Effects of a Policy Reform on the Pace of Childbearing in Sweden in the 1980s." Acta Sociologica, 36(1): 19-31.

Hotz, V Joseph, and Juan Pantano. 2015. "Strategic parenting, birth order, and school performance." Journal of Population Economics, 28(4): 911-936.

Karimi, Arizo, Erica Lindahl, and Peter Skogman Thoursie. 2012. "Labour supply responses to paid parental leave." Working Paper, IFAU-Institute for Evaluation of Labour Market and Education Policy.

Kluve, Jochen, and Marcus Tamm. 2013. "Parental leave regulations, mothers' labor force attachment and fathers' childcare involvement: evidence from a natural experiment." Journal of Population Economics, 26(3): 983-1005. 
Lalive, Rafael, and Josef Zweimüller. 2009. "How Does Parental Leave Affect Fertility and Return to Work? Evidence from Two Natural Experiments." The Quarterly Journal of Economics, 124(3): 1363-1402.

Lee, David S., and David Card. 2008. "Regression discontinuity inference with specification error." Journal of Econometrics, 142(2): 655 - 674. The regression discontinuity design: Theory and applications.

Lee, David S., and Thomas Lemieux. 2010. “Regression Discontinuity Designs in Economics." Journal of Economic Literature, 48(2).

Lequien, Laurent. 2012. "The Impact of Parental Leave Duration on Later Wages." Annals of Economics and Statistics, , (107/108): 267-285.

Liu, Qian, and Oskar Nordström Skans. 2010. “The duration of paid parental leave and children's scholastic performance." The BE Journal of Economic Analysis E Policy, 10(1).

Markus, Gregory B., and R. B. Zajonc. 1977. "Family configuration and intellectual development: A simulation." Behavioral Science, 22(2): 137-142.

McCrary, Justin. 2008. "Manipulation of the running variable in the regression discontinuity design: A density test." Journal of Econometrics, 142(2): 698-714.

Moberg, Ylva. 2017. “Speedy Responses: Effects of higher benefits on take-up and division of parental leave." Mimeo.

Pavan, Ronni. 2016. "On the Production of Skills and the Birth-Order Effect." Journal of Human Resources, 51(3): 699-726.

Persson, Petra, and Maya Rossin-Slater. 2016. "Family ruptures, stress, and the mental health of the next generation."

Pettersson-Lidbom, Per, and Peter Skogman Thoursie. 2009. “Does child spacing affect children's outcomes?" Institute for Labour Market Policy Evaluation, Uppsala, Working Paper, , (2009:7): 7.

Price, Joseph. 2008. "Parent-Child Quality Time: Does Birth Order Matter?" Journal of Human Resources, 43(1): 240-265.

Proposition, 1984/85:78. 1984. “Regeringens proposition om förbättringar inom föräldraförsäkringen, havandeskapspenningen och vissa regler inom sjukpenningförsäkringen." Swedish Government. 
Rasmussen, Astrid Würtz. 2010. "Increasing the length of parents' birth-related leave: The effect on children's long-term educational outcomes." Labour Economics, 17(1): 91-100.

Romano, Joseph P., and Michael Wolf. 2005. "Stepwise Multiple Testing as Formalized Data Snooping." Econometrica, 73(4): 1237-1282.

Rossin, Maya. 2011. “The effects of maternity leave on children's birth and infant health outcomes in the United States." Journal of Health Economics, 30(2): 221 - 239.

Rossin-Slater, Maya. 2017. “Maternity and Family Leave Policy.” National Bureau of Economic Research Working Paper 23069.

Rossin-Slater, Maya, Christopher J. Ruhm, and Jane Waldfogel. 2013. “The Effects of California's Paid Family Leave Program on Mothers' Leave-Taking and Subsequent Labor Market Outcomes." Journal of Policy Analysis and Management, 32(2): 224-245.

Ruhm, Christopher J. 1998. “The Economic Consequences of Parental Leave Mandates: Lessons from Europe*." The Quarterly Journal of Economics, 113(1): 285.

SCB, Statistics Sweden. 1989. "Förskolor, Fritidshem och familjedaghem." Statistics Sweden Serie S 1990.

Schönberg, Uta, and Johannes Ludsteck. 2014. “Expansions in Maternity Leave Coverage and Mothers' Labor Market Outcomes after Childbirth." Journal of Labor Economics, 32(3): 469-505.

SfU, 1984/85:12. 1984. “Socialförsäkringsutskottets betänkande om förbättringar inom föräldraförsäkringen, havandeskapspenningen och vissa regler inom sjukpenningförsäkringen (prop. 1984/85:78 delvis)." Swedish Parliament.

Stearns, Jenna. 2015. “The effects of paid maternity leave: Evidence from Temporary Disability Insurance." Journal of Health Economics, 43: 85-102.

Waldfogel, Jane. 1999. "The impact of the family and medical leave act." Journal of Policy Analysis and Management, 18(2): 281-302.

Zajonc, R. B. 1976. “Family Configuration and Intelligence.” Science, 192(4236): 227-236. 


\section{Tables and Figures}

TABLE 1.

Summary statistics

\begin{tabular}{|c|c|c|}
\hline & 24-month regime & 30-month regime \\
\hline \multicolumn{3}{|l|}{ Parental characteristics } \\
\hline Mother income 1 year pre $1^{\text {st }}$ first birth & $155.341(60.436)$ & $159.757(480.315)$ \\
\hline Mother income 4 years pre $1^{\text {st }}$ first birth & $112.519(69.944)$ & $113.617(126.303)$ \\
\hline Father income 4 years pre $1^{\text {st }}$ first birth & $152.264(998.493)$ & $154.395(935.438)$ \\
\hline Spousal age difference & $-2.772(3.766)$ & $-2.784(3.733)$ \\
\hline Mother Age at $1^{\text {st }}$ birth & $25.742(3.817)$ & $26.065(3.719)$ \\
\hline Father age at $1^{\text {st }}$ birth & $28.516(4.593)$ & $28.861(4.621)$ \\
\hline Mother income 1 year before $2^{\text {nd }}$ birth & $82.204(67.367)$ & $96.089(61.177)$ \\
\hline Father income 1 year before $2^{\text {nd }}$ birth & $189.831(210.085)$ & $207.413(104.537)$ \\
\hline Mother income 1 year after $2^{\text {nd }}$ & $66.503(64.244)$ & $61.205(55.276)$ \\
\hline Father income 1 year after $2^{\text {nd }}$ & $201.455(148.254)$ & $224.431(114.248)$ \\
\hline \multicolumn{3}{|l|}{ Characteristics of first-born child } \\
\hline Boy & $0.513(0.500)$ & $0.513(0.500)$ \\
\hline Gestation (weeks) & $39.699(1.796)$ & $39.435(1.793)$ \\
\hline Birth weight (grams) & $3476.001(514.395)$ & $3454.365(519.909)$ \\
\hline Pre-term birth & $0.045(0.207)$ & $0.054(0.225)$ \\
\hline Low birth weight & $0.031(0.173)$ & $0.035(0.183)$ \\
\hline Apgar $1 \mathrm{~min}$ & $8.663(1.154)$ & $8.676(1.204)$ \\
\hline No Hosp visits age 10 & $0.047(0.346)$ & $0.042(0.339)$ \\
\hline Grade-9 GPA (standardized) & $0.261(0.934)$ & $0.248(0.884)$ \\
\hline High school eligible & $0.950(0.219)$ & $0.944(0.230)$ \\
\hline At most compulsory schooling at age 24 & $0.076(0.265)$ & $0.061(0.239)$ \\
\hline At most High school at age 24 & $0.447(0.497)$ & $0.489(0.500)$ \\
\hline Some college/college at age 24 & $0.477(0.499)$ & $0.450(0.497)$ \\
\hline \multicolumn{3}{|l|}{ Characteristics of second-born child } \\
\hline Boy & $0.514(0.500)$ & $0.514(0.500)$ \\
\hline Gestation (weeks) & $39.502(1.628)$ & $39.492(1.587)$ \\
\hline Birth weight (grams) & $3582.268(519.882)$ & $3608.350(521.737)$ \\
\hline Pre-term birth & $0.035(0.184)$ & $0.033(0.178)$ \\
\hline Low birth weight & $0.021(0.143)$ & $0.021(0.142)$ \\
\hline Apgar $1 \mathrm{~min}$ & $8.890(0.911)$ & $8.856(0.913)$ \\
\hline No Hosp visits age 10 & $0.050(0.428)$ & $0.040(0.397)$ \\
\hline Grade-9 GPA (standardized) & $0.163(0.923)$ & $0.140(0.895)$ \\
\hline High school eligible & $0.939(0.240)$ & $0.933(0.250)$ \\
\hline At most compulsory schooling at age 24 & $0.071(0.256)$ & $0.062(0.242)$ \\
\hline At most High school at age 24 & $0.494(0.500)$ & $0.534(0.499)$ \\
\hline Some college/ college at age 24 & $0.435(0.496)$ & $0.404(0.491)$ \\
\hline Observations & 48,667 & 47,035 \\
\hline
\end{tabular}

NOTE.- Means and (standard deviations) of characteristics of parents, first-, and second-born children. The sample consists of all families whose second child was born 1980-1985 (24-month regime) and 1986-1989 (30month regime), respectively and whose first two children were born within 16-32 months from each other (24month regime), and 22-38 months from each other (30-month regime); i.e., speed premium eligibility cutoff + eight months. 


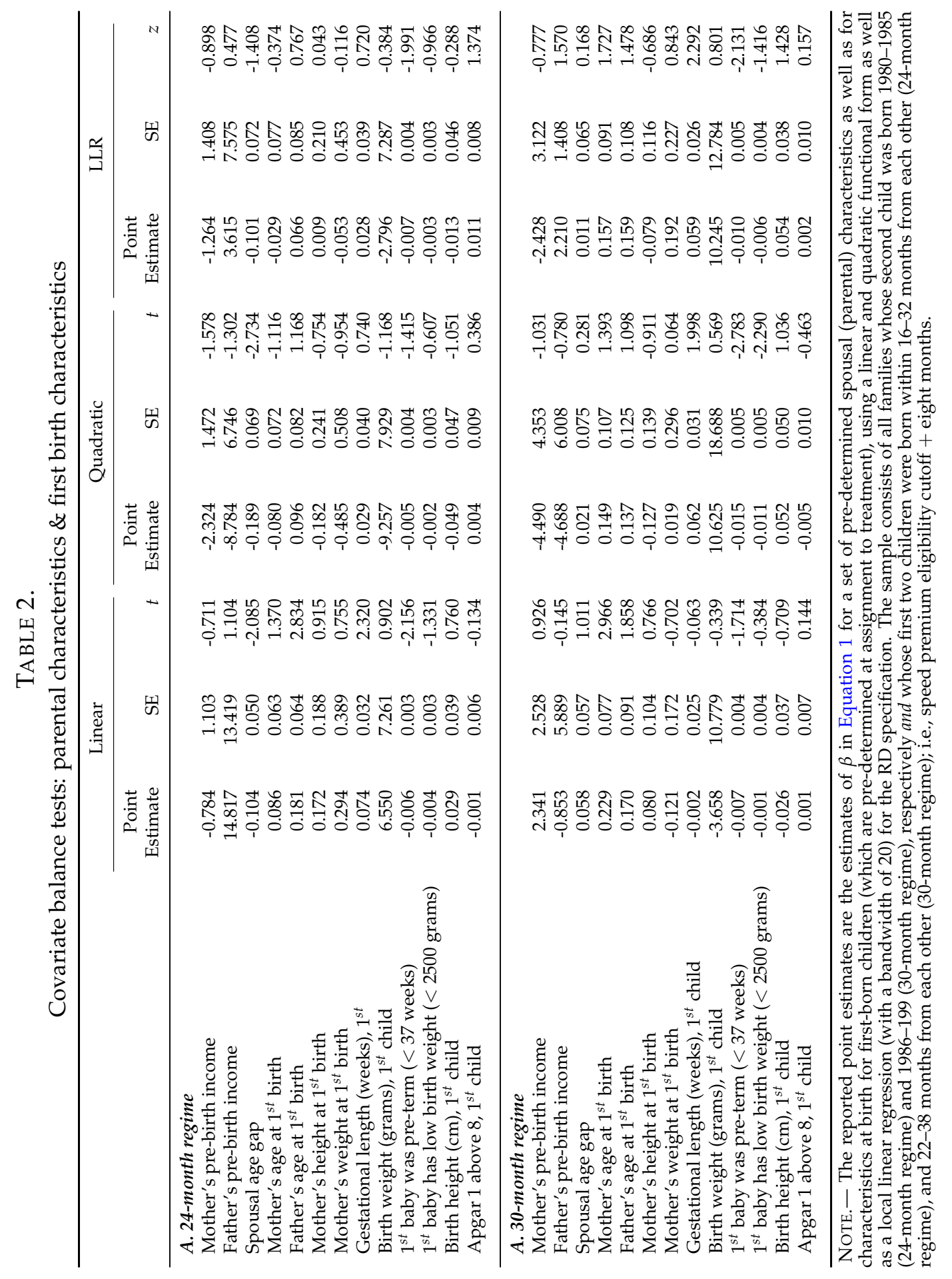


TABLE 3.

Regression Discontinuity estimates of the effect of the SP: second-born child's birth outcomes

\begin{tabular}{lccccccc}
\hline & $\begin{array}{c}(1) \\
\text { Birth } \\
\text { weight } \\
\text { (grams) }\end{array}$ & $\begin{array}{c}(2) \\
\text { Gestation } \\
\text { (weeks) }\end{array}$ & $\begin{array}{c}(3) \\
\text { Low birth } \\
\text { weight }\end{array}$ & $\begin{array}{c}(4) \\
\text { Preterm } \\
\text { birth }\end{array}$ & $\begin{array}{c}(5) \\
\text { Birth } \\
\text { height } \\
(\mathrm{cm})\end{array}$ & $\begin{array}{c}(6) \\
\text { Apgar-1 }\end{array}$ & $\begin{array}{c}(7) \\
\text { Apgar-5 }\end{array}$ \\
\hline $\begin{array}{l}\text { A. 24-month regime } \\
\text { Treated }(\hat{\beta})\end{array}$ & 6.662 & -0.031 & 0.000 & -0.000 & 0.035 & 0.002 & 0.014 \\
& $(8.651)$ & $(0.024)$ & $(0.002)$ & $(0.004)$ & $(0.041)$ & $(0.014)$ & $(0.011)$ \\
Observations & 47,923 & 48,069 & 47,923 & 48,069 & 47,926 & 47,703 & 44,567 \\
Mean of outcome & 3592 & 39.54 & 0.020 & 0.032 & 50.60 & 8.888 & 9.520 \\
$\hat{\beta} /$ Mean & 0.002 & -0.001 & 0.012 & -0.009 & 0.001 & 0.000 & 0.001 \\
\hline B. 30-month regime & & & & & & & \\
Treated $(\hat{\beta})$ & -2.754 & $\mathbf{0 . 0 8 4 * * *}$ & -0.002 & -0.006 & -0.023 & 0.026 & 0.016 \\
& $(10.425)$ & $\mathbf{( 0 . 0 3 1 )}$ & $(0.002)$ & $(0.004)$ & $(0.048)$ & $(0.016)$ & $(0.015)$ \\
Observations & 46,128 & 46,108 & 46,128 & 46,108 & 45,847 & 45,645 & 45,109 \\
Mean of outcome & 3609 & 39.50 & 0.021 & 0.034 & 50.62 & 8.849 & 9.771 \\
$\hat{\beta} /$ Mean & -0.001 & 0.002 & -0.071 & -0.163 & -0.001 & 0.003 & 0.002 \\
\hline
\end{tabular}

NOTE: Data is based on the samples described in columns (1) and (2) of Table 1, for the 24- and 30-month regime, respectively. The table reports the point estimate of $\beta$ from Equation 1 using a linear trend specification. The coefficient estimates displayed in bold are significant at 10\% level when inference is adjusted for multiple hypotheses testing. The mean of the outcome variable is calculated on the control group. Clustered standard errors (at birth week level) in parentheses. ${ }^{* * *} p<0.01,{ }^{* *} p<0.05,{ }^{*} p<0.1$. 


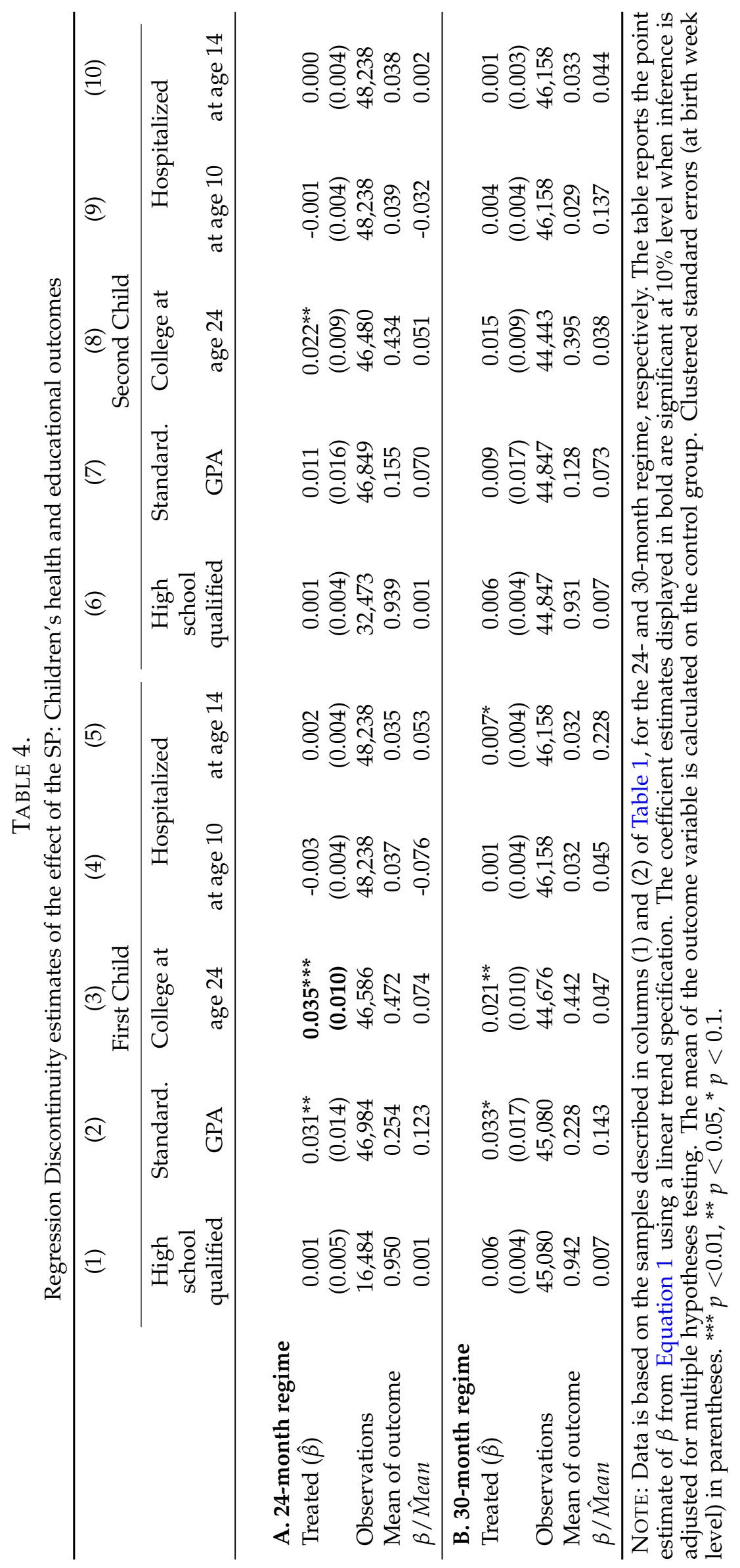


TABLE 5.

Regression Discontinuity estimates of the effect of the SP on children's educational outcomes: heterogeneous effects by child gender

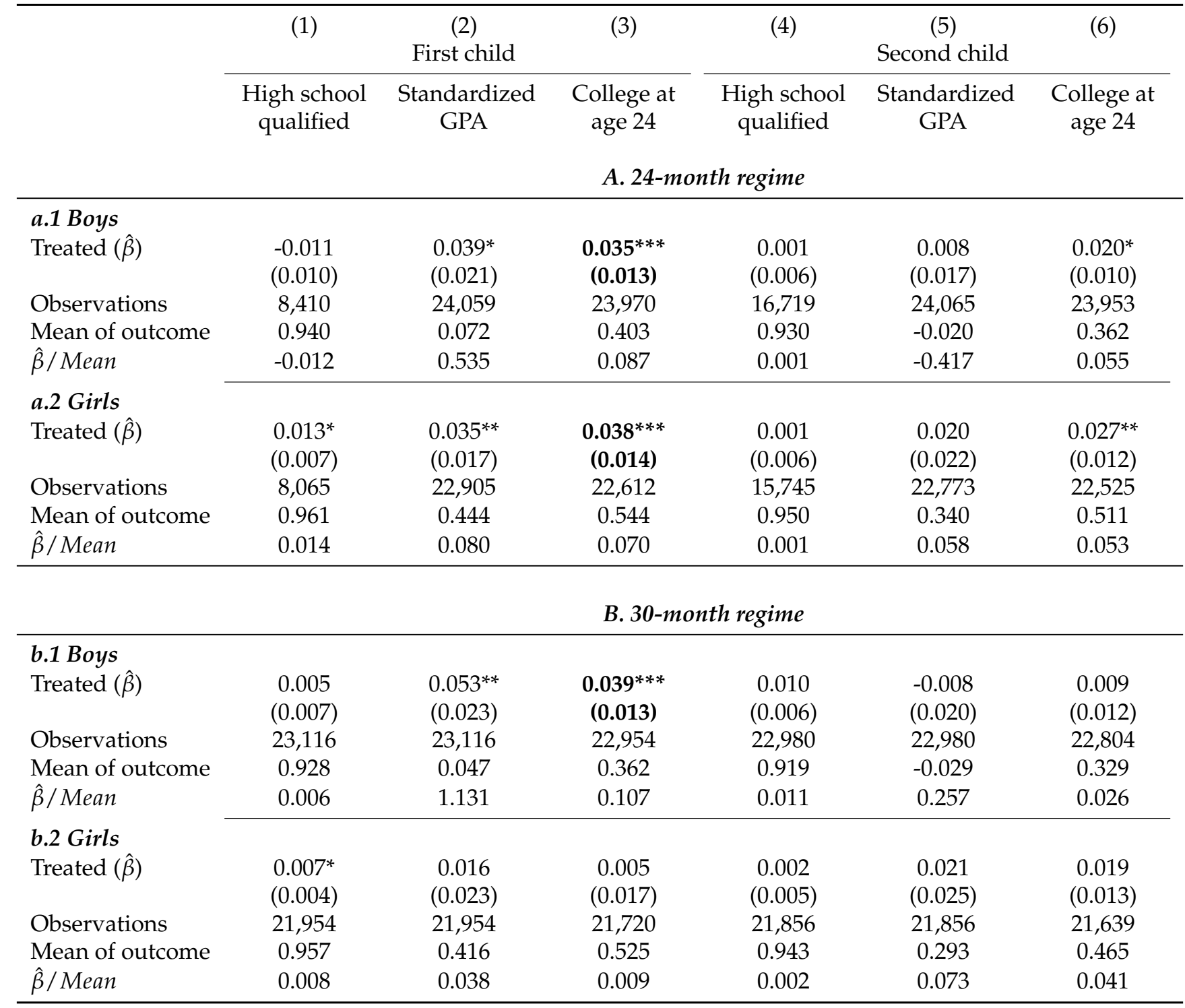

NOTE: Data is based on the samples described in columns (1) and (2) of Table 1, for the 24- and 30-month regime, respectively. The table reports the point estimate of $\beta$ from Equation 1 using a linear trend specification. The coefficient estimates displayed in bold are significant at $10 \%$ level when inference is adjusted for multiple hypotheses testing. The mean of the outcome variable is calculated on the control group. Clustered standard errors (at birth week level) in parentheses. ${ }^{* *} p<0.01,{ }^{* *} p<0.05,{ }^{*} p<0.1$. 


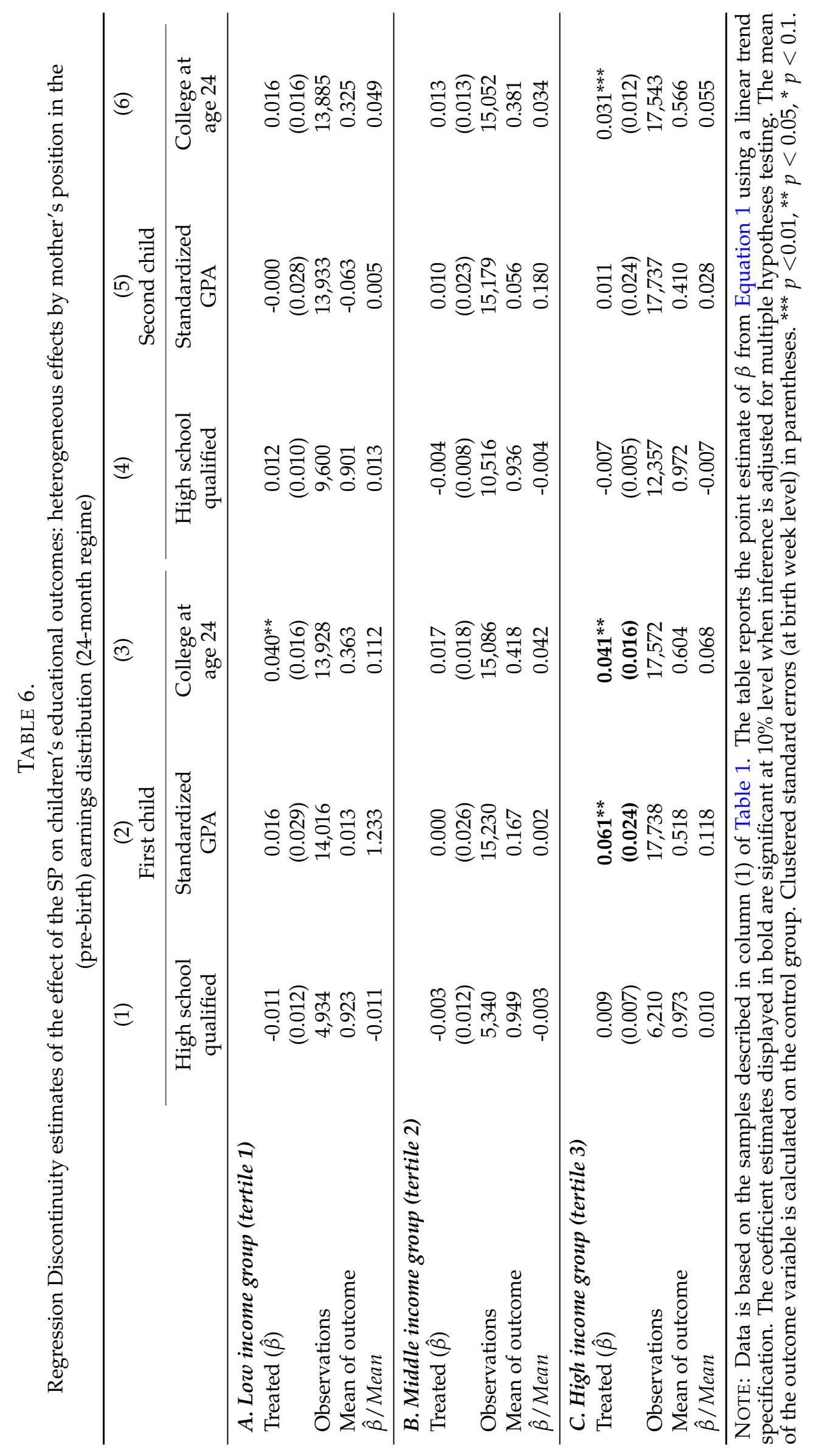




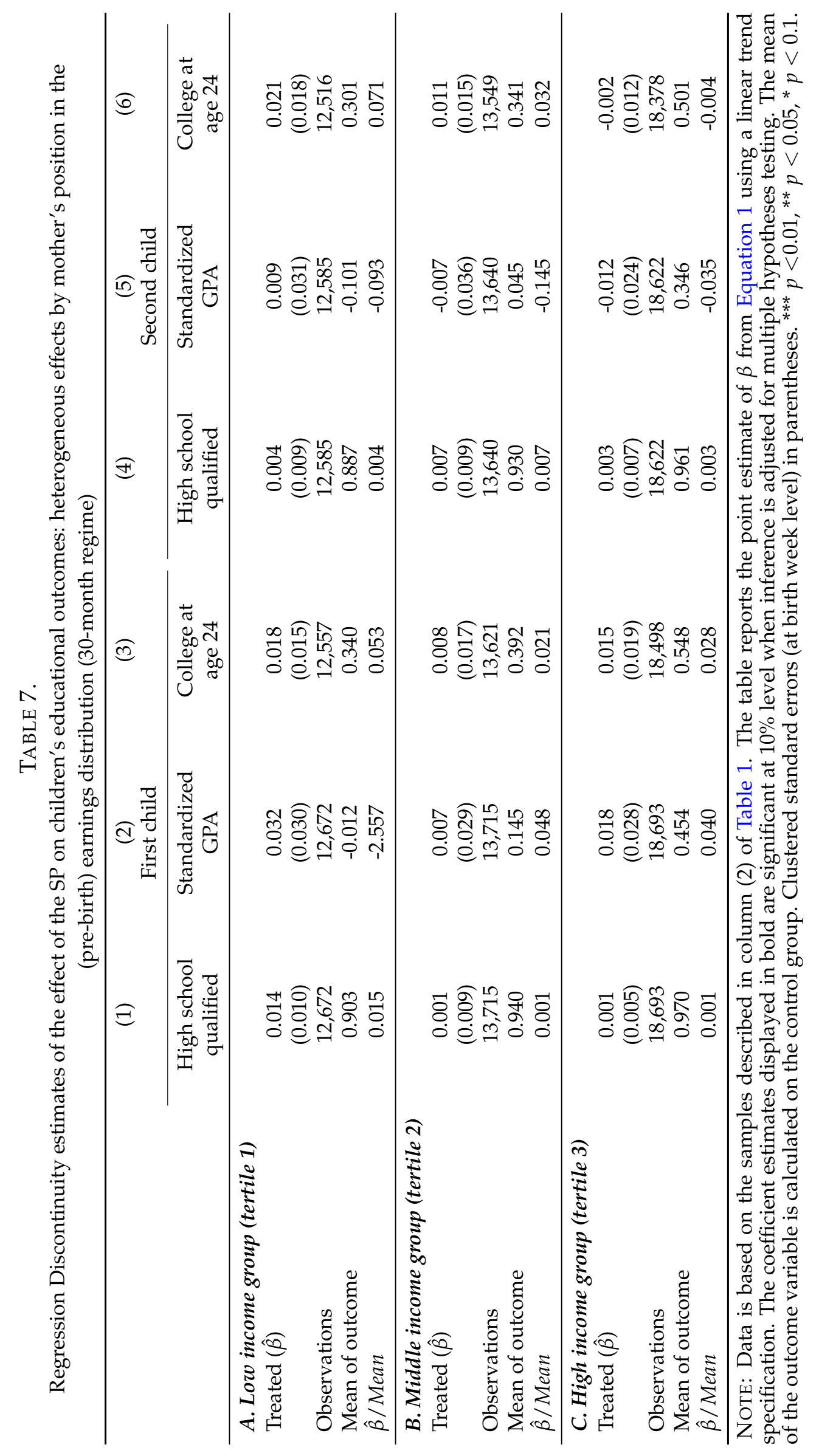


TABLE 8.

Regression Discontinuity estimates of the effect of the SP: educational outcomes of second- and third-born in three-child families

\begin{tabular}{|c|c|c|c|c|c|c|}
\hline & (1) & $\begin{array}{c}\text { (2) } \\
\text { Second child }\end{array}$ & (3) & (4) & $\begin{array}{l}\text { (5) } \\
\text { Third child }\end{array}$ & (6) \\
\hline & $\begin{array}{l}\text { High school } \\
\text { qualified }\end{array}$ & $\begin{array}{l}\text { Standardized } \\
\text { GPA }\end{array}$ & $\begin{array}{l}\text { College at } \\
\text { age } 24\end{array}$ & $\begin{array}{l}\text { High school } \\
\text { qualified }\end{array}$ & $\begin{array}{l}\text { Standardized } \\
\text { GPA }\end{array}$ & $\begin{array}{c}\text { College at } \\
\text { age } 24\end{array}$ \\
\hline $\begin{array}{l}\text { A. 24-month regime } \\
\text { Treated }(\hat{\beta})\end{array}$ & $\begin{array}{c}-0.002 \\
(0.014)\end{array}$ & $\begin{array}{c}0.111^{* * *} \\
(0.030)\end{array}$ & $\begin{array}{c}0.062^{* * *} \\
(0.020)\end{array}$ & $\begin{array}{c}-0.011 \\
(0.012)\end{array}$ & $\begin{array}{c}0.054 \\
(0.038)\end{array}$ & $\begin{array}{c}0.017 \\
(0.021)\end{array}$ \\
\hline $\begin{array}{l}\text { Observations } \\
\text { Mean of outcome } \\
\hat{\beta} / \text { Mean }\end{array}$ & $\begin{array}{r}3,741 \\
0.933 \\
-0.002\end{array}$ & $\begin{array}{l}9,436 \\
0.088 \\
1.253\end{array}$ & $\begin{array}{l}9,382 \\
0.409 \\
0.151\end{array}$ & $\begin{array}{c}6,935 \\
0.918 \\
-0.012\end{array}$ & $\begin{array}{l}9,609 \\
0.036 \\
1.497\end{array}$ & $\begin{array}{l}9,533 \\
0.402 \\
0.044\end{array}$ \\
\hline $\begin{array}{l}\text { B. } 30 \text {-month regime } \\
\text { Treated }(\hat{\beta})\end{array}$ & $\begin{array}{l}0.019^{*} \\
(0.011)\end{array}$ & $\begin{array}{c}0.038 \\
(0.026)\end{array}$ & $\begin{array}{l}-0.005 \\
(0.022)\end{array}$ & $\begin{array}{c}0.009 \\
(0.014)\end{array}$ & $\begin{array}{c}0.041 \\
(0.044)\end{array}$ & $\begin{array}{c}0.028 \\
(0.020)\end{array}$ \\
\hline $\begin{array}{l}\text { Observations } \\
\text { Mean of outcome } \\
\hat{\beta} / \text { Mean }\end{array}$ & $\begin{array}{l}9,876 \\
0.922 \\
0.021\end{array}$ & $\begin{array}{l}9,876 \\
0.097 \\
0.392\end{array}$ & $\begin{array}{r}9,835 \\
0.395 \\
-0.012\end{array}$ & $\begin{array}{l}9,868 \\
0.910 \\
0.010\end{array}$ & $\begin{array}{l}9,868 \\
0.006 \\
6.738\end{array}$ & $\begin{array}{l}9,796 \\
0.378 \\
0.074\end{array}$ \\
\hline
\end{tabular}

NOTE: Data is based on samples corresponding to those described in columns (1) and (2) of Table 1, for the 24- and 30-month regime, respectively, but using families with at least three children, and for which the parent receives or just fails to receive the SP for the third-born child. The table reports the point estimate of $\beta$ from Equation 1 using a linear trend specification. The coefficient estimates displayed in bold are significant at $10 \%$ level when inference is adjusted for multiple hypotheses testing. The mean of the outcome variable is calculated on the control group. Clustered standard errors (at birth week level) in parentheses. ${ }^{* * *} p<0.01,{ }^{* *} p<0.05,{ }^{*} p<0.1$. 
TABLE 9.

Regression Discontinuity estimates of the effect of the SP: spousal and household earnings

\begin{tabular}{|c|c|c|c|c|c|c|}
\hline \multirow[b]{3}{*}{ Years since birth, $2^{\text {nd }}$ birth } & \multirow{2}{*}{\multicolumn{2}{|c|}{$\begin{array}{l}(1) \\
\text { Mother's income }\end{array}$}} & \multirow{2}{*}{\multicolumn{2}{|c|}{$\begin{array}{l}(3) \\
\text { Father's income }\end{array}$}} & & \\
\hline & & & & & \multicolumn{2}{|c|}{ HH disp. income } \\
\hline & Pre-birth & Post birth & Pre-birth & Post birth & Pre-birth & Post birth \\
\hline \multicolumn{7}{|l|}{ 24-month regime } \\
\hline Treated $(\hat{\beta})$ & $\begin{array}{c}-5.458^{* * *} \\
(1.033)\end{array}$ & $\begin{array}{l}-3.436^{* *} \\
(1.607)\end{array}$ & $\begin{array}{l}-1.839 \\
(3.011)\end{array}$ & $\begin{array}{c}10.656^{* *} \\
(4.771)\end{array}$ & $\begin{array}{c}2.455 \\
(1.603)\end{array}$ & $\begin{array}{c}15.374^{* * *} \\
(2.596)\end{array}$ \\
\hline Observations & 47,873 & 47,434 & 47,960 & 47,555 & 48,238 & 48,238 \\
\hline Mean of outcome & 93.99 & 134 & 193.1 & 397.2 & 228.1 & 491.3 \\
\hline$\hat{\beta} /$ Mean & -0.058 & -0.026 & -0.010 & 0.027 & 0.011 & 0.031 \\
\hline \multicolumn{7}{|l|}{ 30-month regime } \\
\hline Treated $(\hat{\beta})$ & $\begin{array}{c}-5.562^{* * *} \\
(0.984)\end{array}$ & $\begin{array}{c}-4.476^{* * *} \\
(1.268)\end{array}$ & $\begin{array}{c}5.293^{* * *} \\
(1.858)\end{array}$ & $\begin{array}{c}10.477^{* *} \\
(4.001)\end{array}$ & $\begin{array}{c}1.593 \\
(1.329)\end{array}$ & $\begin{array}{l}9.022^{* *} \\
(3.420)\end{array}$ \\
\hline Observations & 46,098 & 46,120 & 45,961 & 45,979 & 46,158 & 46,158 \\
\hline Mean of outcome & 118.6 & 124.3 & 208.3 & 435.5 & 280.2 & 593.2 \\
\hline$\hat{\beta} /$ Mean & -0.047 & -0.036 & 0.025 & 0.024 & 0.006 & 0.015 \\
\hline
\end{tabular}

NOTE: Data is based on the samples described in columns (1) and (2) of Table 1, for the 24- and 30-month regime, respectively. The table reports the point estimate of $\beta$ from Equation 1 using a linear trend specification. The prebirth outcome is measured in time period $\tau=(\kappa-1)$, where $\kappa$ denotes the calendar year of birth of the second child. The post-birth outcomes aggregates the incomes over the time periods $\tau=\kappa$ and $\tau=(\kappa+1)$. The coefficient estimates displayed in bold are significant at $10 \%$ level when inference is adjusted for multiple hypotheses testing. The mean of the outcome variable is calculated on the control group. Clustered standard errors (at birth week level) in parentheses. ${ }^{* *} p<0.01,{ }^{* *} p<0.05,{ }^{*} p<0.1$. 
TABLE 10.

Regression Discontinuity estimates of the effect of the SP: maternal labor market participation

(1)

24-month

regime
(2)
(3)

30-month

regime

\begin{tabular}{|c|c|c|c|c|}
\hline \multirow[b]{2}{*}{ Years since 2nd birth } & & \\
\hline & $\tau=(\kappa-1)$ & $\tau=\kappa$ & $\tau=(\kappa-1)$ & $\tau=\kappa$ \\
\hline Treated $(\hat{\beta})$ & $\begin{array}{r}-0.013^{* * *} \\
(0.005)\end{array}$ & $\begin{array}{r}-0.008 \\
(0.006)\end{array}$ & $\begin{array}{l}-0.007^{*} \\
(0.004)\end{array}$ & $\begin{array}{r}-0.007 \\
(0.005)\end{array}$ \\
\hline Observations & 47,873 & 47,835 & 46,098 & 46,148 \\
\hline Mean of outcome & 0.940 & 0.890 & 0.973 & 0.946 \\
\hline$\hat{\beta} /$ Mean & -0.014 & -0.009 & -0.007 & -0.007 \\
\hline
\end{tabular}

NOTE: Data is based on the samples described in columns (1) and (2) of Table 1, for the 24- and 30-month regime, respectively. The table reports the point estimate of $\beta$ from Equation 1 using a linear trend specification. The outcome is measured in time period $\tau=(\kappa-1)$, where $\kappa$ denotes the calendar year of birth of the second child, and in time period $\tau=\kappa$. The mean of the outcome variable is calculated on the control group. Clustered standard errors (at birth week level) in parentheses. ${ }^{* * *} p<0.01,{ }^{* *} p<0.05,{ }^{*} p<0.1$. 
TABLE 11.

Regression Discontinuity estimates of the effect of the SP: spousal and household earnings by mother's position in the (pre-birth) earnings distribution (24-month regime)

\begin{tabular}{|c|c|c|c|c|c|c|}
\hline \multirow[b]{3}{*}{ Years since birth, $2^{\text {nd }}$ birth } & \multirow{2}{*}{\multicolumn{2}{|c|}{$\begin{array}{l}(1) \\
\text { Mother's income }\end{array}$}} & \multirow{2}{*}{\multicolumn{2}{|c|}{$\begin{array}{l}(3) \quad(4) \\
\text { Father's income }\end{array}$}} & \multirow{2}{*}{\multicolumn{2}{|c|}{$\begin{array}{l}(5) \\
\text { HH disp. income }\end{array}$}} \\
\hline & & & & & & \\
\hline & Pre-birth & Post birth & Pre-birth & Post birth & Pre-birth & Post birth \\
\hline \multicolumn{7}{|c|}{ A. Lowest income group (tertile 1) } \\
\hline Treated $(\hat{\beta})$ & $\begin{array}{c}-6.786^{* * *} \\
(1.532)\end{array}$ & $\begin{array}{l}-4.265^{* *} \\
(2.094)\end{array}$ & $\begin{array}{l}-3.038 \\
(5.179)\end{array}$ & $\begin{array}{l}16.605^{*} \\
(9.104)\end{array}$ & $\begin{array}{l}-1.199 \\
(2.430)\end{array}$ & $\begin{array}{l}8.206^{* *} \\
(4.075)\end{array}$ \\
\hline Observations & 14,339 & 14,149 & 14,376 & 14,229 & 14,480 & 14,480 \\
\hline Mean of outcome & 63.36 & 83.68 & 169.6 & 351.9 & 201.4 & 441.4 \\
\hline$\hat{\beta} /$ Mean & -0.107 & -0.051 & -0.018 & 0.047 & -0.006 & 0.019 \\
\hline \multicolumn{7}{|c|}{ B. Middle income group (tertile 2) } \\
\hline Treated $(\hat{\beta})$ & $\begin{array}{c}-6.310^{* * *} \\
(1.576)\end{array}$ & $\begin{array}{c}-6.177^{* * *} \\
(2.237)\end{array}$ & $\begin{array}{l}-6.141 \\
(5.360)\end{array}$ & $\begin{array}{l}-1.272 \\
(5.466)\end{array}$ & $\begin{array}{l}-1.508 \\
(2.076)\end{array}$ & $\begin{array}{l}8.531^{* *} \\
(3.740)\end{array}$ \\
\hline Observations & 15,456 & 15,311 & 15,482 & 15,351 & 15,572 & 15,572 \\
\hline Mean of outcome & 83.12 & 109 & 187.3 & 379.7 & 219.1 & 468.5 \\
\hline$\hat{\beta} /$ Mean & -0.076 & -0.057 & -0.033 & -0.003 & -0.007 & 0.018 \\
\hline \multicolumn{7}{|c|}{ C. Highest income group (tertile 3) } \\
\hline Treated $(\hat{\beta})$ & $\begin{array}{c}-5.366^{* * *} \\
(1.888)\end{array}$ & $\begin{array}{l}-3.635 \\
(3.999)\end{array}$ & $\begin{array}{l}1.454 \\
(6.290)\end{array}$ & $\begin{array}{c}13.525^{* *} \\
(6.143)\end{array}$ & $\begin{array}{c}6.978^{* * *} \\
(2.306)\end{array}$ & $\begin{array}{c}23.898^{* * *} \\
(3.758)\end{array}$ \\
\hline Observations & 18,078 & 17,974 & 18,102 & 17,975 & 18,186 & 18,186 \\
\hline Mean of outcome & 127.5 & 194.9 & 216.6 & 447.6 & 257 & 550.4 \\
\hline$\hat{\beta} /$ Mean & -0.042 & -0.019 & 0.007 & 0.030 & 0.027 & 0.043 \\
\hline
\end{tabular}

NOTE: Data is based on the samples described in column (1) of Table 1. The table reports the point estimate of $\beta$ from Equation 1 using a linear trend specification. The pre-birth outcome is measured in time period $\tau=(\kappa-1)$, where $\kappa$ denotes the calendar year of birth of the second child. The post-birth outcomes aggregates the incomes over the time periods $\tau=\kappa$ and $\tau=(\kappa+1)$. The coefficient estimates displayed in bold are significant at $10 \%$ level when inference is adjusted for multiple hypotheses testing. The mean of the outcome variable is calculated on the control group. Clustered standard errors (at birth week level) in parentheses. ${ }^{* * *} p<0.01,{ }^{* *} p<0.05{ }^{*} p<$ 0.1 . 
TABLE 12.

Regression Discontinuity estimates of the effect of the SP: spousal and household earnings by mother's position in the (pre-birth) earnings distribution (30-month regime

\begin{tabular}{|c|c|c|c|c|c|c|}
\hline \multirow[b]{3}{*}{ Years since birth, $2^{\text {nd }}$ birth } & \multirow{2}{*}{\multicolumn{2}{|c|}{$\begin{array}{l}(1) \quad(2) \\
\text { Mother's income }\end{array}$}} & \multirow{2}{*}{\multicolumn{2}{|c|}{$\begin{array}{l}(3) \\
\text { Father's income }\end{array}$}} & \multirow{2}{*}{\multicolumn{2}{|c|}{$\begin{array}{l}(5) \\
\text { HH disp. income }\end{array}$}} \\
\hline & & & & & & \\
\hline & Pre-birth & Post birth & Pre-birth & Post birth & Pre-birth & Post birth \\
\hline \multicolumn{7}{|c|}{ A. Lowest income group (tertile 1) } \\
\hline Treated $(\hat{\beta})$ & $\begin{array}{c}-5.596^{* * *} \\
(1.489)\end{array}$ & $\begin{array}{c}-7.556^{* * *} \\
(2.073)\end{array}$ & $\begin{array}{l}2.396 \\
(2.766)\end{array}$ & $\begin{array}{l}3.737 \\
(6.675)\end{array}$ & $\begin{array}{l}-2.279 \\
(1.979)\end{array}$ & $\begin{array}{l}-0.658 \\
(3.842)\end{array}$ \\
\hline Observations & 13,048 & 13,049 & 13,002 & 13,000 & 13,063 & 13,063 \\
\hline Mean of outcome & 88.02 & 92.22 & 184 & 385.9 & 257.2 & 551.1 \\
\hline$\hat{\beta} /$ Mean & -0.064 & -0.082 & 0.013 & 0.010 & -0.009 & -0.001 \\
\hline \multicolumn{7}{|c|}{ B. Middle income group (tertile 2) } \\
\hline Treated $(\hat{\beta})$ & $\begin{array}{c}-7.197^{* * *} \\
(1.966)\end{array}$ & $\begin{array}{c}-5.478^{* * * *} \\
(1.916)\end{array}$ & $\begin{array}{c}0.944 \\
(3.481)\end{array}$ & $\begin{array}{l}1.270 \\
(7.482)\end{array}$ & $\begin{array}{l}-2.256 \\
(2.146)\end{array}$ & $\begin{array}{l}0.955 \\
(4.725)\end{array}$ \\
\hline Observations & 14,000 & 14,010 & 13,950 & 13,963 & 14,020 & 14,020 \\
\hline Mean of outcome & 112 & 110.7 & 201.3 & 419.8 & 270.9 & 572.1 \\
\hline$\hat{\beta} /$ Mean & -0.064 & -0.050 & 0.005 & 0.003 & -0.008 & 0.002 \\
\hline \multicolumn{7}{|c|}{ C. Highest income group (tertile 3) } \\
\hline Treated $(\hat{\beta})$ & $\begin{array}{c}-7.950^{* * *} \\
(2.023)\end{array}$ & $\begin{array}{c}-6.320^{* * *} \\
(1.837)\end{array}$ & $\begin{array}{l}7.178^{* *} \\
(2.778)\end{array}$ & $\begin{array}{c}14.941^{* * *} \\
(5.391)\end{array}$ & $\begin{array}{l}3.763^{*} \\
(2.075)\end{array}$ & $\begin{array}{c}15.049^{* * *} \\
(4.528)\end{array}$ \\
\hline Observations & 19,050 & 19,061 & 19,009 & 19,016 & 19,075 & 19,075 \\
\hline Mean of outcome & 144.7 & 156.8 & 230.4 & 481.6 & 303.2 & 638.2 \\
\hline$\hat{\beta} /$ Mean & -0.055 & -0.040 & 0.031 & 0.031 & 0.012 & 0.024 \\
\hline
\end{tabular}

NOTE: Data is based on the samples described in column (2) of Table 1. The table reports the point estimate of $\beta$ from Equation 1 using a linear trend specification. The pre-birth outcome is measured in time period $\tau=(\kappa-1)$, where $\kappa$ denotes the calendar year of birth of the second child. The post-birth outcomes aggregates the incomes over the time periods $\tau=\kappa$ and $\tau=(\kappa+1)$. The coefficient estimates displayed in bold are significant at $10 \%$ level when inference is adjusted for multiple hypotheses testing. The mean of the outcome variable is calculated on the control group. Clustered standard errors (at birth week level) in parentheses. ${ }^{* * *} p<0.01,{ }^{* *} p<0.05{ }^{*} p<$ 0.1 . 


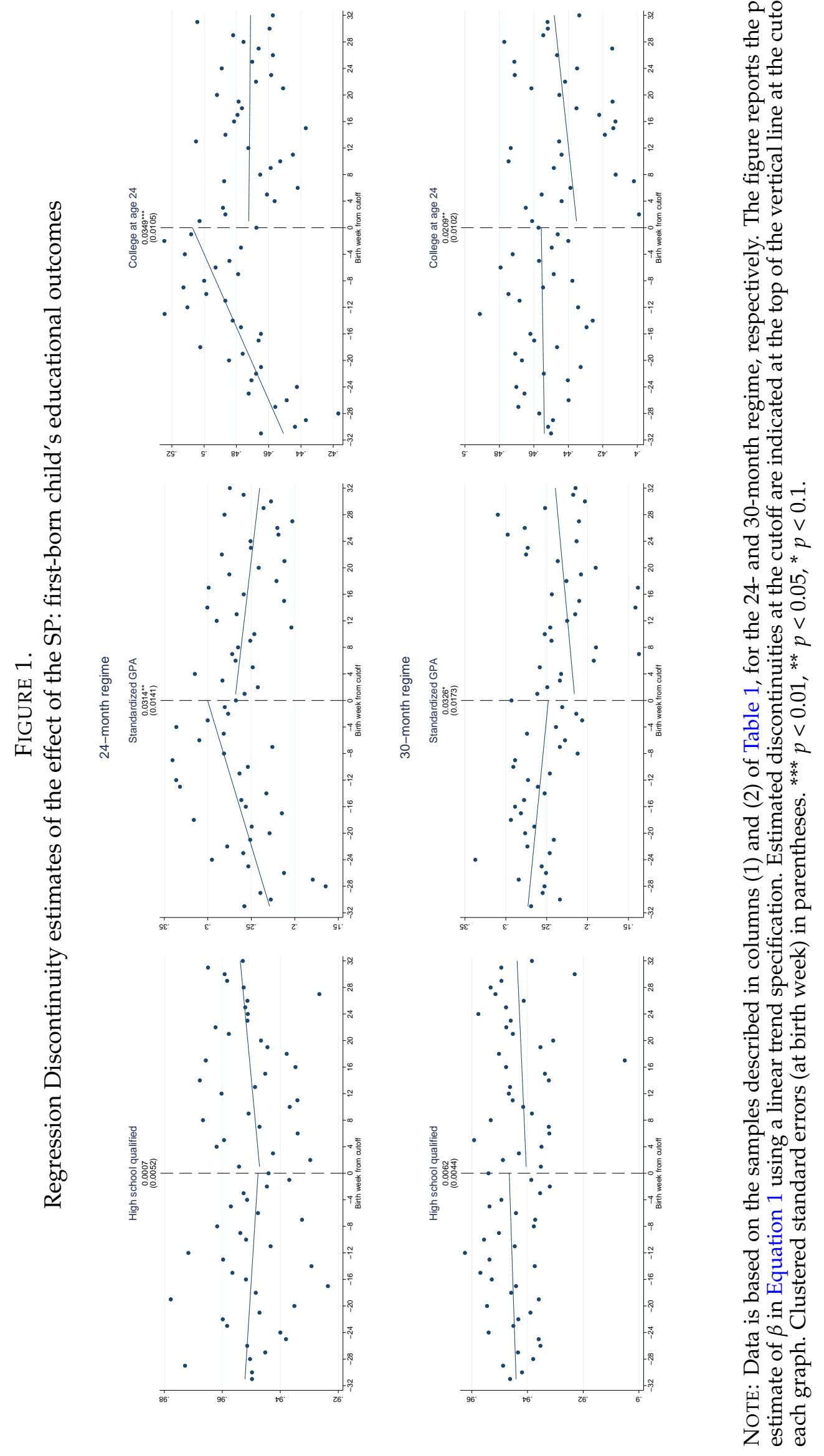






44 


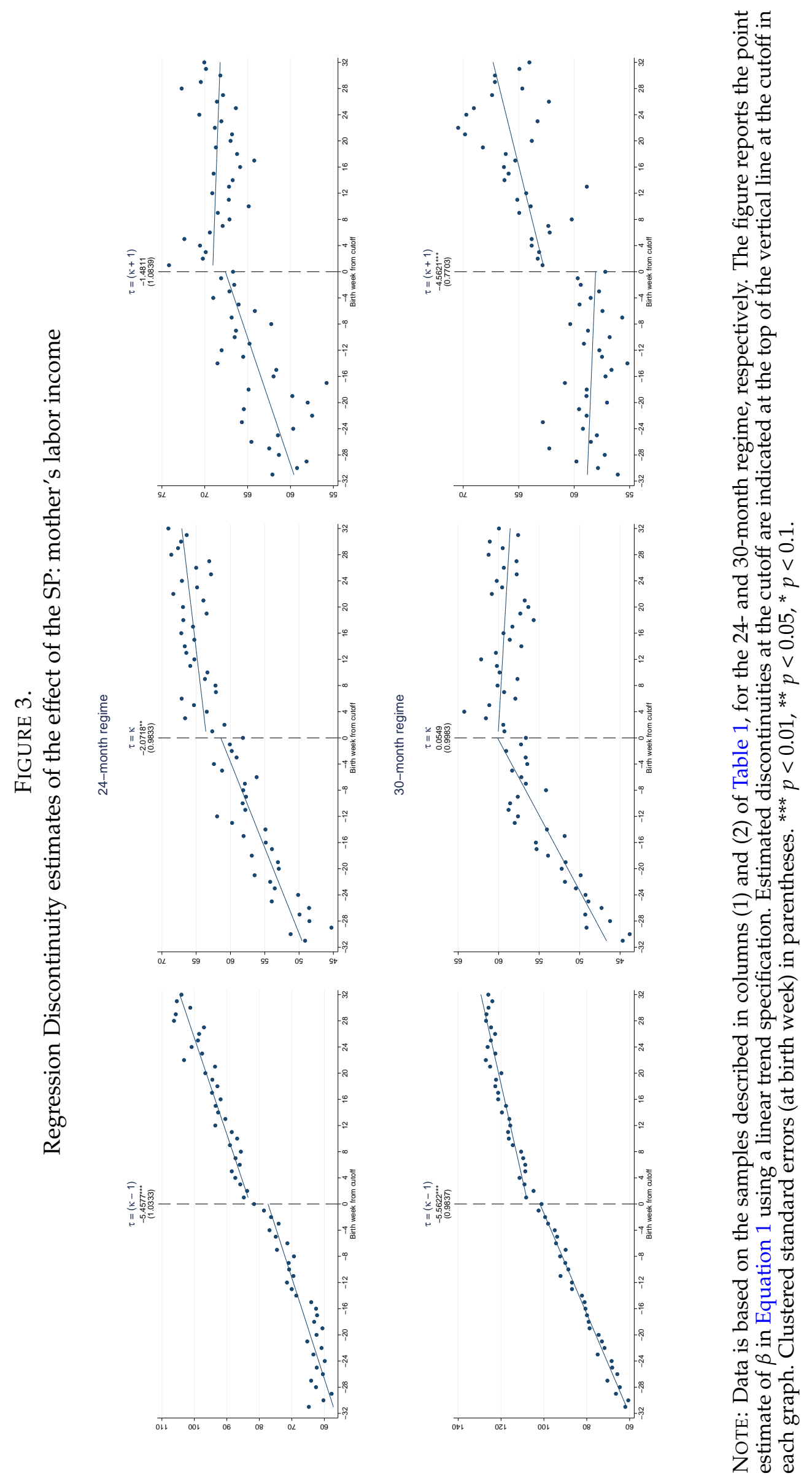




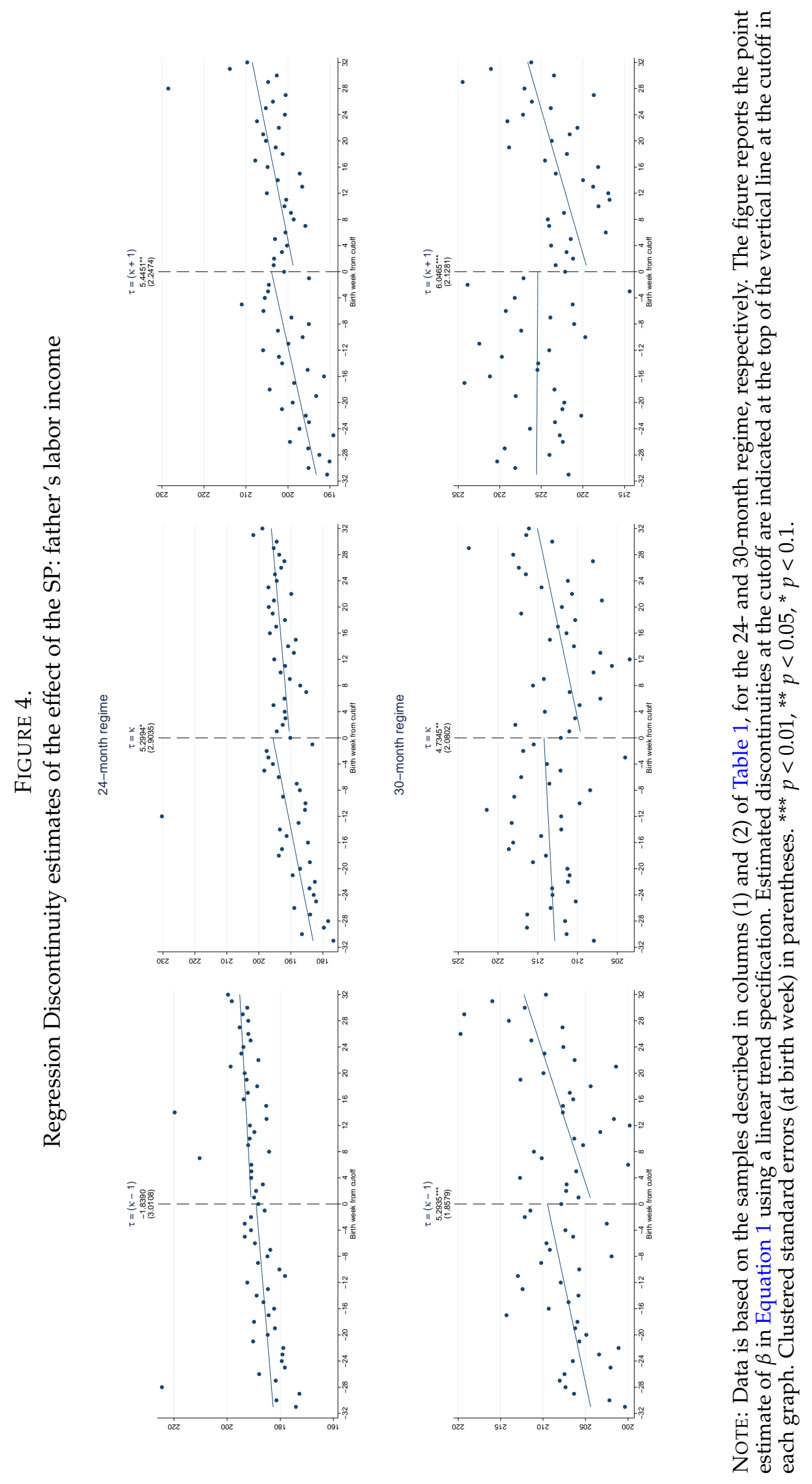


Parental Investments in Early Life and Child Outcomes:

Evidence from Swedish Parental Leave Rule

Rita Ginja, Jenny Jans \& Arizo Karimi

ONLINE APPENDIX

NOT FOR PUBLICATION 


\section{A Additional Tables and Figures}

TABLE A.1.

Changes to the Swedish parental leave system over time

\begin{tabular}{|c|c|c|c|c|c|c|}
\hline Year & $\begin{array}{l}\text { Total paid } \\
\text { days }\end{array}$ & $\begin{array}{c}\text { Wage-replaced } \\
\text { days }\end{array}$ & $\begin{array}{l}\text { Replacement } \\
\text { rate, } \%\end{array}$ & $\begin{array}{c}\text { SEK/day if } \\
\text { SGI }=0\end{array}$ & Flat rate days & $\begin{array}{l}\text { SEK/day, flat } \\
\text { rate }\end{array}$ \\
\hline 1974 & 180 & 180 & 90 & 25 & 0 & 0 \\
\hline 1975 & 210 & 210 & 90 & 25 & 0 & 0 \\
\hline 1976 & 210 & 210 & 90 & 25 & 0 & 0 \\
\hline 1977 & 210 & 210 & 90 & 25 & 0 & 0 \\
\hline 1978 & 270 & 240 & 90 & 32 & 30 & 32 \\
\hline 1979 & 270 & 240 & 90 & 32 & 30 & 32 \\
\hline 1980 & 360 & 270 & 90 & 37 & 90 & 37 \\
\hline 1981 & 360 & 270 & 90 & 37 & 90 & 37 \\
\hline 1982 & 360 & 270 & 90 & 37 & 90 & 37 \\
\hline 1983 & 360 & 270 & 90 & 48 & 90 & 48 \\
\hline 1984 & 360 & 270 & 90 & 48 & 90 & 48 \\
\hline 1985 & 360 & 270 & 90 & 48 & 90 & 48 \\
\hline 1986 & 360 & 270 & 90 & 48 & 90 & 48 \\
\hline 1987 & 360 & 270 & 90 & 48 & 90 & 48 \\
\hline 1988 & 360 & 270 & 90 & 60 & 90 & 60 \\
\hline 1989 & 450 & 360 & 90 & 60 & 90 & 60 \\
\hline 1990 & 450 & 360 & 90 & 60 & 90 & 60 \\
\hline 1991 & 450 & 360 & 90 & 60 & 90 & 60 \\
\hline 1992 & 450 & 360 & 90 & 60 & 90 & 60 \\
\hline 1993 & 450 & 360 & 90 & 60 & 90 & 60 \\
\hline $1994^{a}$ & 450 & 360 & 90 & 64 & $90 / 0$ & $60 / 0$ \\
\hline $1995^{b}$ & 450 & 360 & 80 & 60 & 90 & 60 \\
\hline $1996^{c}$ & 450 & 360 & 75 & 60 & 90 & 60 \\
\hline 1997 & 450 & 360 & 75 & 60 & 90 & 60 \\
\hline 1998 & 450 & 360 & 80 & 60 & 90 & 60 \\
\hline 1999 & 450 & 360 & 80 & 60 & 90 & 60 \\
\hline 2000 & 450 & 360 & 80 & 60 & 90 & 60 \\
\hline 2001 & 450 & 360 & 80 & 60 & 90 & 60 \\
\hline $2002^{d}$ & 480 & 390 & 80 & 120 & 90 & 60 \\
\hline 2003 & 480 & 390 & 80 & 150 & 90 & 60 \\
\hline 2004 & 480 & 390 & 80 & 180 & 90 & 60 \\
\hline 2005 & 480 & 390 & 80 & 180 & 90 & 60 \\
\hline $2006^{e}$ & 480 & 390 & 80 & 180 & 90 & $60 / 180$ \\
\hline 2007 & 480 & 390 & 80 & 180 & 90 & 180 \\
\hline 2008 & 480 & 390 & 80 & 180 & 90 & 180 \\
\hline 2009 & 480 & 390 & 80 & 180 & 90 & 180 \\
\hline
\end{tabular}

NOTE: The table shows the changes to the Swedish parental leave system since its introduction in 1974. a) During the second half of 1994, the flat-rate days were temporarily abolished for children older than one year. b) The first "daddy-month" was introduced for parents to children born on or after January 1st, 1995. For the 30 days of reserved leave, the replacement rate remained at 90 percent of previous earnings. c) For the 30 days of reserved leave, the replacement rate remained at 80 percent of previous earnings. d) The second "daddy-month" was introduced, targeting parents to children born on or after January 1,2002. e) The flat rate was set to $180 \mathrm{SEK} /$ day from July 1, 2006 onwards. SGI indicates that the individual has fulfilled the work requirement that entitles them to wage-replaced parental leave. (Source: National Insurance Board). 
TABLE A.2.

Changes to the speed premium eligibility birth interval over time

\begin{tabular}{lcc}
\hline Year & Eligibility interval & Total paid PL \\
\hline 1974 & $12-15$ months & 6 months \\
$1975-1977$ & $13-16$ months & 7 months \\
$1978-1979$ & $16-18$ months & 9 months \\
$1980-1985$ & 24 months & 12 months \\
$1986-$ & 30 months & $12-16$ months \\
\hline
\end{tabular}

NOTE: The table shows the birth spacing intervals that makes parents eligible for the speed premium, for different time periods. Initially, the eligibility interval was set to statutory duration of paid leave, plus 6 months, which could be extended by up to 3 months. In 1980, the speed premium rule became statutory and the eligibility interval set to 24 months, and further extended to 30 months in 1986. Total paid PL days for the period 1986 onwards is 12-16 months due to gradual extensions of the eligibility for paid leave from 1989 onwards.

TABLE A.3.

Regression Discontinuity estimates of the effect of SP on children's educational outcomes: controlling for calendar month of birth

\begin{tabular}{|c|c|c|c|c|c|c|}
\hline & (1) & $\begin{array}{l}\text { (2) } \\
\text { First child }\end{array}$ & (3) & (4) & $\begin{array}{c}\text { (5) } \\
\text { Second child }\end{array}$ & (6) \\
\hline & $\begin{array}{l}\text { High school } \\
\text { qualified }\end{array}$ & $\begin{array}{l}\text { Standardized } \\
\text { GPA }\end{array}$ & $\begin{array}{l}\text { College at } \\
\text { age } 24\end{array}$ & $\begin{array}{l}\text { High school } \\
\text { qualified }\end{array}$ & $\begin{array}{l}\text { Standardized } \\
\text { GPA }\end{array}$ & $\begin{array}{l}\text { College at } \\
\text { age } 24\end{array}$ \\
\hline $\begin{array}{l}\text { A. 24-month regime } \\
\text { Treated }(\hat{\beta})\end{array}$ & $\begin{array}{c}0.002 \\
(0.005)\end{array}$ & $\begin{array}{c}0.039^{* * *} \\
(0.015)\end{array}$ & $\begin{array}{c}0.037^{* * *} \\
(0.011)\end{array}$ & $\begin{array}{l}-0.000 \\
(0.004)\end{array}$ & $\begin{array}{c}0.007 \\
(0.016)\end{array}$ & $\begin{array}{l}0.023^{* *} \\
(0.009)\end{array}$ \\
\hline Observations & 16484 & 46984 & 46586 & 32473 & 46849 & 46480 \\
\hline $\begin{array}{l}\text { B. 30-month regime } \\
\text { Treated }(\hat{\beta})\end{array}$ & $\begin{array}{l}0.005 \\
(0.004)\end{array}$ & $\begin{array}{c}0.024 \\
(0.016)\end{array}$ & $\begin{array}{l}0.020^{*} \\
(0.010)\end{array}$ & $\begin{array}{l}0.007^{*} \\
(0.004)\end{array}$ & $\begin{array}{c}0.015 \\
(0.017)\end{array}$ & $\begin{array}{c}0.014 \\
(0.009)\end{array}$ \\
\hline Observations & 45080 & 45080 & 44676 & 44847 & 44847 & 44443 \\
\hline
\end{tabular}

NOTE: Data is based on the samples described in columns (1) and (2) of Table 1, for the 24- and 30-month regime, respectively. The table reports the point estimate of $\beta$ from Equation 1 using a linear trend specification, including calendar month of birth fixed effects. The mean of the outcome variable is calculated on the control group. Clustered standard errors (at birth week level) in parentheses. ${ }^{* * *} p<0.01{ }^{* *} p<0.05{ }^{*} p<0.1$. 
TABLE A.4.

Regression Discontinuity difference-in-differences estimates of the effect of the SP: children's educational outcomes (24-month regime)

(1)

(2)

(3)

(4)

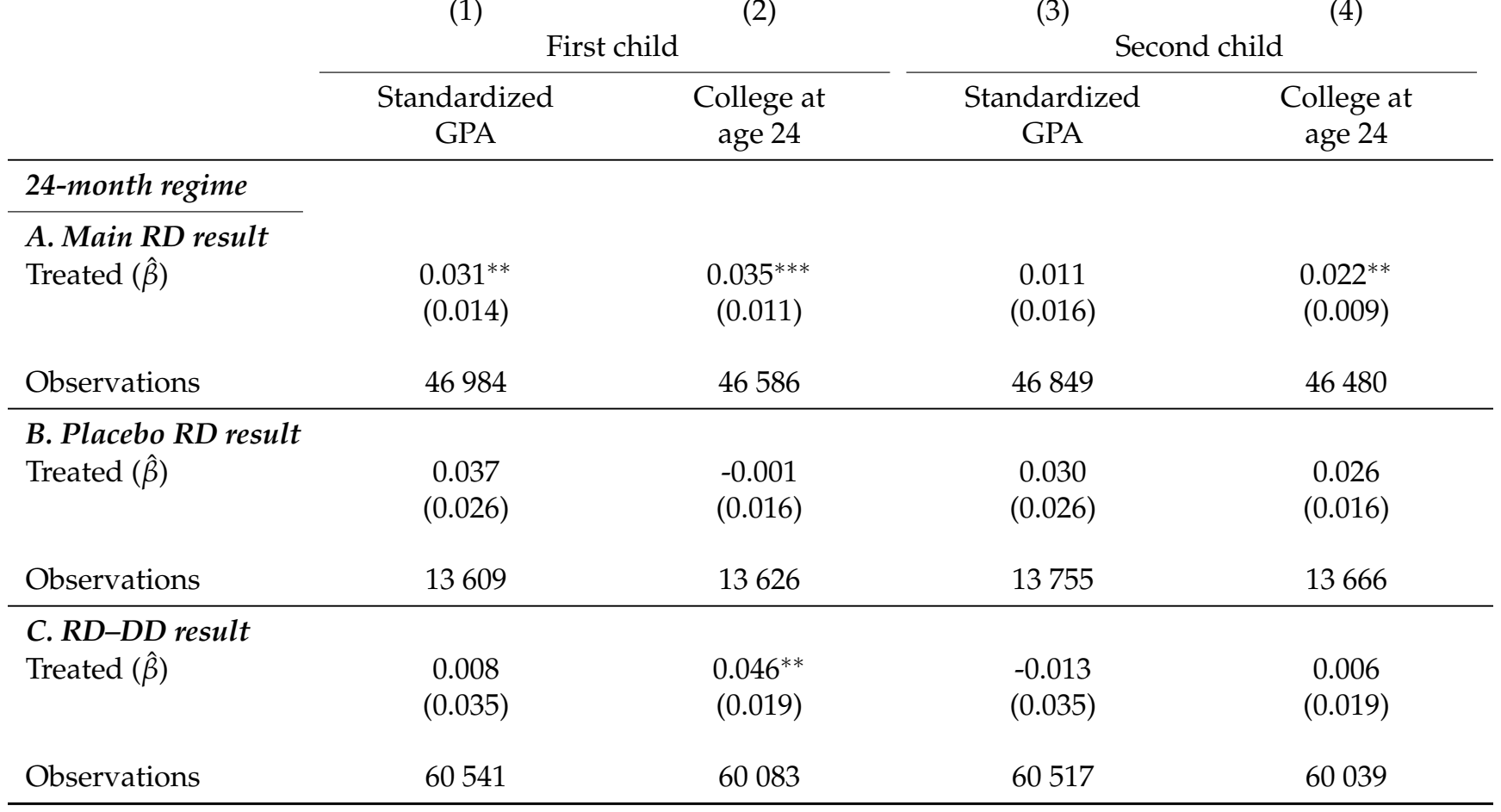

NotE: Table estimates in the upper panel are based on the samples described in column (1) of Table 1. Estimates in the middle panel are based on corresponding samples of families in which the second-child was born in 19771979. The lower panel combines treatment and placebo-year data. The table reports the point estimate of $\beta$ from Equation 1 using a linear trend specification. The mean of the outcome variable is calculated on the control group. Clustered standard errors (at birth week level) in parentheses. ${ }^{* * *} p<0.01,{ }^{* *} p<0.05,{ }^{*} p<0.1$. 
TABLE A.5.

Regression Discontinuity difference-in-differences estimates of the effect of the SP: children's educational outcomes (30-month regime)

(1)

(2)

(3)

(4)

First child

Second child

$\begin{array}{cccc}\begin{array}{c}\text { Standardized } \\ \text { GPA }\end{array} & \begin{array}{c}\text { College at } \\ \text { age 24 }\end{array} & \begin{array}{c}\text { Standardized } \\ \text { GPA }\end{array} & \begin{array}{c}\text { College at } \\ \text { age 24 }\end{array}\end{array}$

30-month regime

A. Main RD result

Treated $(\hat{\beta})$

$0.033^{*} \quad 0.021^{* *}$

0.009

0.015

(0.017)

(0.010)

(0.017)

(0.009)

Observations

45080

44676

44847

44443

B. Placebo RD result

Treated $(\hat{\beta})$

$-0.001$

$(0.011)$

$-0.003$

(0.008)

$-0.002$

(0.012)

$-0.011$

(0.007)

Observations

71046

70631

70883

70279

\section{C. $R D-D D$ result}

Treated $(\hat{\beta})$

0.032

$0.028^{* *}$

0.014

$0.031^{* *}$

(0.022)

(0.012)

(0.022)

(0.012)

Observations

116191

115287

115705

114696

NOTE: Table estimates in the upper panel are based on the samples described in column (2) of Table 1. Estimates in the middle panel are based on corresponding samples of families in which the second-child was born in 19771985. The lower panel combines treatment and placebo-year data. The table reports the point estimate of $\beta$ from Equation 1 using a linear trend specification. The mean of the outcome variable is calculated on the control group. Clustered standard errors (at birth week level) in parentheses. ${ }^{* *} p<0.01,{ }^{* *} p<0.05,{ }^{*} p<0.1$. 
TABLE A.6.

Regression Discontinuity estimates of the effect of the SP on children's educational outcomes: sensitivity to the choice of data range around the cutoff (24-month regime)

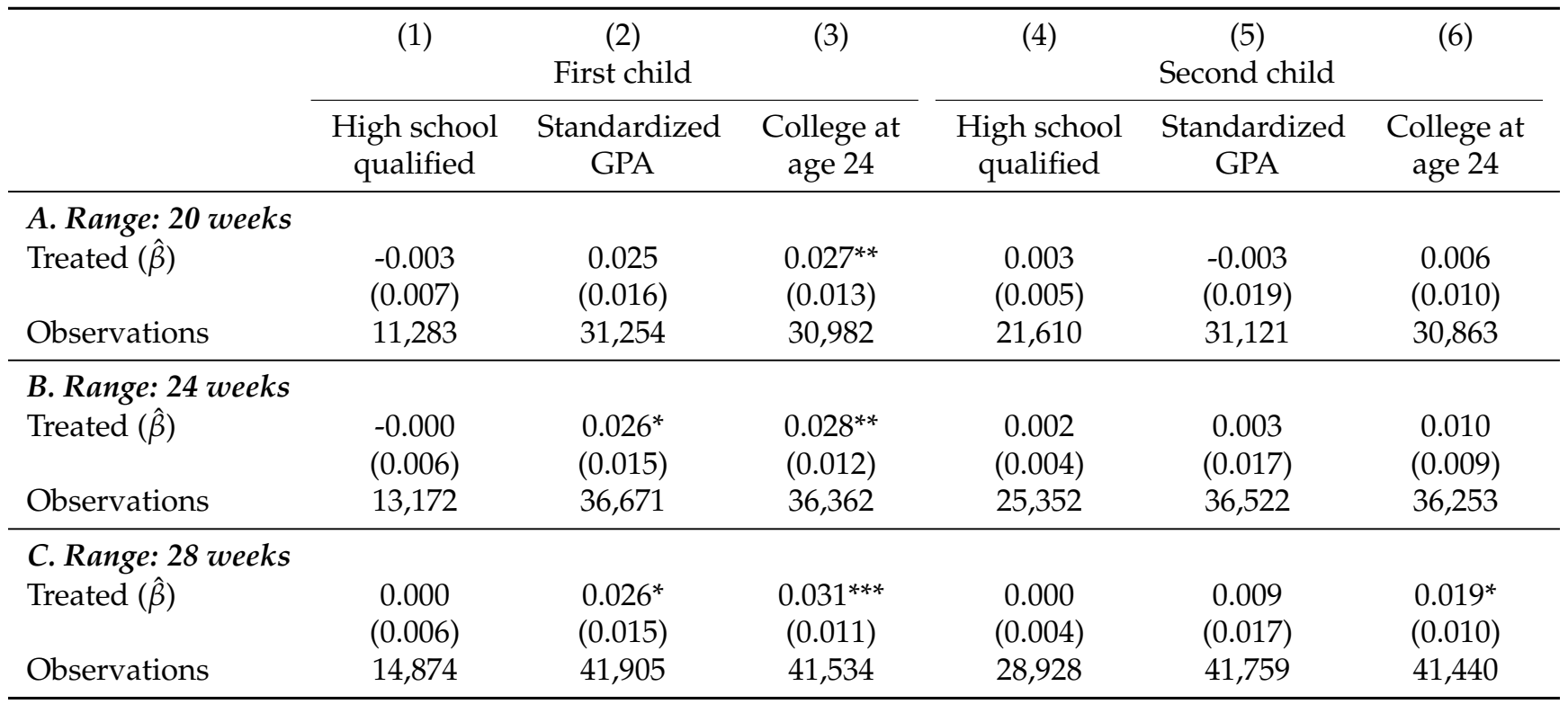

NOTE: Data is based on sub-groups (defined by the data window around the cutoff used) of the samples described in column (1) of Table 1 . The table reports the point estimate of $\beta$ from Equation 1 using a linear trend specification. The mean of the outcome variable is calculated on the control group. Clustered standard errors (at birth week level) in parentheses. ${ }^{* *} p<0.01,{ }^{* *} p<0.05,{ }^{*} p<0.1$.

TABLE A.7.

Regression Discontinuity estimates of the effect of the SP on children's educational outcomes: sensitivity to the choice of data range around the cutoff (30-month regime)

\begin{tabular}{|c|c|c|c|c|c|c|}
\hline & (1) & $\begin{array}{c}(2) \\
\text { First child }\end{array}$ & (3) & \multicolumn{3}{|c|}{ Second child } \\
\hline & $\begin{array}{l}\text { High school } \\
\text { qualified }\end{array}$ & $\begin{array}{l}\text { Standardized } \\
\text { GPA }\end{array}$ & $\begin{array}{c}\text { College at } \\
\text { age } 24\end{array}$ & $\begin{array}{l}\text { High school } \\
\text { qualified }\end{array}$ & $\begin{array}{l}\text { Standardized } \\
\text { GPA }\end{array}$ & $\begin{array}{l}\text { College at } \\
\text { age } 24\end{array}$ \\
\hline \multicolumn{7}{|c|}{ A. Range: 20 weeks } \\
\hline Treated $(\hat{\beta})$ & -0.001 & -0.007 & 0.010 & 0.007 & -0.008 & 0.005 \\
\hline Observations & 27,658 & 27,658 & 27,428 & 27,533 & 27,533 & 27,285 \\
\hline \multicolumn{7}{|c|}{ B. Range: 24 weeks } \\
\hline \multirow[t]{2}{*}{ Treated $(\hat{\beta})$} & 0.004 & 0.018 & 0.019 & $0.009^{*}$ & 0.010 & 0.014 \\
\hline & $(0.005)$ & $(0.019)$ & $(0.012)$ & $(0.005)$ & $(0.021)$ & $(0.011)$ \\
\hline Observations & 33,520 & 33,520 & 33,229 & 33,334 & 33,334 & 33,035 \\
\hline \multicolumn{7}{|c|}{ C. Range: 28 weeks } \\
\hline \multirow[t]{2}{*}{ Treated $(\hat{\beta})$} & 0.007 & 0.031 & $0.020^{*}$ & 0.007 & 0.010 & 0.017 \\
\hline & $(0.005)$ & $(0.020)$ & $(0.011)$ & $(0.004)$ & $(0.018)$ & $(0.010)$ \\
\hline Observations & 39,365 & 39,365 & 39,013 & 39,151 & 39,151 & 38,795 \\
\hline
\end{tabular}

NotE: Data is based on sub-groups (defined by the data window around the cutoff used) of the samples described in column (2) of Table 1. The table reports the point estimate of $\beta$ from Equation 1 using a linear trend specification. The mean of the outcome variable is calculated on the control group. Clustered standard errors (at birth week level) in parentheses. ${ }^{* * *} p<0.01,{ }^{* *} p<0.05,{ }^{*} p<0.1$. 
TABLE A.8.

Regression Discontinuity estimates of the effect of SP on children's educational outcomes: controlling for calendar year of birth

\begin{tabular}{|c|c|c|c|c|c|c|}
\hline & (1) & $\begin{array}{l}(2) \\
\text { First child }\end{array}$ & (3) & (4) & $\begin{array}{c}\text { (5) } \\
\text { Second child }\end{array}$ & (6) \\
\hline & $\begin{array}{l}\text { High school } \\
\text { qualified }\end{array}$ & $\begin{array}{l}\text { Standardized } \\
\text { GPA }\end{array}$ & $\begin{array}{l}\text { College at } \\
\text { age } 24 \\
\text { A. } 24-m\end{array}$ & $\begin{array}{l}\text { High school } \\
\text { qualified } \\
\text { th regime }\end{array}$ & $\begin{array}{l}\text { Standardized } \\
\text { GPA }\end{array}$ & $\begin{array}{l}\text { College at } \\
\text { age } 24\end{array}$ \\
\hline \multicolumn{7}{|l|}{ A1. All } \\
\hline Treated $(\hat{\beta})$ & $\begin{array}{c}0.001 \\
(0.005)\end{array}$ & $\begin{array}{l}0.033^{* *} \\
(0.014)\end{array}$ & $\begin{array}{c}0.035^{* * *} \\
(0.011)\end{array}$ & $\begin{array}{c}0.001 \\
(0.004)\end{array}$ & $\begin{array}{c}0.010 \\
(0.016)\end{array}$ & $\begin{array}{l}0.023^{* *} \\
(0.009)\end{array}$ \\
\hline Mean of outcome & 0.950 & 0.254 & 0.472 & 0.939 & 0.155 & 0.434 \\
\hline$\hat{\beta} /$ Mean & 0.001 & 0.128 & 0.074 & 0.001 & 0.068 & 0.053 \\
\hline \multicolumn{7}{|l|}{ A2. Boys } \\
\hline Treated $(\hat{\beta})$ & $\begin{array}{l}-0.011 \\
(0.009)\end{array}$ & $\begin{array}{l}0.040^{*} \\
(0.021)\end{array}$ & $\begin{array}{l}0.035^{* * *} \\
(0.013)\end{array}$ & $\begin{array}{c}0.001 \\
(0.007)\end{array}$ & $\begin{array}{c}0.007 \\
(0.017)\end{array}$ & $\begin{array}{l}0.021^{* *} \\
(0.010)\end{array}$ \\
\hline Mean of outcome & 0.940 & 0.0723 & 0.403 & 0.930 & -0.020 & 0.362 \\
\hline$\hat{\beta} /$ Mean & -0.011 & 0.557 & 0.088 & 0.002 & -0.339 & 0.059 \\
\hline \multicolumn{7}{|l|}{ A3. Girls } \\
\hline Treated $(\hat{\beta})$ & $\begin{array}{l}0.013^{*} \\
(0.007)\end{array}$ & $\begin{array}{l}0.036^{* *} \\
(0.017)\end{array}$ & $\begin{array}{l}0.038^{* * *} \\
(0.014)\end{array}$ & $\begin{array}{c}0.000 \\
(0.006)\end{array}$ & $\begin{array}{c}0.020 \\
(0.022)\end{array}$ & $\begin{array}{l}0.028^{* *} \\
(0.012)\end{array}$ \\
\hline Mean of outcome & 0.961 & 0.444 & 0.544 & 0.950 & 0.340 & 0.511 \\
\hline \multirow[t]{2}{*}{$\hat{\beta} /$ Mean } & 0.013 & 0.081 & 0.069 & 0.002 & 0.058 & 0.054 \\
\hline & \multicolumn{6}{|c|}{ B. 30-month regime } \\
\hline \multicolumn{7}{|l|}{ B1. All } \\
\hline Treated $(\hat{\beta})$ & $\begin{array}{c}0.006 \\
(0.004)\end{array}$ & $\begin{array}{l}0.031^{*} \\
(0.017)\end{array}$ & $\begin{array}{l}0.022^{* *} \\
(0.010)\end{array}$ & $\begin{array}{c}0.006 \\
(0.004)\end{array}$ & $\begin{array}{c}0.011 \\
(0.017)\end{array}$ & $\begin{array}{l}0.015^{*} \\
(0.009)\end{array}$ \\
\hline Mean of outcome & 0.942 & 0.228 & 0.442 & 0.931 & 0.128 & 0.395 \\
\hline$\hat{\beta} /$ Mean & 0.007 & 0.137 & 0.049 & 0.007 & 0.084 & 0.039 \\
\hline \multicolumn{7}{|l|}{ B2. Boys } \\
\hline Treated $(\hat{\beta})$ & $\begin{array}{c}0.005 \\
(0.007)\end{array}$ & $\begin{array}{l}0.049^{* *} \\
(0.023)\end{array}$ & $\begin{array}{c}0.038^{* * *} \\
(0.013)\end{array}$ & $\begin{array}{l}0.010^{*} \\
(0.006)\end{array}$ & $\begin{array}{l}-0.006 \\
(0.020)\end{array}$ & $\begin{array}{c}0.009 \\
(0.012)\end{array}$ \\
\hline Mean of outcome & 0.928 & 0.047 & 0.362 & 0.919 & -0.029 & 0.329 \\
\hline$\hat{\beta} /$ Mean & 0.006 & 1.042 & 0.105 & 0.011 & 0.201 & 0.027 \\
\hline \multicolumn{7}{|l|}{ B3. Girls } \\
\hline Treated $(\hat{\beta})$ & $\begin{array}{l}0.007^{*} \\
(0.004)\end{array}$ & $\begin{array}{c}0.017 \\
(0.024)\end{array}$ & $\begin{array}{c}0.007 \\
(0.017)\end{array}$ & $\begin{array}{c}0.002 \\
(0.005)\end{array}$ & $\begin{array}{c}0.022 \\
(0.025)\end{array}$ & $\begin{array}{c}0.019 \\
(0.013)\end{array}$ \\
\hline Mean of outcome & 0.957 & 0.416 & 0.525 & 0.943 & 0.293 & 0.465 \\
\hline$\hat{\beta} /$ Mean & 0.008 & 0.041 & 0.013 & 0.002 & 0.075 & 0.041 \\
\hline
\end{tabular}

NOTE: Data is based on the samples described in columns (1) and (2) of Table 1, for the 24- and 30-month regime, respectively. The table reports the point estimate of $\beta$ from Equation 1 using a linear trend specification, including calendar year of birth fixed effects. The mean of the outcome variable is calculated on the control group. Clustered standard errors (at birth week level) in parentheses. ${ }^{* * *} p<0.01,{ }^{* *} p<0.05,{ }^{*} p<0.1$. 
TABLE A.9.

Placebo Regression Discontinuity estimates of the effect of the SP: spousal and household earnings

\begin{tabular}{|c|c|c|c|c|c|c|}
\hline \multirow[b]{3}{*}{ Years since birth, $2^{\text {nd }}$ birth } & \multirow{2}{*}{\multicolumn{2}{|c|}{$\begin{array}{l}(1) \\
\text { Mother's income }\end{array}$}} & \multirow{2}{*}{\multicolumn{2}{|c|}{$\begin{array}{l}(3) \quad(4) \\
\text { Father's income }\end{array}$}} & \multirow{2}{*}{\multicolumn{2}{|c|}{$\begin{array}{l}\text { (5) } \\
\text { HH disp. income }\end{array}$}} \\
\hline & & & & & & \\
\hline & Pre-birth & Post birth & Pre-birth & Post birth & Pre-birth & Post birth \\
\hline \multicolumn{7}{|l|}{ A. 24-month placebo years } \\
\hline Treated $(\hat{\beta})$ & $\begin{array}{c}0.732 \\
(2.080)\end{array}$ & $\begin{array}{c}2.687 \\
(4.275)\end{array}$ & $\begin{array}{c}2.280 \\
(3.151)\end{array}$ & $\begin{array}{l}5.008 \\
(6.629)\end{array}$ & $\begin{array}{l}-0.650 \\
(3.286)\end{array}$ & $\begin{array}{c}0.457 \\
(3.842)\end{array}$ \\
\hline Observations & 13,756 & 14,096 & 14,066 & 14,070 & 14,122 & 14,122 \\
\hline \multicolumn{7}{|l|}{ B. 30-month placebo years } \\
\hline Treated $(\hat{\beta})$ & $\begin{array}{l}-1.595 \\
(1.445)\end{array}$ & $\begin{array}{l}-2.379 \\
(2.154)\end{array}$ & $\begin{array}{l}-0.582 \\
(1.986)\end{array}$ & $\begin{array}{c}10.63 \\
(9.361)\end{array}$ & $\begin{array}{c}-3.289^{* *} \\
(1.326)\end{array}$ & $\begin{array}{l}-4.691^{*} \\
(2.411)\end{array}$ \\
\hline Observations & 44,438 & 44,546 & 44,924 & 44,695 & 45,139 & 45,139 \\
\hline \multicolumn{7}{|c|}{$\begin{array}{l}\text { NOTE: Table estimates in the upper panel are based on a sample corresponding to that described in column (1) of } \\
\text { Table 1, using families in which the second child was born 1977-1979. Table estimates in the lower panel are based } \\
\text { on a sample corresponding to that described in column (2) of Table 1, using families in which the second child was } \\
\text { born 1977-1985. The table reports the point estimate of } \beta \text { from Equation } 1 \text { using a linear trend specification. The } \\
\text { mean of the outcome variable is calculated on the control group. Clustered standard errors (at birth week level) } \\
\text { in parentheses. }{ }^{* * *} p<0.01,{ }^{* *} p<0.05, * p<0.1 \text {. }\end{array}$} \\
\hline
\end{tabular}

TABLE A.10.

Regression Discontinuity estimates of the effect of the SP: spousal and household earnings in three-child families

\begin{tabular}{|c|c|c|c|c|c|c|}
\hline \multirow[b]{3}{*}{ Years since birth, $2^{\text {nd }}$ birth } & \multirow{2}{*}{\multicolumn{2}{|c|}{$\begin{array}{l}(1) \\
\text { Mother's income }\end{array}$}} & \multirow{2}{*}{\multicolumn{2}{|c|}{$\begin{array}{l}(3) \\
\text { Father's income }\end{array}$}} & \multirow{2}{*}{\multicolumn{2}{|c|}{$\begin{array}{l}\text { (5) } \\
\text { HH disp. income }\end{array}$}} \\
\hline & & & & & & \\
\hline & Pre-birth & Post birth & Pre-birth & Post birth & Pre-birth & Post birth \\
\hline \multicolumn{7}{|l|}{ A. 24-month regime } \\
\hline Treated $(\hat{\beta})$ & $\begin{array}{l}-4.138 \\
(2.710)\end{array}$ & $\begin{array}{l}-1.766 \\
(4.380)\end{array}$ & $\begin{array}{c}20.538 \\
(12.426)\end{array}$ & $\begin{array}{l}12.837 \\
(8.200)\end{array}$ & $\begin{array}{l}6.240^{* *} \\
(2.682)\end{array}$ & $\begin{array}{c}10.479^{* *} \\
(5.179)\end{array}$ \\
\hline Observations & 9,863 & 9,803 & 9,900 & 9,805 & 9,958 & 9,958 \\
\hline Mean of outcome & 88.63 & 125.5 & 196.8 & 402.5 & 237 & 525.2 \\
\hline$\hat{\beta} /$ Mean & -0.047 & -0.014 & 0.104 & 0.032 & 0.026 & 0.020 \\
\hline \multicolumn{7}{|l|}{ B. 30-month regime } \\
\hline Treated $(\hat{\beta})$ & $\begin{array}{l}-6.241^{* * *} \\
(2.329)\end{array}$ & $\begin{array}{l}-9.502^{* * *} \\
(2.960)\end{array}$ & $\begin{array}{l}-0.229 \\
(4.635)\end{array}$ & $\begin{array}{l}-5.346 \\
(9.397)\end{array}$ & $\begin{array}{l}-0.889 \\
(2.169)\end{array}$ & $\begin{array}{l}-0.229 \\
(4.510)\end{array}$ \\
\hline Observations & 10,250 & 10,253 & 10,205 & 10,206 & 10,261 & 10,261 \\
\hline Mean of outcome & 110.3 & 116.8 & 210.4 & 436.4 & 294.5 & 631.7 \\
\hline$\hat{\beta} /$ Mean & -0.057 & -0.081 & -0.001 & -0.012 & -0.003 & -0.000 \\
\hline
\end{tabular}

Note: Data is based on samples corresponding to those described in columns (1) and (2) of Table 1, for the 24- and 30-month regime, respectively, but using families with at least three children, and for which the parent receives or just fails to receive the SP for the third-born child. The table reports the point estimate of $\beta$ from Equation 1 using a linear trend specification. The coefficient estimates displayed in bold are significant at $10 \%$ level when inference is adjusted for multiple hypotheses testing. The mean of the outcome variable is calculated on the control group. Clustered standard errors (at birth week level) in parentheses. ${ }^{* * *} p<0.01,{ }^{* *} p<0.05,{ }^{*} p<0.1$. 
TABLE A.11.

Regression Discontinuity estimates of the effect of the SP on first-born children's educational outcomes: heterogeneous effects by sibling sex-composition

\begin{tabular}{|c|c|c|c|c|c|c|}
\hline & (1) & (2) & (3) & (4) & (5) & (6) \\
\hline & $\begin{array}{l}\text { High school } \\
\text { qualified }\end{array}$ & $\begin{array}{l}\text { Standardized } \\
\text { GPA }\end{array}$ & $\begin{array}{l}\text { College at } \\
\text { age } 24\end{array}$ & $\begin{array}{l}\text { High school } \\
\text { qualified }\end{array}$ & $\begin{array}{l}\text { Standardized } \\
\text { GPA }\end{array}$ & $\begin{array}{l}\text { College at } \\
\text { age } 24\end{array}$ \\
\hline & \multicolumn{6}{|c|}{ First Child: Boy } \\
\hline & \multicolumn{3}{|c|}{ Second Child: Boy } & \multicolumn{3}{|c|}{ Second Child: Girl } \\
\hline A. 24-months regime & & & & & & \\
\hline Treated $(\hat{\beta})$ & $\begin{array}{l}-0.007 \\
(0.015)\end{array}$ & $\begin{array}{c}0.048 \\
(0.030)\end{array}$ & $\begin{array}{c}0.050^{* * *} \\
(0.016)\end{array}$ & $\begin{array}{l}-0.016 \\
(0.014)\end{array}$ & $\begin{array}{c}0.022 \\
(0.032)\end{array}$ & $\begin{array}{c}0.012 \\
(0.016)\end{array}$ \\
\hline Observations & 4,269 & 12,188 & 12,169 & 4,074 & 11,677 & 11,607 \\
\hline Mean of outcome & 0.941 & 0.075 & 0.401 & 0.939 & 0.070 & 0.406 \\
\hline$\hat{\beta} /$ Mean & -0.007 & 0.637 & 0.125 & -0.017 & 0.321 & 0.030 \\
\hline \multicolumn{7}{|l|}{ B. 30-months regime } \\
\hline Treated $(\hat{\beta})$ & $\begin{array}{c}0.005 \\
(0.009)\end{array}$ & $\begin{array}{c}0.082^{* * *} \\
(0.028)\end{array}$ & $\begin{array}{l}0.041^{* *} \\
(0.018)\end{array}$ & $\begin{array}{c}0.006 \\
(0.010)\end{array}$ & $\begin{array}{c}0.030 \\
(0.032)\end{array}$ & $\begin{array}{l}0.037^{*} \\
(0.022)\end{array}$ \\
\hline Observations & 11,758 & 11,758 & 11,689 & 11,206 & 11,206 & 11,113 \\
\hline Mean of outcome & 0.932 & 0.049 & 0.367 & 0.924 & 0.045 & 0.357 \\
\hline$\hat{\beta} /$ Mean & 0.006 & 1.672 & 0.113 & 0.006 & 0.658 & 0.105 \\
\hline
\end{tabular}

First Child: Girl

\begin{tabular}{lcccccc} 
& \multicolumn{3}{c}{ Second Child: Boy } & \multicolumn{3}{c}{ Second Child: Girl } \\
\cline { 2 - 7 } A. 24-months regime & & & & & \\
Treated $(\hat{\beta})$ & 0.017 & $0.064^{* *}$ & $\mathbf{0 . 0 4 8 * *}$ & 0.012 & 0.008 & 0.025 \\
& $(0.010)$ & $(0.031)$ & $\mathbf{( 0 . 0 1 7 )}$ & $(0.012)$ & $(0.027)$ & $(0.019)$ \\
Observations & 4,171 & 11,778 & 11,637 & 3,835 & 10,963 & 10,814 \\
Mean of outcome & 0.956 & 0.431 & 0.539 & 0.966 & 0.457 & 0.550 \\
$\hat{\beta} /$ Mean & 0.018 & 0.147 & 0.090 & 0.012 & 0.017 & 0.046 \\
\hline B. 30-months regime & & & & & & 0.004 \\
Treated $(\hat{\beta})$ & 0.000 & -0.015 & 0.004 & $\mathbf{0 . 0 1 5 * *}$ & 0.052 & $(0.024)$ \\
Observations & $(0.007)$ & $(0.034)$ & $(0.020)$ & $\mathbf{( 0 . 0 0 6 )}$ & $(0.038)$ & 10,441 \\
Mean of outcome & 11,257 & 11,257 & 11,149 & 10,565 & 10,565 & 0.529 \\
$\hat{\beta} /$ Mean & 0.957 & 0.406 & 0.519 & 0.957 & 0.426 & 0.008 \\
\hline
\end{tabular}

NOTE: Data is based on the samples described in columns (1) and (2) of Table 1, for the 24- and 30-month regime, respectively. The table reports the point estimate of $\beta$ from Equation 1 using a linear trend specification. The coefficient estimates displayed in bold are significant at $10 \%$ level when inference is adjusted for multiple hypotheses testing. The mean of the outcome variable is calculated on the control group. Clustered standard errors (at birth week level) in parentheses. ${ }^{* * *} p<0.01,{ }^{* *} p<0.05,{ }^{*} p<0.1$. 
FIGURE A.1.

Spacing between first and second birth over time

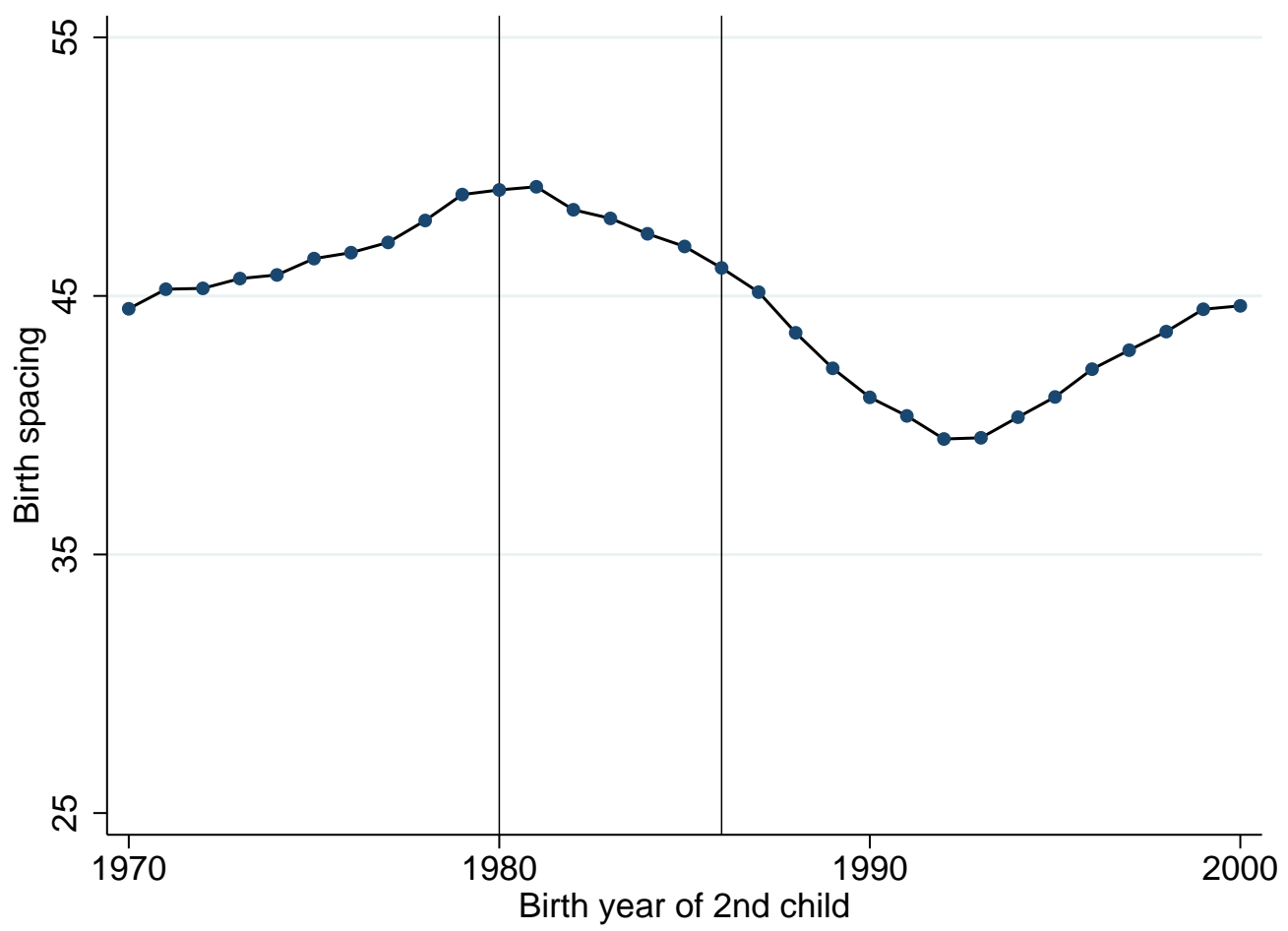

NotE: The figure shows the average age difference - in months - between the first and second child, by second child birth cohort. The sample includes the full population of mothers whose first child was born 1970 or later. 
FIGURE A.2.

Labor market conditions during the 1980s

(A)

Employment and Unemployment

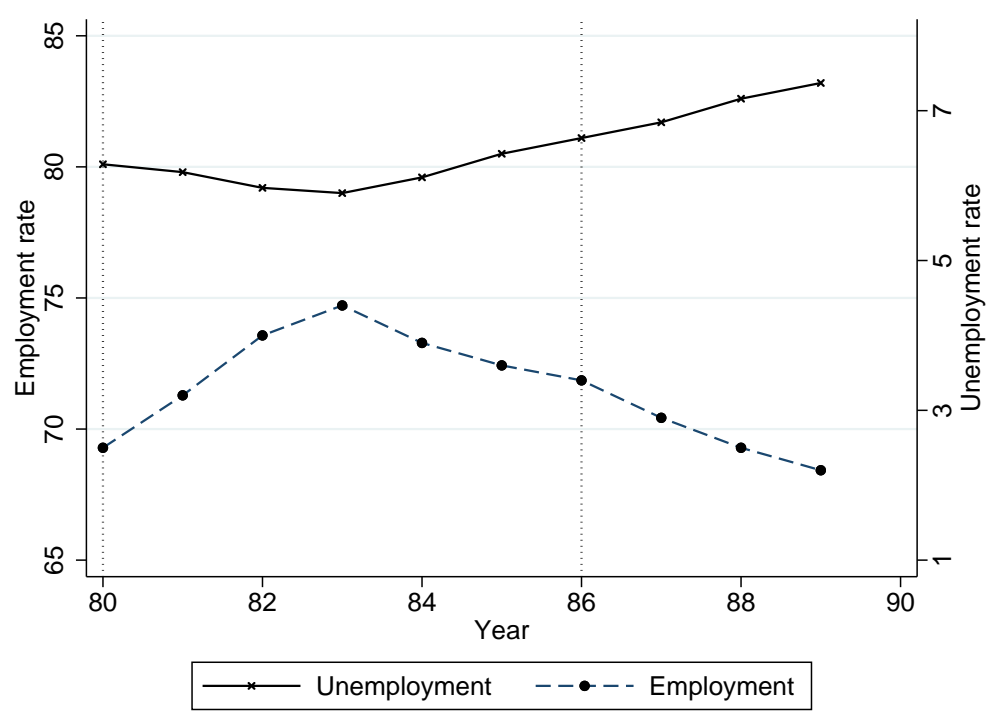

(B)

Labor Earnings

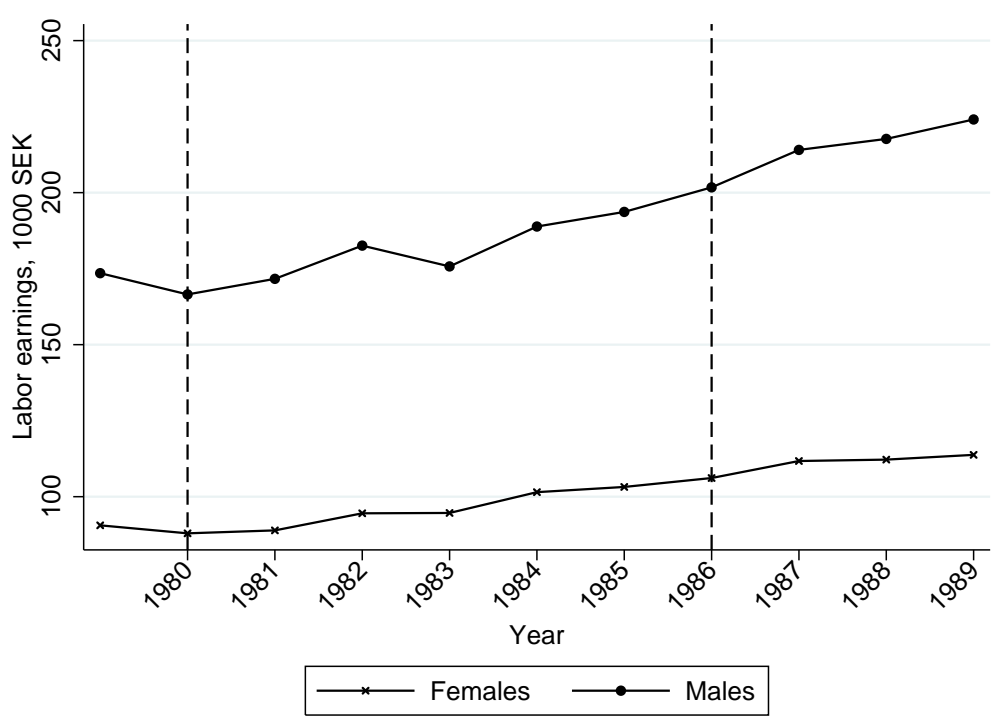

NOTE: The upper panel shows the trend in national employment- and unemployment rates over the time period studied, with figures from the Swedish Labor Force Survey's. The lower panel shows the average annual labor income of females and males (including zero-earners) based on our register data. 
FIGURE A.3.

Strategic manipulation of birth timing: difference between expected and actual date of birth (days)
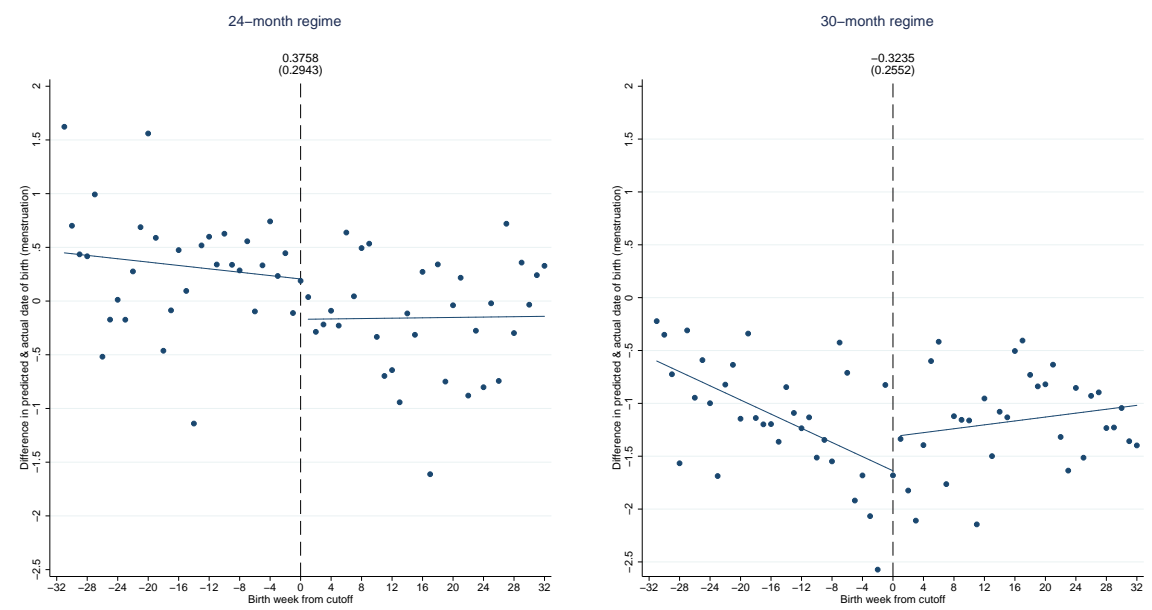

Note: Data is based on the samples described in columns (1) and (2) of Table 1, for the 24- and 30-month regime, respectively. The figure reports the point estimate of $\beta$ in Equation 1 using a linear trend specification. Estimated discontinuities at the cutoff are indicated at the top of the vertical line at the cutoff in each graph. Clustered standard errors (at birth week) in parentheses. ${ }^{* * *} p<0.01$, $^{* *} p$ $<0.05, * p<0.1$. Expected due date is based on the date of last menstruation.

FIGURE A.4.

Strategic manipulation of birth timing: bunching estimates
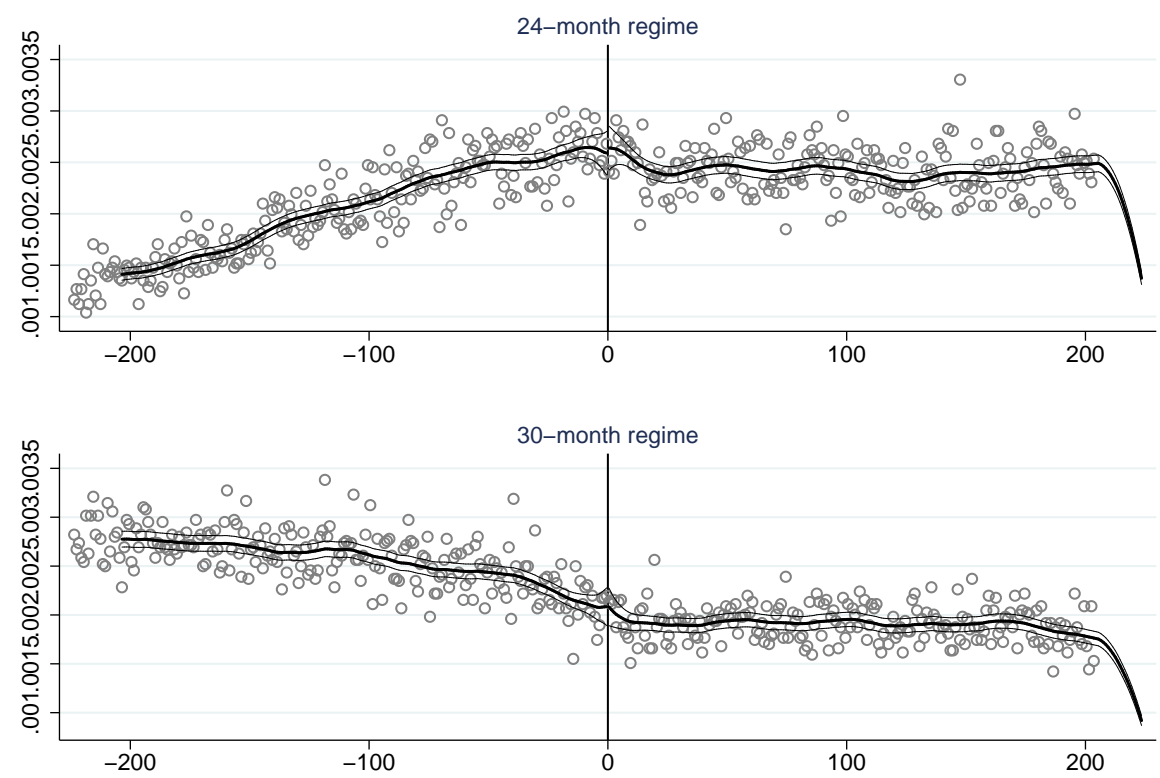

NOTE: Each circle shows the average frequency of births in each daily bin of the running variable - birth spacing. The solid lines represent estimated density functions of birth spacing, with 95-percent confidence intervals. The bin size is 1 day and the bandwidth 20 days. 


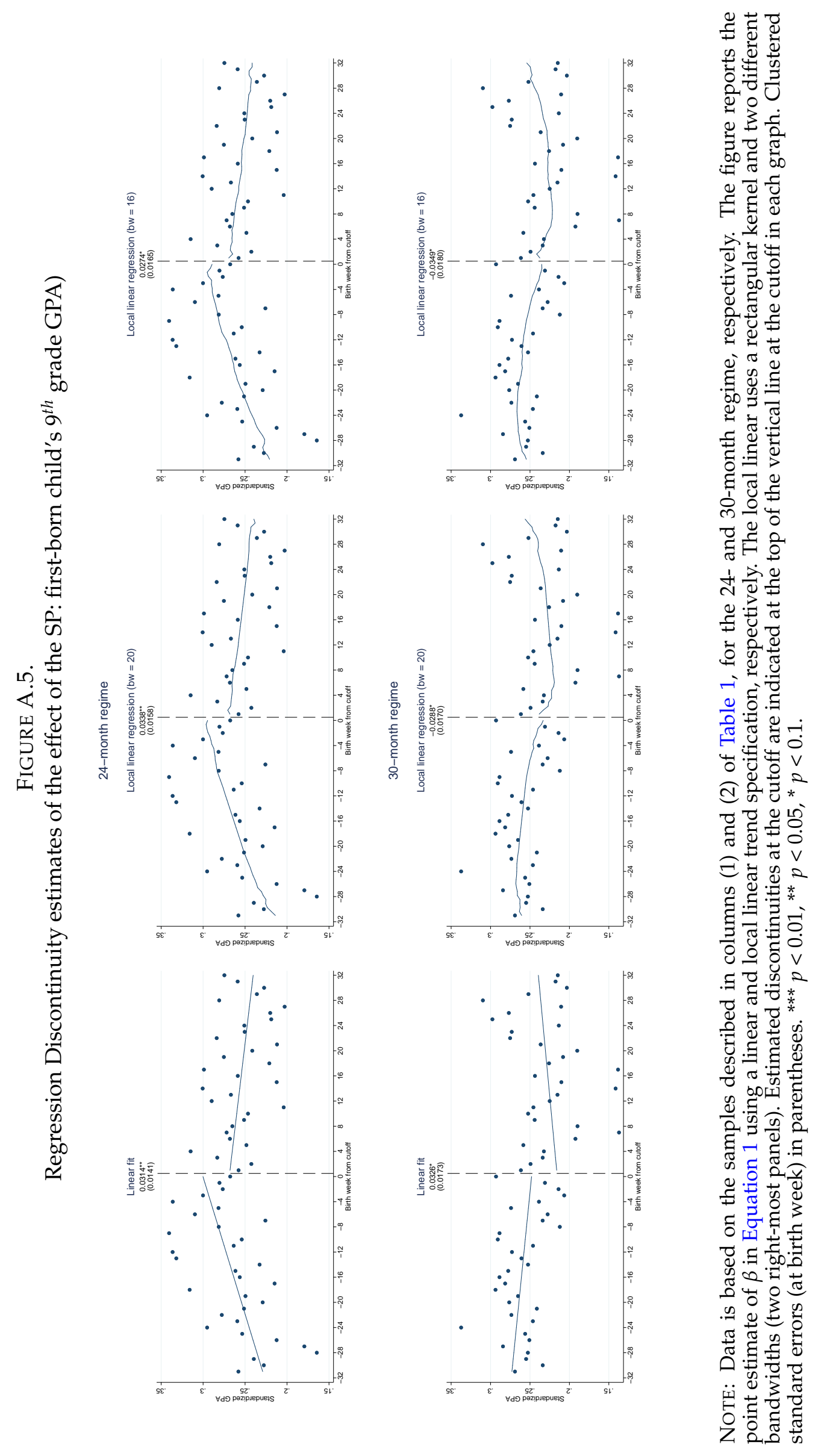




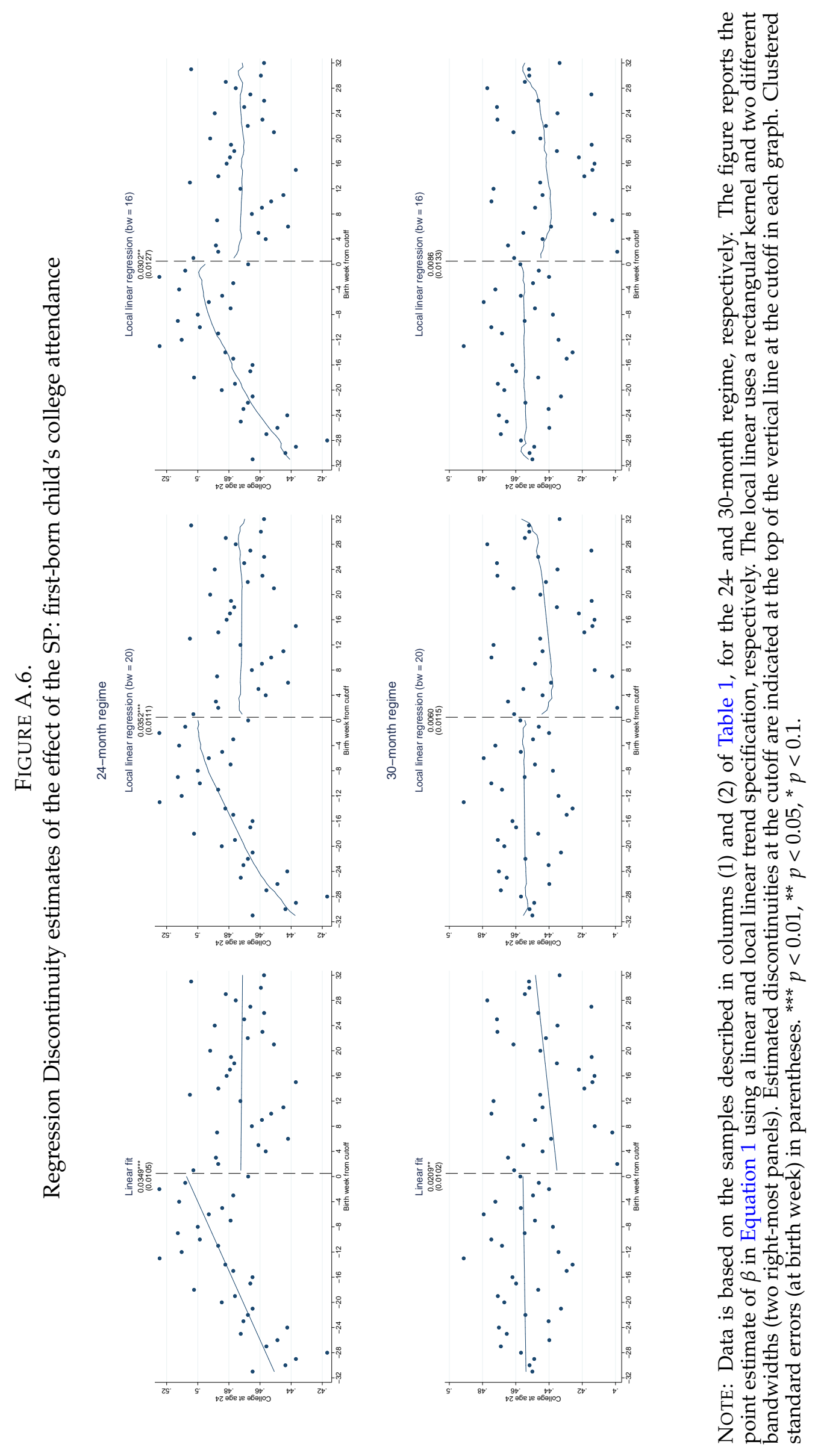




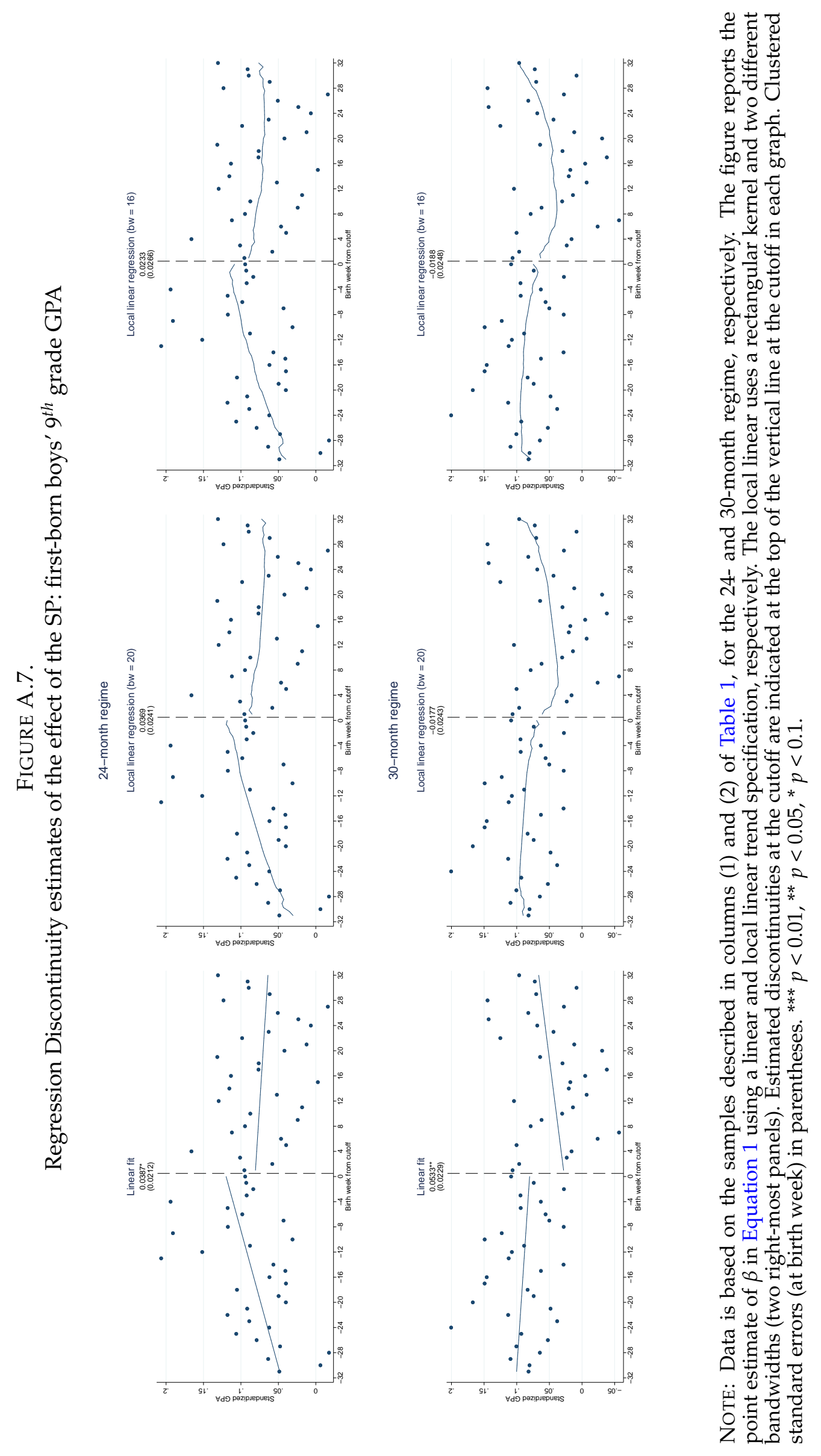




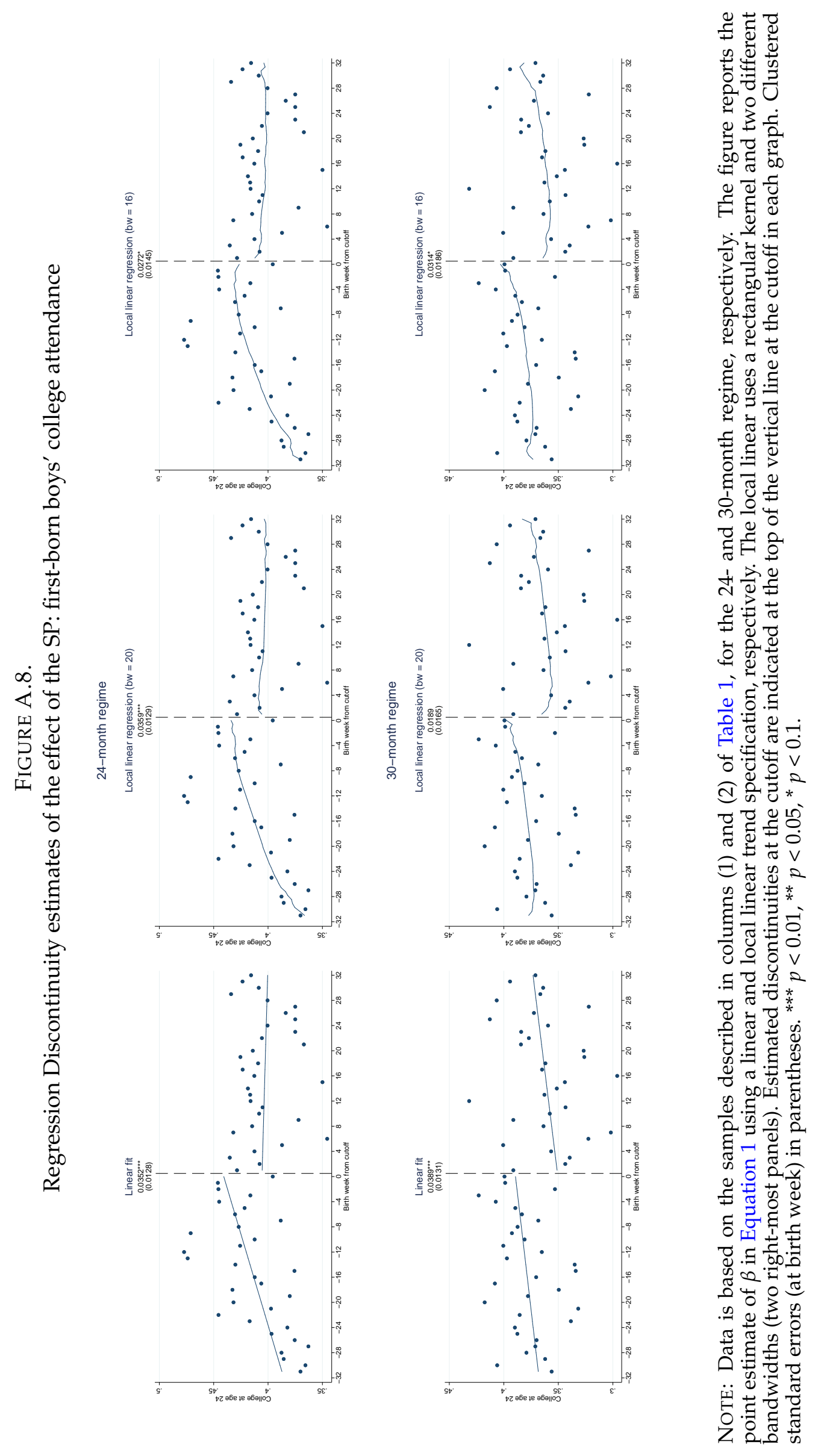




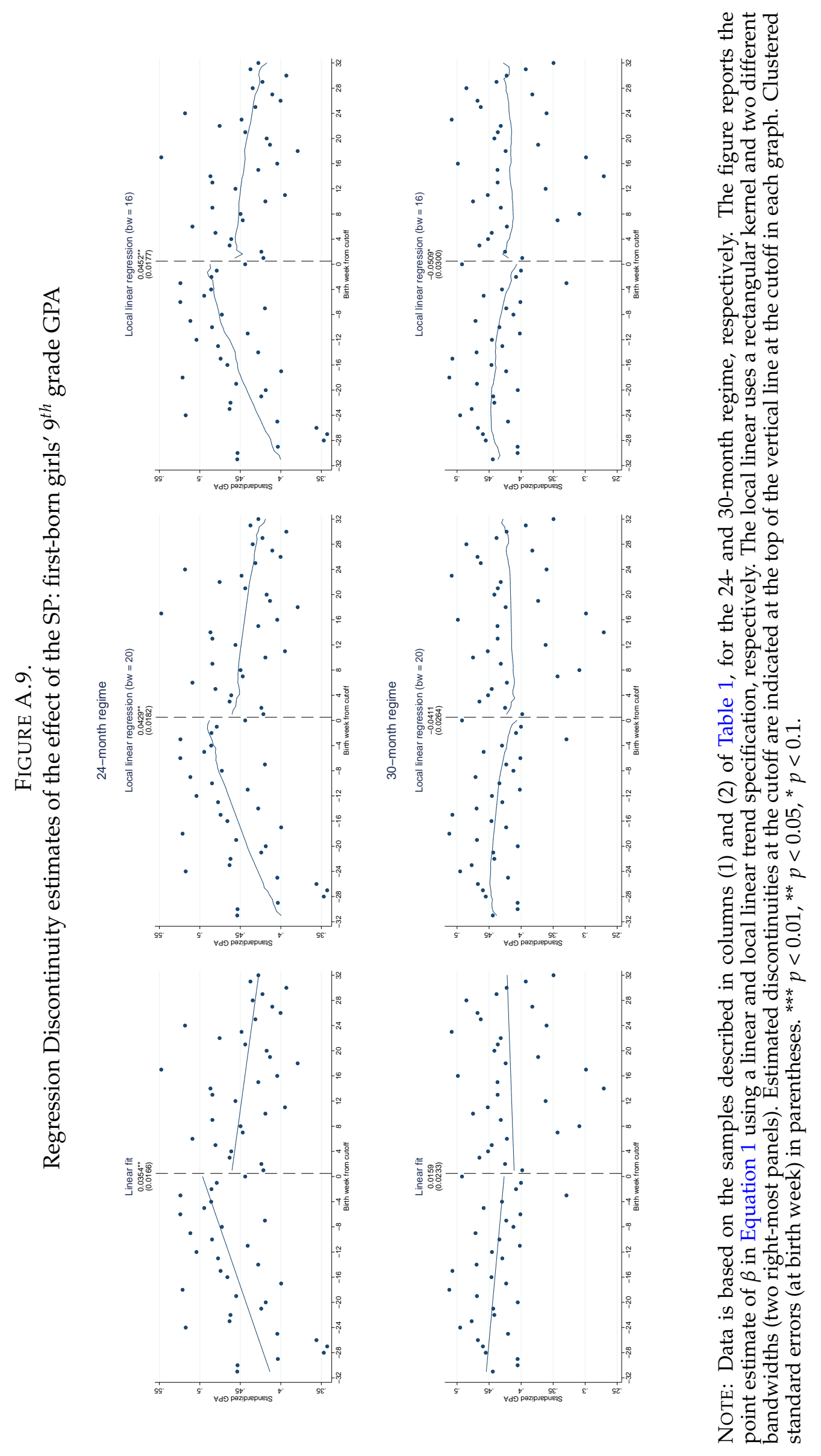




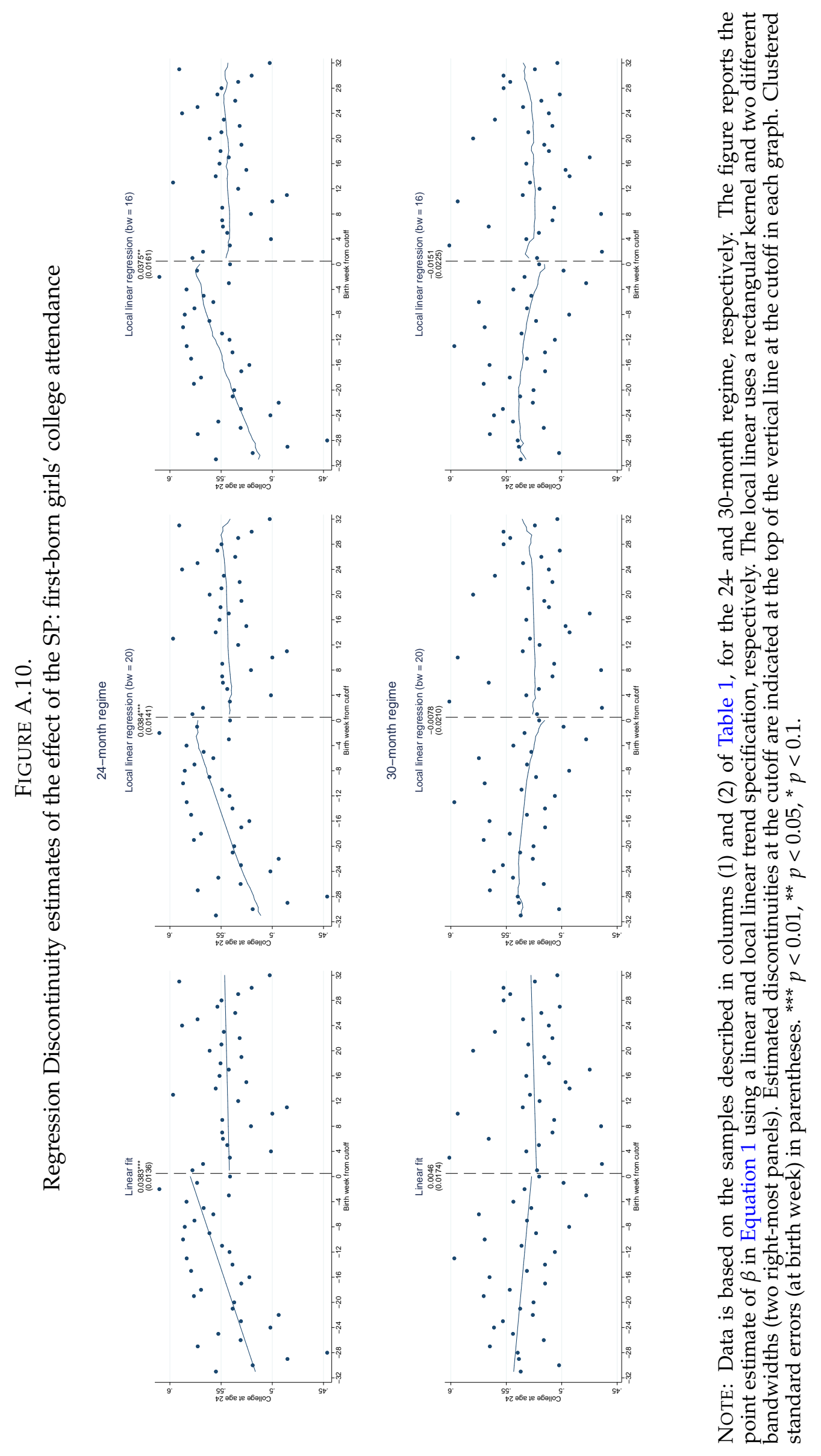




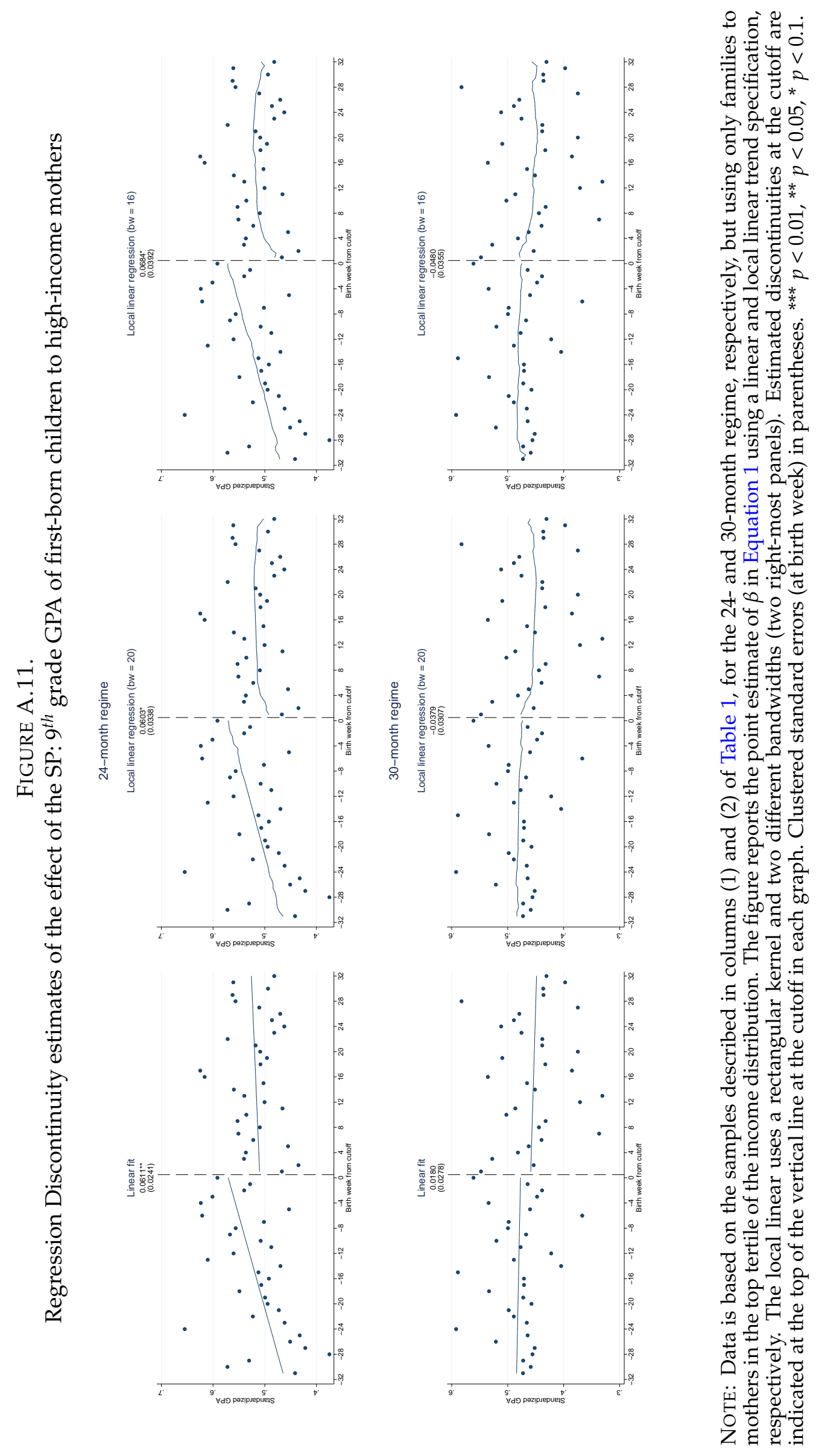




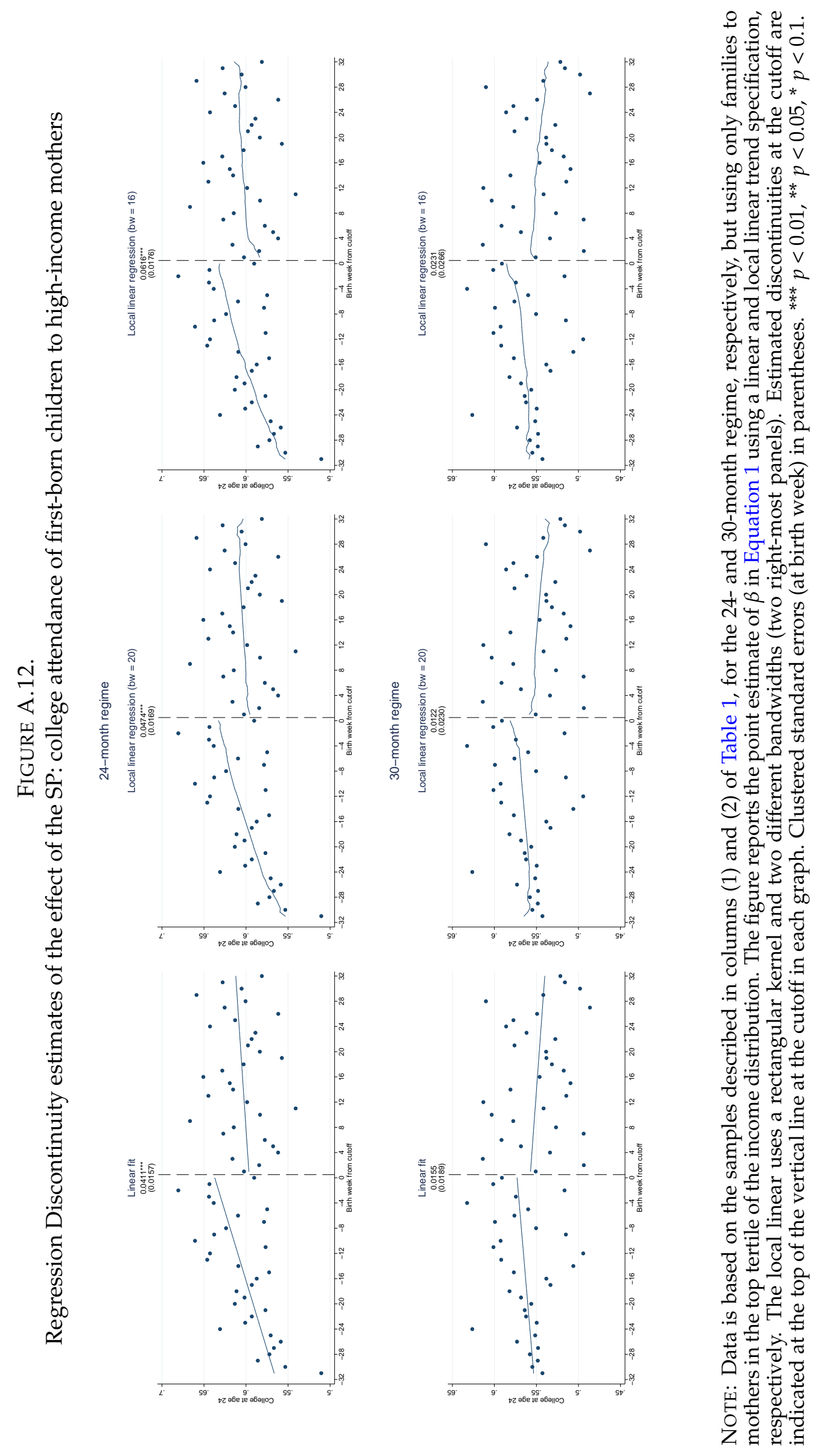


FIGURE A.13.

Labor supply and income effects in the medium run
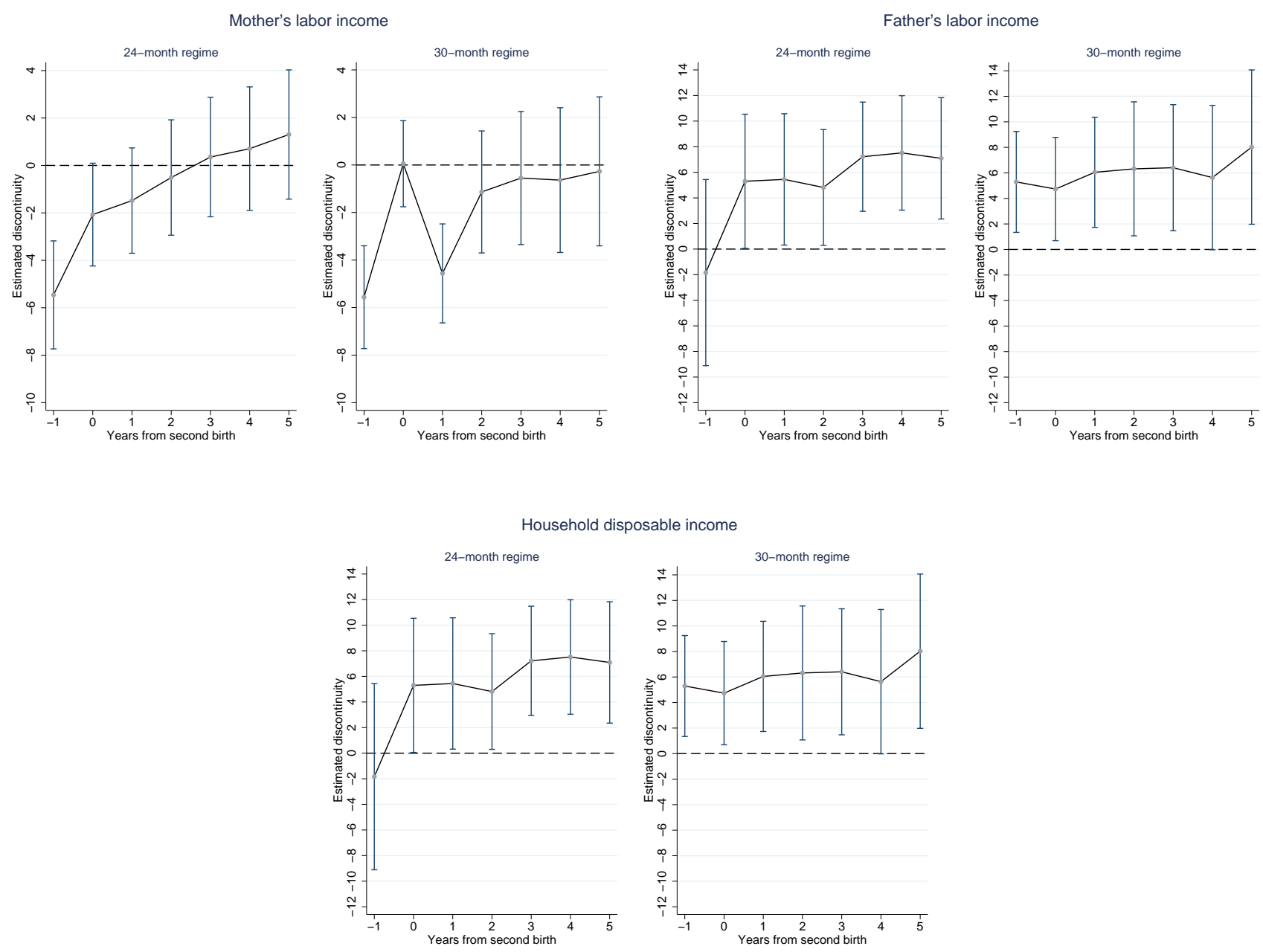


\section{FIGURE A.14.}

Proportion children enrolled in child care by child age and year

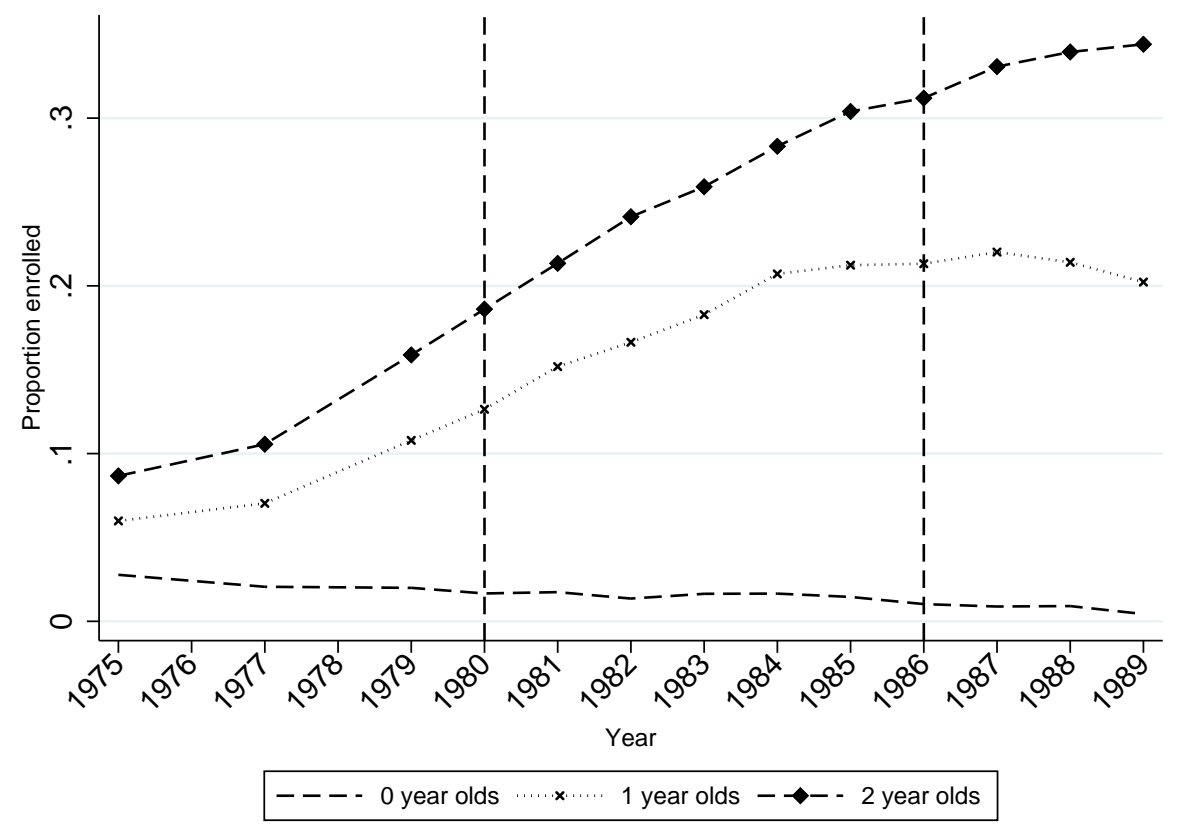

Note: The figure shows the fraction of children aged 0, 1, and 2 enrolled in child care during the time period studied. Source: SCB (1989). 